Check for updates

Cite this: Mater. Adv., 2021, 2, 3188

Received 22nd February 2021, Accepted 14th April 2021

DOI: $10.1039 / \mathrm{d} 1 \mathrm{ma} 00158 \mathrm{~b}$

rsc.li/materials-advances

\title{
Advances in electrochemical energy storage with covalent organic frameworks $\nmid$
}

\begin{abstract}
Vikram Singh (D) *abc and Hye Ryung Byon (D)*ab
The use of all-organic materials for electrochemical energy storage holds great promise for the development of foldable cellphones, lightweight computers, stretchable patch-type electronic devices, and other technologically advanced applications. Thus, the development of stable, scalable, and inexpensive electroactive organic materials has been extensively investigated. Covalent organic frameworks (COFs) are attractive candidates for two- and three-dimensional integration of small organic molecules. They offer regular-sized pore channels, a rich diversity of the desired chemical motifs, and feasible designs of chemical and bulk structure through the availability of various synthetic approaches. In this review, we highlight the recent studies in the design of COFs for rechargeable metal-ion batteries, (pseudo)capacitors, ion conductors, and solid-state electrolytes. We also discuss the advantages and challenges of future COF design to satisfy the criteria of industrial production.
\end{abstract}

\section{Introduction}

The ongoing development of electronic devices and efforts aiming to reduce our dependence on fossil fuels have increased the demand for electrochemical energy storage techniques. ${ }^{1-3}$ In particular, energy density defining the operation time per charging process should be significantly ameliorated with the drastic development of cutting-edge technologies ranging from portable electronics to electric vehicles. ${ }^{4,5}$ In addition, versatile energy storage concepts are vital to utilize both traditionally rigid and robust devices as well as lightweight, flexible, and foldable electronics (e.g., foldable cellphones, flimsy computers, and stretchable patch-type electronic devices). ${ }^{6,7}$ Given the broad application scope of these devices, diverse up-to-date electronics are expected to become ubiquitous in the near future, which highlights the need for new types of batteries and capacitors. ${ }^{1,8,9}$ As conventional inorganic compound-based materials are not suitable for such devices, much effort has been directed at the development of reasonably cheap all-organic-molecule batteries with performances similar to those of their inorganic material-based counterparts. ${ }^{10-13}$

In an organic electrode, redox-active organic motifs interact with charge carriers and should be integrated with low-density

\footnotetext{
${ }^{a}$ Department of Chemistry, Korea Advanced Institute of Science and Technology (KAIST), 291 Daehak-ro, Yuseong-gu, Daejeon 34141, Republic of Korea. E-mail: hrbyon@kaist.ac.kr,vsingh@kaist.ac.kr

${ }^{b}$ Advanced Battery Centre, KAIST Institute for NanoCentury, Daejeon 34141, Republic of Korea

${ }^{c}$ National Science Research Centre, Korea Advanced Institute of Science and Technology (KAIST), 291 Daehak-ro, Yuseong-gu, Daejeon 34141, Republic of Korea

$\dagger$ Electronic supplementary information (ESI) available. See DOI: 10.1039/d1ma00158b
}

organic frameworks that help to establish the overall electrode structure, prevent dissolution, and provide electron- and iontransport channels. ${ }^{14-18}$ Deep knowledge of molecular engineering and conglomeration allows for tunable structural design and electrochemical characteristic adjustment. ${ }^{14,16,19}$ For example, much attention has been directed at the fabrication of organic electrodes and solid electrolytes from polymers. ${ }^{17,20,21}$ However, irregular frameworks comprising polymeric layers may not provide channels for efficient electron and ion transport, and their currently unimpressive performance is ascribed to the lack of periodic porosity and poor electronic conductivity. ${ }^{15,22}$

Covalent organic frameworks (COFs) are promising electrode materials with metal-free crystalline organic structures. Organic building blocks are regularly integrated through covalent bonds to afford two-dimensional (2D) porous sheets. These organic sheets are stacked via $\pi-\pi$ interactions to establish a threedimensional (3D) framework. Pores create porous channels and provide a high surface area and low density. Yaghi's group first used reticular chemistry to fabricate $2 \mathrm{D}$ and 3D COFs featuring organic building blocks linked by boronate ester and/or boroxine units. $^{23,24}$ These organic frameworks had long-range order and formed a polycrystalline network owing to the partial reversibility of covalent bond formation in the condensation reaction, a phenomenon termed as dynamic covalent chemistry. ${ }^{25-33}$ Typically, COFs have higher synthetic flexibility than porous organic polymers and zeolites while exhibiting higher stability than metal-organic frameworks. Therefore, these organic structures are highly promising for the fabrication of electrodes and electrolytes for electrochemical energy storage.

Herein, we review the design of COF chemical moieties and structures for capacitors, batteries, and ionic conductors/solid 
electrolyte applications. Many studies on multiple synthetic methods and functions of chemical groups that are periodically combined constitute a COF library. This compiling knowledge underscores the importance of structural aspects, including $\pi$-conjugation in both in-plane and out-of-plane directions, pore engineering, crystallinity, and symmetrical motifs. COF structure is determined by molecular interactions such as strong covalent bonding between organic building blocks. In addition, the desired chemical moieties integrated into the building blocks should communicate with charge carriers in the target system through electrostatic interactions, dipoledipole interactions, hydrogen bonds, or ionic bonds. All of these components should be stable toward acids, bases, oxidants, reductants, and electrochemical environments. As the design of COFs should primarily target their electrochemical energy storage applications, this review presents various trials and errors for each application to ameliorate cell performance and reveals that such libraries facilitate the fabrication of better and more versatile organic materials for energy storage. Numerous studies have focused on the role of linkages, pore size, symmetry, interlayer interactions, electronic structure, and in-plane/out-of-plane conductivity of COFs, revealing the current challenges and future prospects for electrochemical energy storage.

\section{Design and characterization of electroactive COFs}

\section{Design of COF active materials}

COFs comprise periodically arranged organic units, and the role and performance of COFs as active materials for electrochemical energy storage are determined by the organic species serving as linkages and chemical functionalities. Favorable combinations of organic material properties such as polarity, electrostatic charge, electron delocalization, rigidity, and flexibility offer cooperative characteristics that can be tuned depending on target applications.

COFs comprise both electroactive and -inactive organic species, which act as electrochemical reactors and rigid skeletons, respectively. Quinones, imides, carboxylates $(\mathrm{C}=\mathrm{O})$, imines $(\mathrm{C}=\mathrm{N})$, azo compounds $(\mathrm{N}=\mathrm{N})$, pyridines, phenazines, and triazines are often used as electroactive units suitable for the implementation of both faradaic and non-faradaic processes. These active moieties are introduced into COFs through pre- or post-functionalization. In addition, the introduction of ionic (e.g., imidazolate and sulfonic acid) groups and hydrophobic/ hydrophilic (e.g., perfluoroalkyl, polyethylene glycol, and polyethylene oxide) groups increases the mobility of charge carriers through the long porous COF channels, making them useful as ion conductors and solid-state electrolytes. ${ }^{34}$

The COF skeleton is established using linkage chemistry, with the linker size and symmetry determining the pore size, pore volume, and 3D stacking structure (Table S1, ESI $\dagger$ ). ${ }^{26}$ In bulk COFs, the pores are connected to form nanoporous channels (diameter $=1-6 \mathrm{~nm}$, length $=$ several microns) that enable the transport of ions and electrolyte solutions. The grafting of polar moieties along pore walls enhances wetting and promotes the access of charge carriers to COF redox-active moieties. Control over the COF structure thickness may also allow one to alter wettability. In particular, thin COF films directly synthesized on conductive carbons (e.g., carbon nanotubes and graphene) or formed by exfoliation of bulk COFs via chemical or mechanical methods have been extensively employed to enhance wettability and increase electronic conductivity. The imine and $\beta$-ketoenamine moieties widely used in linkage chemistry are often unstable under electrochemical and chemical operating conditions. Specifically, at high $\mathrm{pH}$ the imine group is prone to hydrolysis and induces interlayer repulsions in the COF structure, ${ }^{35,36}$ whereas the $\beta$-ketoenamine group suffers from electron delocalization deficiency and may not be an ideal choice under the stringent electrochemical conditions required for molecular redox chemistry. ${ }^{37}$ Therefore, optimum linkage choice is crucial to avoid COF skeleton degradation.

\section{General characterization of COFs}

COF crystals are synthesized using various (e.g., solvothermal, ionothermal, microwave, microfluidic, and mechanochemical) methods $^{38-41}$ under diverse temperature ${ }^{42}$ and reaction time conditions. ${ }^{40,43}$ Subsequently, the residuals (reaction/washing solvents and pore-attached impurities) in pores are removed by heating at high temperatures $\left(100-200{ }^{\circ} \mathrm{C}\right)$ and very low pressures $\left(\sim 10^{-5}\right.$ torr $)$ for $>12 \mathrm{~h}$. COFs are generally obtained as powders that are insoluble in both aqueous and non-aqueous solvents ${ }^{28}$ and are analyzed by solid-state characterization techniques to determine chemical functionality, purity, and crystallinity.

Infrared and nuclear magnetic resonance (NMR) spectroscopies are commonly used to probe the functional groups in COFs and confirm the negligible content of residuals, ${ }^{44}$ whereas the thermal stability of COFs in $\mathrm{O}_{2}$ or $\mathrm{N}_{2}$ environments is probed by thermogravimetric analysis. In general, COFs should be stable up to $350{ }^{\circ} \mathrm{C}$ under $\mathrm{N}_{2}$. COF crystallinity can be confirmed by powder X-ray diffraction (PXRD). The PXRD patterns of many COFs feature very intense peaks at low angles $\left(<5^{\circ}\right)$, which can be used to determine the degree of crystallinity. Moreover, the peak at $\sim 27^{\circ}$ indicates a $\pi-\pi$ stacked layer structure if weak but reflects poor stacking interactions when broad and intense. The presence of small organic groups tethered to COFs does not generally change the overall framework geometry. Simulated PXRD patterns can be compared with experimental ones using Rietveld, Pawley, and other refinement methods to identify the true COF crystal structure. Strong $\pi-\pi$ interlayer interactions typically favor an eclipsed structure, whereas several COFs have been reported to feature staggered and stair-cased structures. ${ }^{45-48}$ Grazing incidence X-ray diffraction has been used to identify the vertical orientation of $\mathrm{COF}$ stacks relative to the substrate and determine film crystallinity. ${ }^{49}$ The porosity of residual-free COFs can be determined from their $\mathrm{N}_{2}$ adsorption-desorption isotherms recorded at $77 \mathrm{~K}$, which are commonly of type IV and indicate microporosity as well as significant $\mathrm{N}_{2}$ uptake at low pressures. The obtained isotherms can be used to calculate surface areas, pore sizes, and pore 
volumes using Brunauer-Emmett-Teller (BET; $\left.S_{\mathrm{BET}}\right)$ and BarrettJoyner-Halenda $\left(S_{\mathrm{BJH}}\right)$ methods. Microscopic imaging sheds light on COF morphology and thickness and is typically performed using scanning electron microscopy and transmission electron microscopy. ${ }^{50}$ In the case of COF thin films or exfoliated COF layers, atomic force microscopy is employed for deciphering film thickness. ${ }^{51,52}$ Scanning tunneling microscopy (STM) supplies atomic-resolution images of the crystal lattice and its defects as well as provides information on electronic structure. ${ }^{53}$ For instance, Feyter group used STM to demonstrate a localized reversible transformation of supramolecular networks to COFs. ${ }^{54,55}$

\section{COF electrode preparation and COF conductivity enhancement}

\section{Preparation of COF electrodes}

Typically, electrodes are prepared by mixing the COF, conductive carbon (e.g., Super $\mathrm{P}$ and acetylene black), and a binder (e.g., poly(vinylidene fluoride)). For battery applications, the COF (i.e., active material) should account for $>70 \mathrm{wt} \%$ of the electrode mass. The above three components are blended using a solvent (e.g., $N$-methyl pyrrolidone, and water), and the resulting slurry is deposited on metallic substrates through drop-casting or doctor-blading. The complete electrodes are dried under vacuum or in ambient air at a suitable temperature.

In the case of sulfur batteries, where COFs serve as the host material to confine elemental sulfur, the COF and sulfur are ground, placed inside a sealed container, and annealed at 150-200 ${ }^{\circ} \mathrm{C}$ for several hours to achieve the impregnation of sulfur into the porous channels of the COF.

In the case of ionic conductors, the ground COFs are pressed using a pellet maker and sandwiched between conducting substrates such as $\mathrm{Ti}, \mathrm{Li}$, and $\mathrm{Cu}$ using cold-pressing or oilpressing for impedance measurements.

\section{Enhancement of COF conductivity}

The nanoporous channels in the vertically aligned structure of COFs can serve as ionic channels and provide high pore volume and excellent surface area. However, tens of micron-scale ionic channels retard wetting inside the bulk COF. In addition, strong interlayer interactions in the COF structure may hinder the access of charge carriers to the active moieties or the interlayers. From an electronic point of view, organic materials typically have low conductivity unless electron-delocalized $\pi$-conjugation is established in the in-plane of COF. The electron/ion transport in the vertical direction, that is, in the out-of-plane direction, should also be reasonably rapid to enable fast charging.

Three key strategies have been developed to increase COF conductivity (Fig. 1). In the first method, ion diffusion length is decreased using few-layer covalent organic nanosheets (CONs), which are either prepared by COF exfoliation or synthesized directly, as discussed in detail by Zamora's and Tang's groups. ${ }^{30,56}$ Briefly, the exfoliation approach can be realized through liquid-phase or mechanical exfoliation, with the former commonly performed by sonication (to weaken interlayer interactions) ${ }^{57}$ and chemical (stereo-controlled (e.g., Diels-Alder) reactions, ${ }^{58}$ introduction of charged (e.g., guanidinium) linkers, ${ }^{59}$ or the use of self-exfoliating (e.g., triazole functionalities) ${ }^{51}$ techniques. Mechanical exfoliation can be achieved through the mechano-assisted synthesis or mechanical grinding of bulk COFs using a pestle/mortar or ball milling. ${ }^{60}$ However, the decrease in lateral dimensions due to such top-down exfoliation can deteriorate crystallinity. Alternatively, CONs can be fabricated directly from monomer precursors via on-surface or interfacial synthesis. For on-surface synthesis, monomers are deposited on ultraclean oriented substrates (e.g., $\mathrm{SiO}_{2}, \mathrm{Au}(111), \mathrm{Ag}(111)$, and highly oriented pyrolytic graphite) under solvent-free and ultra-high-vacuum (UHV) conditions at high temperatures. ${ }^{30}$ Moreover, on-surface synthesis can be

\section{Bottom-up approach \\ Growing few COF layers on suitable substrates using} Ultra high vacuum mode synthesis • Liquid-assisted synthesis - Liquid-Liquid interface synthesis

Top-down approach

- Liquid phase exfoliation of bulk COF - Self-exfoliation of charged COFs - Mechanical Exfoliation

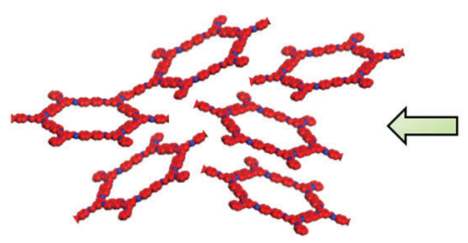

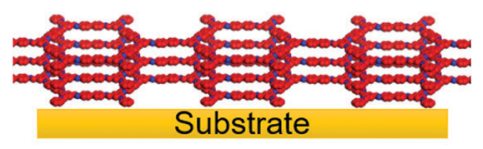

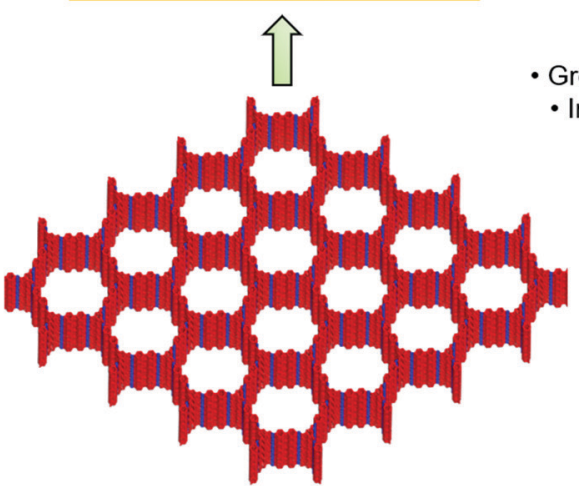

Conductive Matrix

- Adding Conductive carbons Grow few layered COFs on CNTs/graphene - Introduce heteroatoms in COFs-derived carbonaceous materials

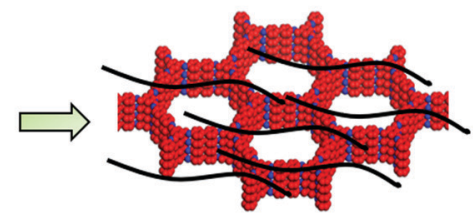

Fig. 1 Depiction of three key strategies to improve intrinsic and extrinsic conductivity of covalent organic frameworks. 
realized via the drop-casting of monomers onto the desired substrate. As covalent bonds can be formed in the equilibrium state of a chemical reaction, liquid-assisted synthesis is superior to UHV-condition synthesis, affording CONs with fewer defects and higher crystallinity on a long-range order of 200 $\times 200 \mathrm{~nm}^{2}$ to $1 \mu \mathrm{m}^{2} .{ }^{49,61}$ Interfacial synthesis utilizes monomer reactions at air-liquid or liquid-liquid interfaces using immiscible solvents and affords films that are suspended at the interface and can be easily transferred to the substrate. The advantage of this method is the precise control of film thickness through repeated transfer. Considering the COF-electrode interaction, thin CON deposition/growth on carbon nanotubes (CNTs) or graphene can enhance electron transport. Moreover, the conjugated nature of CONs and CNTs/graphene results in strong $\pi-\pi$ interactions.

Although the $\mathrm{Li}^{+}$diffusion length decreases with decreasing COF structure thickness, which generally results in increased electrical conductivity, the COF content is concomitantly reduced. As an active material (COF) loading of $>70 \mathrm{wt} \%$ is required for batteries, we believe that the optimization of porous channels is a better strategy.

\section{Capacitors}

Capacitors are generally operated through the physisorption of charge carriers, mostly ions, at the electrified interface. This capacitive process, giving rise to the so-called electrochemical double-layer capacitance (EDLC), is fast and does not involve chemical reactions. ${ }^{62}$ Typically, such supercapacitors have seamless carbon electrodes and should have a high surface area and a large pore volume to exhibit a sufficiently high EDLC. The physical events in capacitors takes advantage of the high power density and high stability toward long-term cycling in a wide temperature range. In comparison, the doping of carbon electrodes with heteroatoms such as oxygen and nitrogen preferentially improves wettability and provides sites for faradaic chemical adsorption (giving rise to pseudo-capacitance) in aqueous electrolyte solutions. Although pseudo-capacitive behavior accounts for a small portion of the overall capacitance, its contribution is significant. Thus, to improve capacitance, one should achieve a high surface area, pore volume, and chemical modification with various moieties.

Electrochemical characterizations are typically performed by cyclic voltammetry (CV) in a three-electrode setup, with the rectangular shape of the CV curve attributed to EDLC. The appearance of redox waves in the rectangular profile indicates the contribution of a pseudo-capacitive process. This interfacial event is determined not only by the electrode, but also by the electrolyte. Compared to other ions $\left(\mathrm{Na}^{+}, \mathrm{K}^{+}\right.$, and ionic liquid components), protons $\left(\mathrm{H}^{+}\right)$have the largest mobility and ability to enhance the faradaic events involving the heteroatoms of the carbon electrode. The corresponding performance can be evaluated by galvanostatic charge-discharge cycling. Although three-electrode cells are often used for such cycling, the evaluation of practical electrochemical capacitors and hybrid ion capacitors should ideally be performed using two-electrode full cells. ${ }^{63}$

\section{Pseudo-capacitors}

The first demonstration of a COF-based pseudo-capacitor was achieved by the Dichtel group in 2013, who designed 2,6diaminoanthraquinone (DAAQ)-linked 1,3,5-triformylphloroglucinol (Tp) to form a $\beta$-ketoenamine linked DAAQ-Tp COF (Fig. 2). ${ }^{64}$ This COF had a surface area $\left(S_{\mathrm{BET}}\right)$ of $\sim 1800 \mathrm{~m}^{2} \mathrm{~g}^{-1}$ and exhibited high chemical stability under acidic conditions.

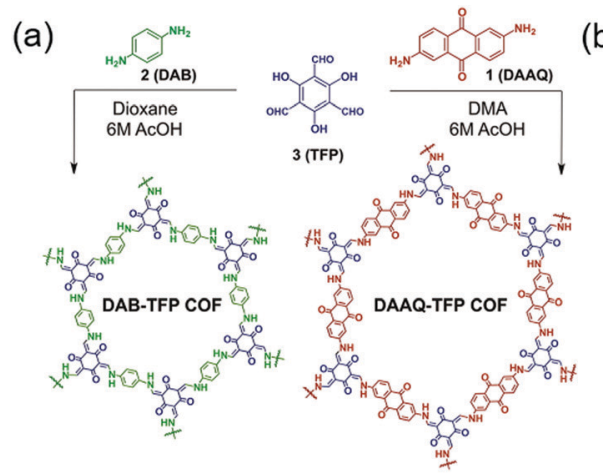

(c)

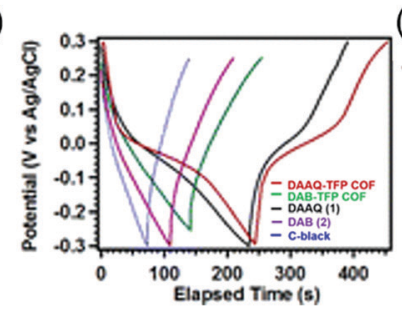

(d)

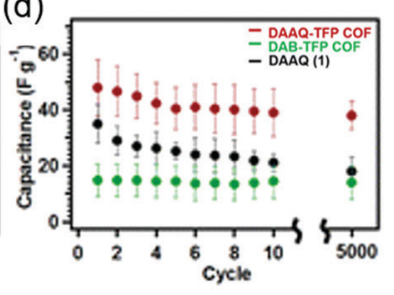

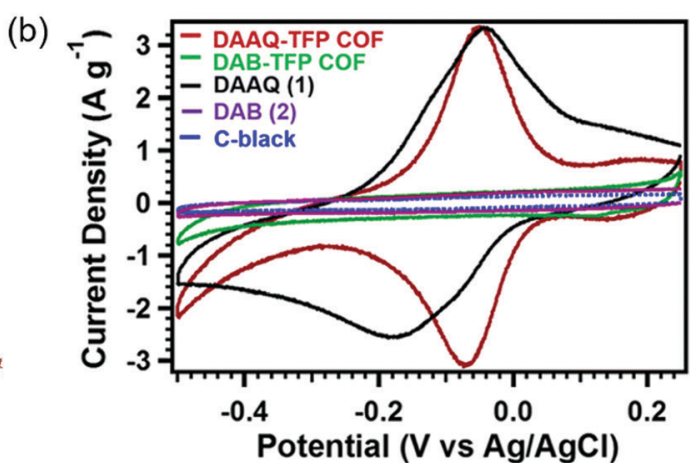

(e)

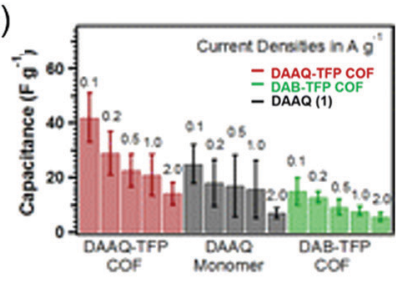

Fig. 2 Pseudo-capacitor performance of anthraquinone COFs. (a) Synthesis scheme for COFs. (b) Cyclic voltammogram of monomers and COFs in a three-electrode set-up. (c) Galvanostatic charge-discharge profiles of monomers and COFs at $0.1 \mathrm{~A} \mathrm{~g}^{-1}$. (d) Average charge capacitance of monomer and COFs. (e) Plot of the average capacitances at different current densities of monomer and COFs. Reproduced with permission. ${ }^{64}$ Copyright 2013 , American Chemical Society. 
In a three-electrode setup, the DAAQ-Tp COF electrode showed a voltage plateau at $-0.05 \mathrm{~V}$ vs. $\mathrm{Ag} / \mathrm{AgCl}$ in $1.0 \mathrm{M} \mathrm{H}_{2} \mathrm{SO}_{4}(\mathrm{aq})$ and delivered a capacitance of $40 \pm 9 \mathrm{~F} \mathrm{~g}^{-1}$ at $0.1 \mathrm{~A} \mathrm{~g}^{-1}$ over 5000 galvanostatic cycles. However, the utilization extent of the anthraquinone redox moiety was low (2.5\%) and, hence, the accessibility of $\mathrm{H}^{+}$adsorption to anthraquinone, were low. As a control experiment, the researchers tested a diaminobenzenebased DAB-Tp COF that did not have redox-active sites. The obtained rectangular $\mathrm{CV}$ curve and the shark-fin-shaped galvanostatic curve allowed the contribution of EDLC to be estimated as $15 \pm 6 \mathrm{~F} \mathrm{~g}^{-1}$. Lei's group grew a multilayer COF on a 3D graphene aerogel to improve the electronic conductivity and participation of anthraquinone in the pseudocapacitive process. The imine-linked anthraquinone COF was synthesized via the condensation of DAAQ with benzene-1,3,5-tricarbaldehyde (BTA) on graphene layers and was denoted as DAAQ-BTA, with the COF mass loading and thickness equaling $0.253 \mathrm{mg} \mathrm{cm}$ and $180 \mathrm{~nm}$, respectively. ${ }^{65}$ Under alkaline conditions $(1.0 \mathrm{M}$ $\mathrm{KOH}(\mathrm{aq})$ ), three-electrode cells with DAAQ-BTA exhibited a formal redox potential $\left(E^{0^{\prime}}\right)$ of $-0.85 \mathrm{~V} v s$. Ag/AgCl. Galvanostatic tests showed that the degree of anthraquinone utilization was close to $13.5 \%$ at a current density of $0.025 \mathrm{~mA} \mathrm{~cm}^{-2}$. However, after 500 cycles at $0.5 \mathrm{~mA} \mathrm{~cm}^{-2}$, capacitance rapidly decayed to $30 \%$ of the initial value $\left(31.7 \mathrm{mF} \mathrm{cm}^{-2}\right)$. Notably, the DAAQ monomer incompletely reacted with BTA during synthesis or remained trapped in COF pores, which was indicative of amorphous structure of the COF. Thus, the above COF was concluded to undergo decomposition and dissolution during cycling.

The Dichtel group further investigated the structural orientation of DAAQ-Tp COF in electrodes and its effect on capacitor performance (Fig. 3). In particular, a thin-film DAAQ-Tp COF (thickness $=60-560 \mathrm{~nm}$ ) was deposited on Au substrates. ${ }^{49,66}$ The significant (001) peak observed in the grazing-incidence $\mathrm{X}$-ray diffraction pattern of this film indicated the predominantly vertical orientation of the COF with respect to the substrate. When $0.1 \mathrm{M} \mathrm{TBAPF} \mathrm{T}_{6} / \mathrm{CH}_{3} \mathrm{CN}$ was employed as the electrolyte, the utilization extent of anthraquinone increased with decreasing initial concentration of DAAQ and COF thickness, e.g., $250 \mathrm{~nm}$-thick
COF films attained an areal capacitance of $3.0 \mathrm{mF} \mathrm{cm}^{-2}$ at $0.15 \mathrm{~mA} \mathrm{~cm}^{-2}$. In addition, a capacitance loss of only $\sim 7 \%$ was observed after 5000 galvanostatic cycles. In comparison, the capacitance of a powder COF electrode approached $0.40 \mathrm{mF} \mathrm{cm}^{-2}$, i.e., was 7.5 times lower than that of the above thin-film electrode. Nonetheless, such thin-film electrodes cannot sustain high current densities, which significantly reduces power density. To tackle this limitation, Dichtel group introduced a conducting polymer, poly(3,4-ethylenedioxythiophene) (PEDOT), into the nanopores of DAAQ-Tp COF through electropolymerization (Fig. 4). ${ }^{67} \mathrm{~A} 1 \mu \mathrm{m}$-thick DAAQ-Tp/PEDOT film delivered a charge storage of $9.3 \mathrm{mC}$ in $0.5 \mathrm{M} \mathrm{H}_{2} \mathrm{SO}_{4}(\mathrm{aq})$, which was more than 40 times higher than that of the PEDOT-free DAAQ-Tp COF. The three-electrode cells demonstrated a high charging rate of up to $1600 \mathrm{C}$, retaining $50 \%$ of the maximum capacitance $\left(600 \mathrm{~F} \mathrm{~cm}^{-3}\right)$. In addition, a capacitance of $450 \mathrm{~F} \mathrm{~cm}^{-3}$ was maintained at $100 \mathrm{C}$ for 10000 galvanostatic cycles. Two-electrode cells assembled with porous carbon electrodes displayed a charging rate of up to $800 \mathrm{C}$.

One of the advantages of organic electrodes is their ability to mechanically sustain flexible electrodes and capacitors. Banerjee's group used a DAAQ-Tp COF with variable contents of a $\pi$-electronrich anthracene (Da), ${ }^{68}$ showing that enhanced non-covalent interactions between COF layers increased electrode flexibility. The pure Da-Tp COF (i.e., that without DAAQ units) displayed the best mechanical robustness, showing a breaking strain of $9 \%$, which exceeded that of the more fragile DAAQ-only COF (2\%). Flexible electrodes were prepared with a 1:1 molar ratio of DAAQ and Da, namely the $\mathrm{DAAQ}_{1} \mathrm{Da}_{1} \mathrm{Tp} \mathrm{COF}$ film, which was adhered to a graphite substrate using conductive carbon tape. These COF films (thickness $=25-100 \mu \mathrm{m}$ ) displayed a geometric area of $15 \mathrm{~cm}^{2}, 68$ while an aerial capacitance of $8.5 \mathrm{mF} \mathrm{cm}^{-2}$ was observed at $0.39 \mathrm{~mA} \mathrm{~cm}{ }^{-2}$. While the $\mathrm{DAAQ}_{1} \mathrm{Da}_{1} \mathrm{Tp}$ COF achieved a $90 \%$ capacitance retention over 2500 galvanostatic cycles owing to its favorable redox and mechanical properties, the DAAQ-Tp COF showed capacitance retention of only $80 \%$ under the same conditions.

Jiang's group covalently linked a stable redox-active organic radical, 4-azido-2,2,6,6-tetramethyl-1-piperidinyloxy (TEMPO),
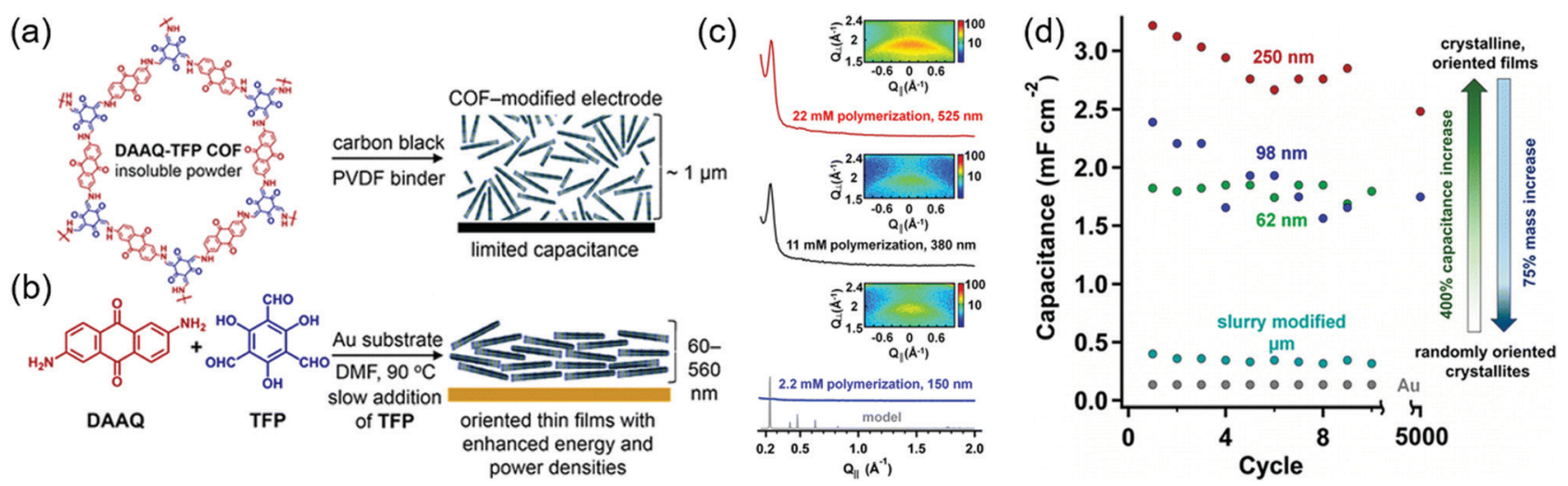

Fig. 3 Fabrication of COF thin films and pseudo-capacitor performance. (a) COF structure as 2D-layered microcrystalline powder. (b) Solvothermally grown COF thin film on Au electrodes. (c) Grazing incidence X-ray diffraction (GIXD) of COF films grown using different monomer concentrations. (d) Capacitance of COF thin films of varying thickness derived from galvanostatic charge-discharge experiments. Reproduced with permission. ${ }^{49}$ Copyright 2015, American Chemical Society. 
(a) (b)
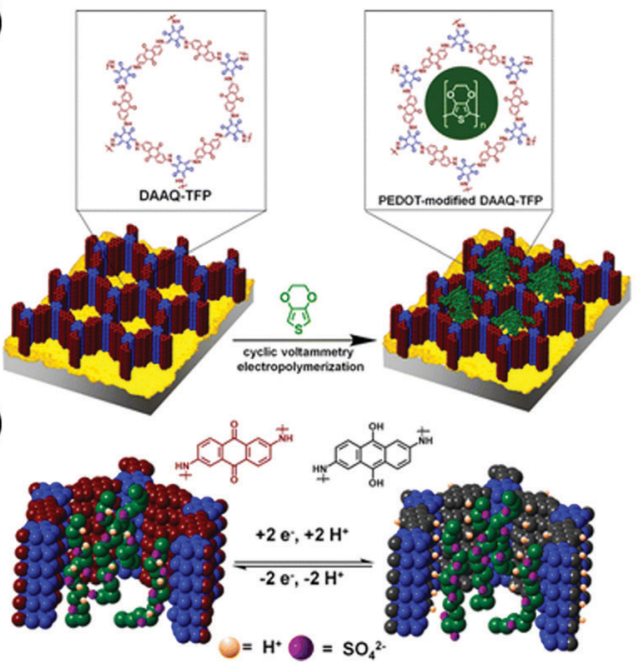

(c)

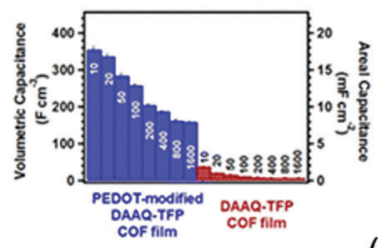

(d)

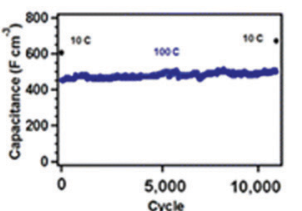

(g)

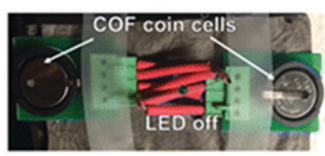

(e)

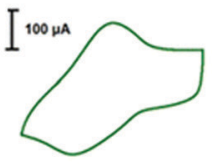

(f)
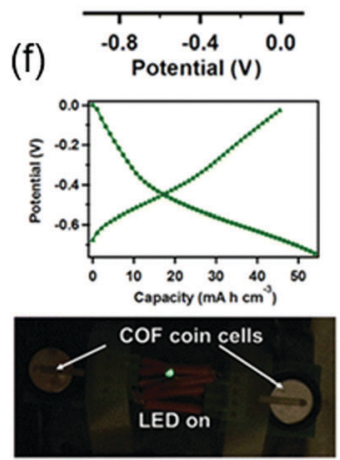

Fig. 4 Fabrication of COF thin films and pseudo-capacitor performance. (a) COF structure as 2D-layered microcrystalline powder. (b) Solvothermally grown COF thin film on Au electrodes. (c) Grazing incidence X-ray diffraction (GIXD) of COF films grown using different monomer concentrations. (d) Capacitance of COF thin films of varying thickness derived from galvanostatic charge-discharge experiments. (d) Long cycling. (e) Representative CV and (f) charge-discharge profile of PDOT-modified COF in a two-electrode configuration. (g) Image of a working device based on of PDOT-modified COF. Reproduced with permission. ${ }^{67}$ Copyright 2015, American Chemical Society.

to the porous walls of nickel-porphyrin COFs (NiP COF) to afford a new redox core (Fig. 5). ${ }^{69} \mathrm{NiP}$ COFs with ethynyl group contents of 50 and $100 \%$ were functionalized with TEMPO through click chemistry, and the obtained products were named as [TEMPO $]_{50 \%}$ $\mathrm{NiP}$ and [TEMPO] $]_{100 \%}-\mathrm{NiP}$, respectively. The $S_{\mathrm{BET}}$ of the latter COF $\left(5.2 \mathrm{~m}^{2} \mathrm{~g}^{-1}\right)$ was much less than that of the non-functionalized parent COF $\left(1219 \mathrm{~m}^{2} \mathrm{~g}^{-1}\right)$, indicating the dense loading of TEMPO in $[\mathrm{TEMPO}]_{100 \%}-\mathrm{NiP}$. In a three-electrode cell with $0.1 \mathrm{M} \mathrm{TBAClO}_{4} /$ $\mathrm{CH}_{3} \mathrm{CN}$, the capacitances of [TEMPO $]_{100 \%}-\mathrm{NiP}$ and [TEMPO $]_{50 \%}-\mathrm{NiP}$ were determined as 113 and $101 \mathrm{~F} \mathrm{~g}^{-1}$ at $2 \mathrm{~A} \mathrm{~g}^{-1}$, respectively. Thus, both TEMPO-functionalized COFs featured comparable capacitances, and [TEMPO $]_{50 \%}$-NiP additionally provided stable cyclability.

Tang's group utilized a pyridine (Py)-linked $\beta$-ketoenamine to create a TpPa-Py COF. ${ }^{70}$ The two redox waves observed at
-0.3 and $0.4 \mathrm{~V}$ vs. $\mathrm{Ag} / \mathrm{AgCl}$ in $1.0 \mathrm{M} \mathrm{H}_{2} \mathrm{SO}_{4}(\mathrm{aq})$ were ascribed to the reduction of Py units to afford a pyridinyl radical and then dihydropyridine. Capacitances of 209 and $164 \mathrm{~F} \mathrm{~g}^{-1}$ were determined at 0.5 and $5.0 \mathrm{~A} \mathrm{~g}^{-1}$, respectively. According to $\mathrm{CV}$ measurements performed at a scan rate of $1 \mathrm{mV} \mathrm{s}^{-1}$, the Py unit was utilized to $2.7 \%$. Galvanostatic cyclability tests showed that only $\sim 8 \%$ of capacitance was lost after 6000 cycles at $2 \mathrm{~A} \mathrm{~g}^{-1}$. The monomer diaminopyridine provided only $47 \mathrm{~F} \mathrm{~g}^{-1}$ at $0.5 \mathrm{~A} \mathrm{~g}^{-1}$, which underscores the role of COFs in hindering the dissolution of redox-active molecules. A triazine-based COF (TDFP-1) reported by Bhaumick's group ${ }^{71}$ achieved a maximum specific capacitance of $354 \mathrm{Fg}^{-1}$ at a CV scan rate of $2 \mathrm{mV} \mathrm{s}^{-1}$ in a conventional three-electrode setup with $0.1 \mathrm{M} \mathrm{H}_{2} \mathrm{SO}_{4}(\mathrm{aq})$. In addition, a capacitance retention of $\sim 95 \%$ was achieved after (a)

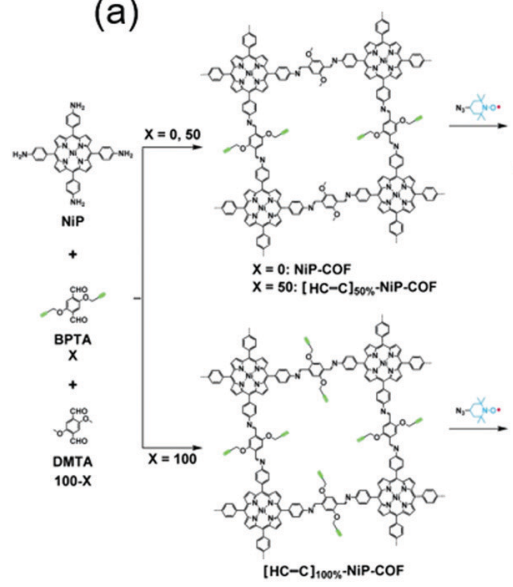

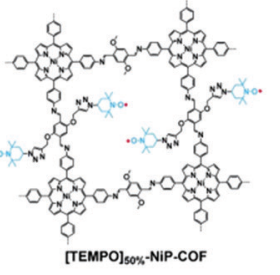

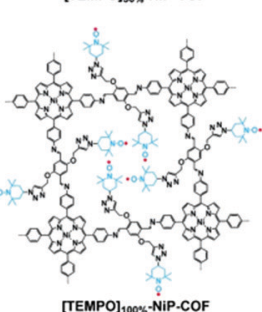

(b)

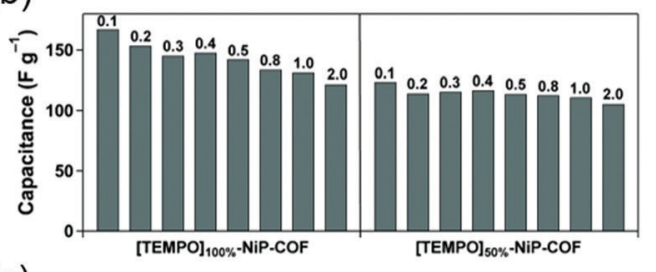

(c)

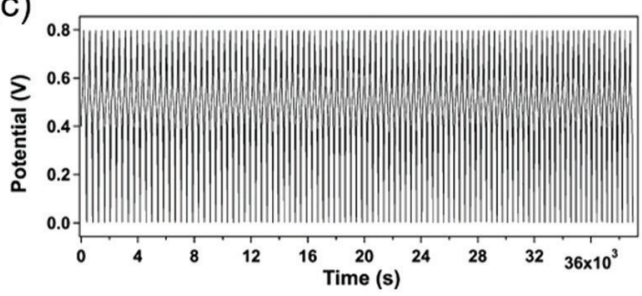

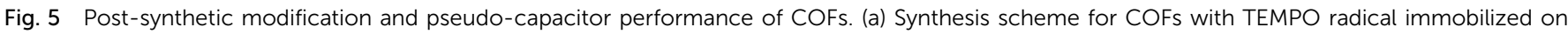

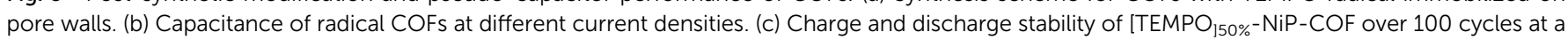
current density of $500 \mathrm{~mA} \mathrm{~g}^{-1}$. Reproduced with permission. ${ }^{69}$ Copyright 2015 , Wiley VCH. 
1000 cycles at $10 \mathrm{Ag}^{-1}$. This superior performance was ascribed to the high surface area $\left(651 \mathrm{~m}^{2} \mathrm{~g}^{-1}\right)$ of TDFP-1.

Banerjee's group focused on the role of interlayer hydrogen bonding in COFs for capacitor applications ${ }^{37,72}$ and synthesized a hydroquinone-based COF with $\beta$-ketoenamine linkage $\left(\mathrm{TpPa}-(\mathrm{OH})_{2}\right) \cdot{ }^{72}$ In a three-electrode setup with $1.0 \mathrm{M}$ phosphate buffer $(\mathrm{pH}=7.2)$, capacitances of 211 and $416 \mathrm{~F} \mathrm{~g}^{-1}$ were obtained at a $\mathrm{CV}$ scan rate of $2 \mathrm{mV} \mathrm{s}^{-1}$ and a galvanostatic current density of $0.5 \mathrm{~A} \mathrm{~g}^{-1}$, respectively. Both of the above values exceeded that of the aforementioned thin-film DAAQ-Tp COF and were ascribed to the benzoquinone/hydroquinone redox event in the $\mathrm{pH}$ range of 3.6-7.2. In addition, a capacitance retention of $66 \%$ was obtained after 10000 galvanostatic cycles at $5 \mathrm{~A} \mathrm{~g}^{-1}$. This highly stable cell performance was ascribed to hydrogen bonding between the carbonyl oxygen $(\mathrm{C}=\mathrm{O})$ of benzoquinone and the secondary $\mathrm{N}$ atom of the $\beta$-ketoenamine linkage. The above researchers also prepared a hydrogen bondfree phenolic group-based COF, TpBD- $(\mathrm{OH})_{2}$, for comparison, achieving a capacitance of $86 \mathrm{~F} \mathrm{~g}^{-1}$ at a CV scan rate of $2 \mathrm{mV} \mathrm{s}^{-1}$ and a capacitance retention of $2 \%$ after 1000 cycles. This poor performance was attributed to the formation of unstable phenoxy radicals during reduction. In contrast, when the DAAQ COF was modified with both imine linkage and methoxy (OMe) functional groups to afford TpOMe-DAAQ,${ }^{37}$ the $\mathrm{C}=\mathrm{N}$ groups of the imine linkage, which repelled each other through interlayers, were stabilized by forming interlayer hydrogen bonds with the OMe

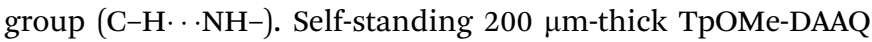
COF films in three-electrode cells delivered capacities of $1600 \mathrm{mF} \mathrm{cm}^{-2}$ (or $169 \mathrm{~F} \mathrm{~g}^{-1}$ ) at $3.3 \mathrm{~mA} \mathrm{~cm}^{-2}$. Galvanostatic cycling revealed high stability, showing a negligible capacitance loss for up to 100000 cycles at $10 \mathrm{~mA} \mathrm{~cm}^{-2}$. Vaidyanathan group employed triazine and Py as redox-active moieties and prepared imine-linked triazine-Py COFs containing one, two, or three hydroxyl groups (IISERP-COF10, 11, 12, respectively). ${ }^{73}$ As expected, the hydroxyl groups could stabilize Py and/or triazine via hydrogen bonding and prevented hydrolysis by invoking keto-enol tautomerism. In a three-electrode cell with $1.0 \mathrm{M}$ $\mathrm{H}_{2} \mathrm{SO}_{4}(\mathrm{aq})$, all three COFs exhibited multiple redox peaks, with the redox characteristics due to triazine and Py appearing even at a high scan rate of $1000 \mathrm{mV} \mathrm{s}^{-1}$. Capacitance also increased with increasing quantity of heteroatoms ( $\mathrm{N}$ atoms) in COFs. IISERP-COF10 had the highest $S_{\mathrm{BET}}$ of $1233 \mathrm{~m}^{2} \mathrm{~g}^{-1}$ and attained the highest capacitance of $546 \mathrm{~F} \mathrm{~g}^{-1}$ at $0.5 \mathrm{~A} \mathrm{~g}^{-1}$. However, the capacity retention obtained after 5000 cycles at $5 \mathrm{~A} \mathrm{~g}^{-1}(70 \%)$ was lower than those of IISERP-COF11 (75\%) and IISERPCOF12 (82\%), which demonstrated the stabilizing effect of hydroxy groups due to keto-enol tautomerism. Yang's group studied a melamine-containing triazine COF denoted as PDC-MA-COF. ${ }^{74}$ The $\mathrm{C}-\mathrm{H} \cdots \mathrm{N}$ hydrogen bonds in the adjacent layers of piperazine rings could ameliorate molecular stability during the redox process. ${ }^{75}$ Under strongly alkaline conditions (6 $\mathrm{M} \mathrm{KOH}(\mathrm{aq})$ ), the three-electrode system showed redox peaks arising from the triazine units, attaining a capacity of $335 \mathrm{~F} \mathrm{~g}^{-1}$ at $1.0 \mathrm{~A} \mathrm{~g}^{-1}$ by utilizing $19.71 \%$ of redox-active triazine units. Two-electrode cells assembled with carbon electrodes achieved a capacity of $94 \mathrm{~F} \mathrm{~g}^{-1}$ at $1.0 \mathrm{~A} \mathrm{~g}^{-1}$ and a capacitance retention of $88 \%$ after 20000 cycles.

Eddaoudi's group integrated two (benzoquinone and phenazine) redox-active cores to afford COFs that were denoted as Hex-Aza-COF- $x(x=2,3)$ (Fig. 6$){ }^{76}$ These COFs were synthesized by combining cyclohexanehexone and aromatic tetramines with benzoquinone (Hex-Aza-COF-2) or phenazine (Hex-Aza-COF-3). Both COFs had high capacitances of 585 and $663 \mathrm{~F} \mathrm{~g}^{-1}$ at $1 \mathrm{~A} \mathrm{~g}^{-1}$, respectively. Two-electrode cells with Hex-Aza-COF-3 as the negative electrode and $\mathrm{RuO}_{2}$ as the positive electrode delivered a capacitance of $64 \mathrm{~F} \mathrm{~g}^{-1}$ at $1 \mathrm{~A} \mathrm{~g}^{-1}$ and a capacity retention of $89 \%$ after 7500 cycles at $5 \mathrm{~A} \mathrm{~g}^{-1}$.

\section{Electric double-layer capacitors}

The $\mathrm{N}$ moiety does not show an apparent faradaic process in proton-free solutions, which can be applied to non-faradaic EDLC capacitors. Deng's group proposed that the $\mathrm{N}$ moiety can
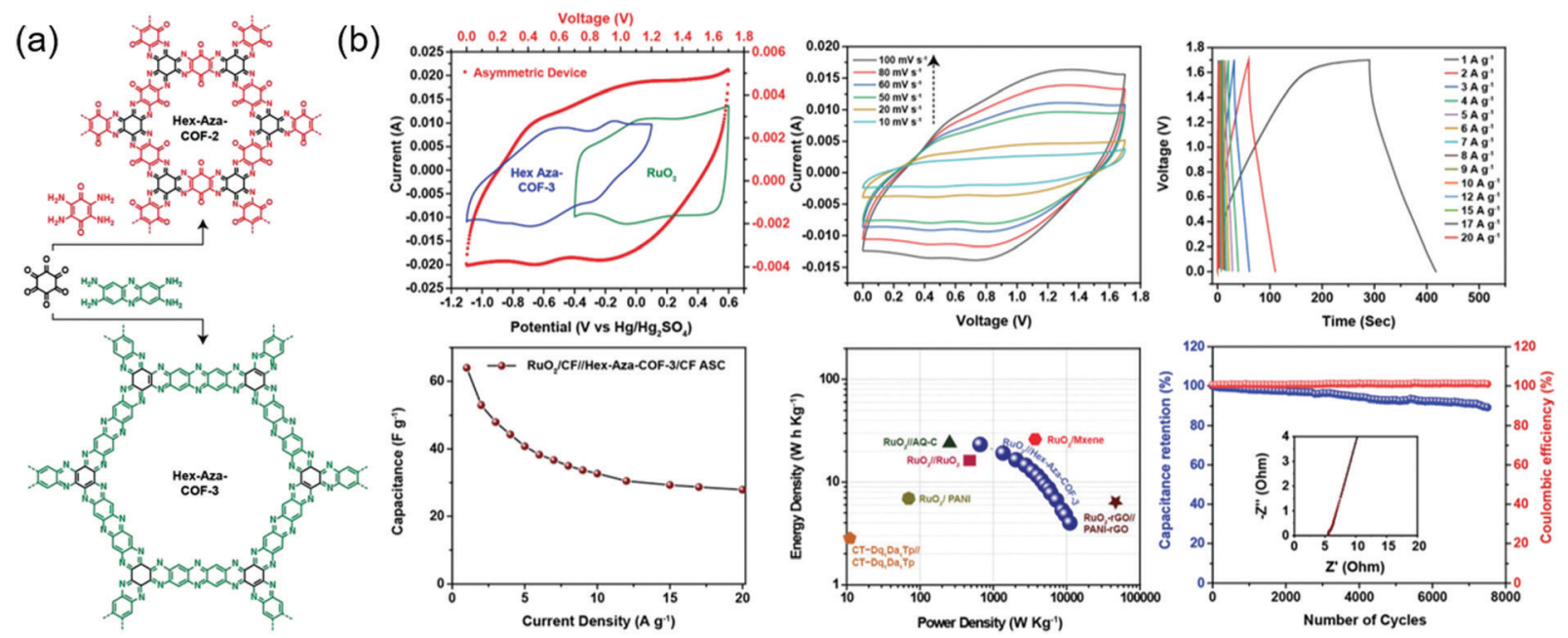

Fig. 6 Electrochemical performance of COF based asymmetric capacitor. (a) Synthesis and design of Hex-Aza-COFs. (b) Electrochemical performance of $\mathrm{RuO}_{2} / \mathrm{Hex}-\mathrm{Aza}-\mathrm{COF}-3$ in an asymmetric device. Reproduced with permission. ${ }^{76}$ Copyright 2020, Wiley VCH. 
promote ion transfer at the electrode interface along with a large surface area associated with EDLC. ${ }^{77}$ These researchers synthesized tetracyanoquinodimethane-derived covalent triazinebased frameworks, TCNQ-CTFs, and annealed them at $400-900{ }^{\circ} \mathrm{C}$ to modulate surface area $\left(1174-4000 \mathrm{~m}^{2} \mathrm{~g}^{-1}\right)$, pore size $(0.5-4 \mathrm{~nm})$, and nitrogen content (21.79-4.56\%). Three-electrode cells with $1.0 \mathrm{M} \mathrm{KOH}(\mathrm{aq})$ and all $\mathrm{CTF}$ electrodes displayed quasirectangular $\mathrm{CV}$ curves in the range of -0.8 to $0.1 \mathrm{~V}$ and shark-fin galvanostatic curves at $1 \mathrm{~A} \mathrm{~g}^{-1}$, which was indicative of EDLC behavior. TCNQ-CTF annealed at $800{ }^{\circ} \mathrm{C}$ displayed a specific capacitance of $383 \mathrm{~F} \mathrm{~g}^{-1}$ at $0.2 \mathrm{~A} \mathrm{~g}^{-1}$ and a capacitance retention of $\sim 100 \%$ over 10000 cycles, which was attributed to the high surface area $\left(3663 \mathrm{~m}^{2} \mathrm{~g}^{-1}\right)$ and large nitrogen content $(8.13 \mathrm{wt} \%)$ of this COF. Charge-discharge curves recorded in a two-electrode system with an ionic liquid electrolyte (1-ethyl-3methylimidazolium tetrafluoroborate) revealed EDLC behavior. However, a low capacitance of $100 \mathrm{~F} \mathrm{~g}^{-1}$ at $0.1 \mathrm{~A} \mathrm{~g}^{-1}$ was observed because of the high viscosity of the ionic liquid. Wang's group improved the electrical conductivity of a triazine-based COF (COF TTA-DHTA $)$ consisting of $4,4^{\prime}, 4^{\prime \prime}$-(1,3,5-triazine-2,4,6-triyl)trianiline (TTA) with 2,5-dihydroxyterephthaldehyde (DHTA) monomers. ${ }^{78}$ Notably, a highly ordered $\mathrm{COF}_{\text {TTA-DHTA }}$ was grown on amine-functionalized CNTs. In a three-electrode system with 1.0 $\mathrm{M} \mathrm{Na}_{2} \mathrm{SO}_{4}(\mathrm{aq})$, a capacitance of $98.7 \mathrm{~F} \mathrm{~g}^{-1}$ was recorded at $2 \mathrm{~A} \mathrm{~g}^{-1}$. The total capacitance of $127.5 \mathrm{~F} \mathrm{~g}^{-1}$ at $0.4 \mathrm{~A} \mathrm{~g}^{-1}$ was mostly due to EDLC, and the faradaic process arising from phenolic hydroxyl and/or $\mathrm{N}$ atoms on $\mathrm{COF}_{\text {TTA-DHTA }}$ was marginal. Under these conditions, the $\mathrm{COF}_{\text {TTA-DHTA }} / \mathrm{CNT}$ system showed a $30 \%$ higher capacitance than the bulk $\mathrm{COF}_{\text {TTA-DHTA }}$.

Zhang's group reported a CNT-conjugated COF $\left(\mathrm{g}-\mathrm{C}_{34} \mathrm{~N}_{6}-\mathrm{COF}\right)$ electrode patterned on a flexible polymer substrate to fabricate micro-supercapacitors. ${ }^{79}$ These micro-supercapacitors with a LiCl/ polyvinyl alcohol electrolyte solution showed an areal capacitance of $15.2 \mathrm{mF} \mathrm{cm}^{-2}$ at a $\mathrm{CV}$ scan rate of $2 \mathrm{mV} \mathrm{s}^{-1}$. Fang's group reported chemically exfoliated COFs comprising a hydroxylcontaining monomer and a porphyrin-based building block, named JUC (Fig. 7). ${ }^{80}$ JUC-510 contained a non-metallated porphyrin, whereas JUC-511 and JUC-512 comprised nickeland copper-coordinated porphyrins, respectively. The exfoliated COFs showed thicknesses of 36, 22, and $19 \mathrm{~nm}$ for JUC-510, JUC-511, and JUC-512, respectively. For all COFs, rectangularshaped CV curves reflecting pure EDLC behavior were observed. Exfoliated JUC-511 and JUC-512 delivered areal capacitances of 5.46 and $5.85 \mathrm{mF} \mathrm{cm}^{-2}$, respectively, at $1000 \mathrm{mV} \mathrm{s}^{-1}$ while featuring a $100 \%$ capacitance retention after 1000 galvanostatic cycles. Presumably, the hydroxyl group stabilized these COFs through hydrogen bonding between layers, while the metal ions increased overall conductivity.

Table S2 (ESI $\dagger$ ) summarizes all COFs-based capacitors. The above discussion shows that the design of electroactive COFs is of key importance for obtaining higher capacitance. The abundance of COFs prepared to date represents a continuing pursuit of optimum utilization and performance for application in practical capacitors.

\section{Alkali metal-COF hybrid batteries}

Commercial lithium-ion batteries (LIBs) use mixed lithiumtransition metal (e.g., cobalt and nickel) oxides as positive electrode materials. However, cobalt and nickel are not cheap and have become more expensive with the increasing demand for LIBs caused by the widespread use of portable electronics and electric vehicles. Therefore, alternative electrode materials are highly sought after. For example, the low density and flexibility of organic electrodes make them suitable for portable electronics. The active electrochemical functionalities such as carbonyl, organosulfur, azo, and phenazine moieties are vital for inducing chemical interactions with charge carriers and providing the associated redox potential and capacity. ${ }^{81-83}$ The challenge of organic electrodes is their susceptibility to side reactions and structural deformation during galvanostatic cycling. ${ }^{84-87}$ In addition, the poor electronic conductivity of these electrodes
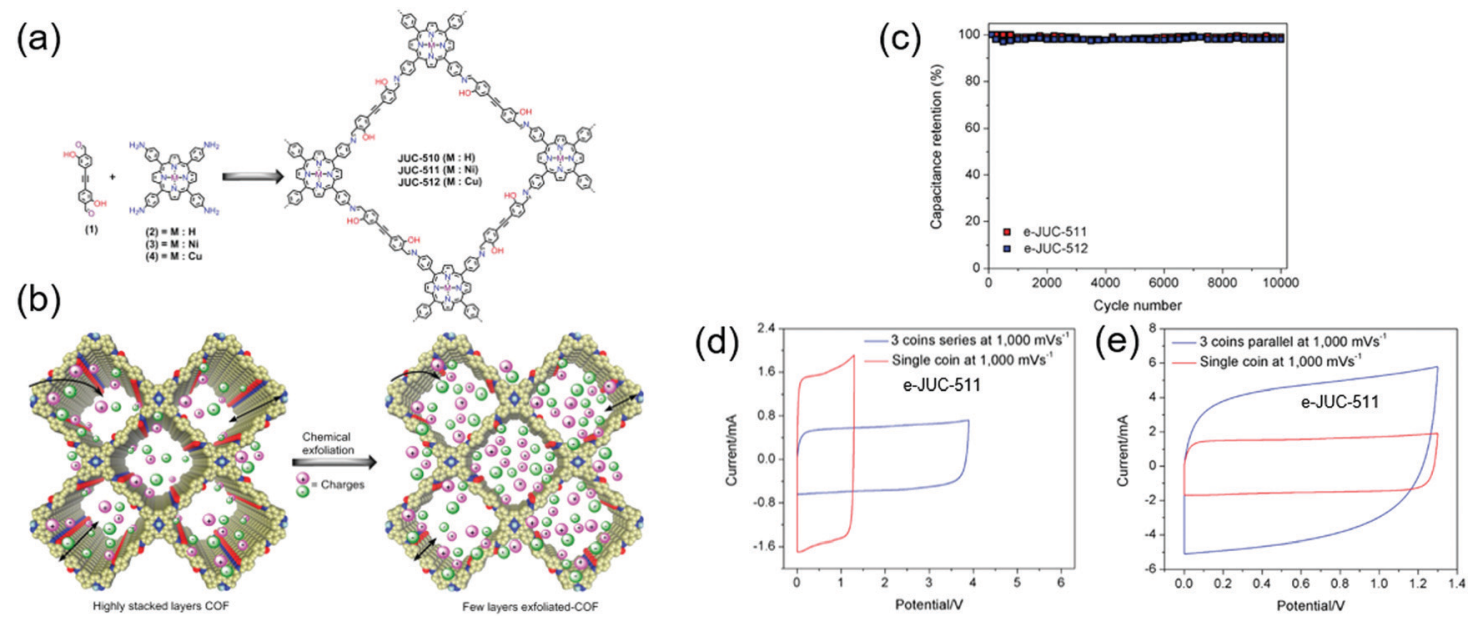

Fig. 7 Exfoliation of COFs and their capacitor performance of COFs. (a) Design synthesis of JUC-COFs series. (b) Depiction of charge storage behavior between COFs and exfoliated COFs (e-COFs). (c) 10000 galvanostatic charge-discharge cycles showing capacitance retention of e-COFs capacitor cells. CV curve of e-COF at $1 \mathrm{~V} \mathrm{~s}^{-1}$ (d) in series and (e) in parallel configuration. Reproduced with permission. ${ }^{80} \mathrm{Copyright} 2020$, Wiley VCH. 
(a)

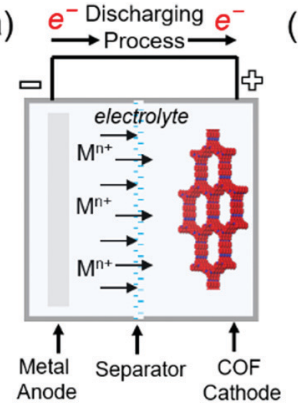

(b)

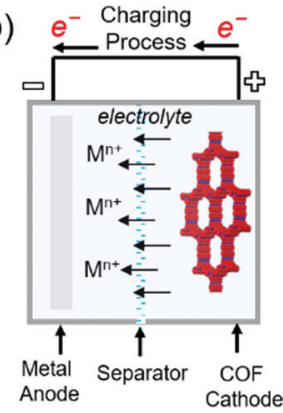

Fig. 8 Representation of working principles in alkali metal-COF hybrid batteries. (a) Discharging process (b) charging process in metal-COF batteries.

(typically from $10^{-15}$ to $10^{-10} \mathrm{~S} \mathrm{~cm}^{-1}$ ) impedes the charging rate-determining process of electron transfer. ${ }^{83}$ Thus, the design of organic molecule-containing frameworks is a task of high significance. Interlocking redox-active moieties establishing covalently linked and $\pi$-conjugated structures can improve electronic conductivity and mechanical strength while suppressing the dissolution of molecules. COFs satisfy these requirements and feature periodic nanopores that provide ionic channels to ameliorate ionic conductivity. COFs have been investigated as both negative and positive electrode materials for rechargeable batteries using $\mathrm{Li}^{+}, \mathrm{Na}^{+}, \mathrm{K}^{+}$, and $\mathrm{Zn}^{2+}$ as charge carriers. During charging, charge carriers are stored in the negative electrode, where the reduction reaction takes place, and settle down in the positive electrode during discharge (Fig. 8). The formation of radicals from the redox-active moieties of COFs undergoing these chemical reactions results in chemical degradation and is an important challenge to be mitigated. At very negative potentials (below $1.0 \mathrm{~V}$ $v s . \mathrm{Li} / \mathrm{Li}^{+}$in the $\mathrm{LiB}$ case), for example, the charge carrier $\left(\mathrm{Li}^{+}\right)$can be intercalated into the COF interlayer, which is similar to that in graphite. Although this process offers additional capacity, the decomposition of non-aqueous electrolytes under these conditions

creates a solid-electrolyte interphase layer on the electrode. This layer, despite its positive role in protecting the electrode from the further decomposition of the electrolyte solution, can increase surface resistance and consume the electrolyte solution up to dryness, which results in capacity fading if continuous decomposition occurs. In this section, we highlight the recent development in the design of COF electrodes for non-aqueous $\mathrm{Li}$-, Na-, and K-ion batteries as well as aqueous $\mathrm{Zn}$-ion batteries.

\section{Lithium-COF batteries}

Jiang's group first developed a boronate-linked naphthalene diimide (NDI) COF $\left(D_{\mathrm{TP}}-\mathrm{A}_{\mathrm{NDI}} \mathrm{COF}\right)$ as an electrode material for Li hybrid cells (Fig. 9). ${ }^{88}$ Typical two-electrode cells assembled with metallic Li and 1.0 M LiPF 6 in 1/1 wt\% of ethylene carbonate (EC)/dimethyl carbonate (DMC) showed two lithiation peaks at 2.1 and $2.4 \mathrm{~V} v$ s. $\mathrm{Li} / \mathrm{Li}^{+}$due to NDI enolization and a single broad delithiation peak at $2.5 \mathrm{~V}$. The COF-powder-based electrode attained a capacity of $42 \mathrm{~mA} \mathrm{~h} \mathrm{~g}{ }^{-1}$ at a current density of 200 $\mathrm{mA} \mathrm{g}^{-1}$ (2.4C). However, when $\mathrm{D}_{\mathrm{TP}}-\mathrm{A}_{\mathrm{NDI}}-\mathrm{COF}$ was directly grown on CNTs, the capacity increased to $67 \mathrm{~mA} \mathrm{~h} \mathrm{~g}^{-1}$ (82\% of the theoretical value). Electrochemical impedance spectroscopy (EIS) showed that $\mathrm{D}_{\mathrm{TP}}-\mathrm{A}_{\mathrm{NDI}} \mathrm{COF} / \mathrm{CNT}$ featured a lower charge-transfer resistance $(8.5 \Omega)$ than $\mathrm{D}_{\mathrm{TP}}-\mathrm{A}_{\mathrm{NDI}} \mathrm{COF}(129 \Omega)$, which underscores the importance of conductive carbon materials for charge transport, as $\mathrm{D}_{\mathrm{TP}}-\mathrm{A}_{\mathrm{NDI}} \mathrm{COF}$ had a relatively poor electronic conductivity. Notably, $\mathrm{D}_{\mathrm{TP}}-\mathrm{A}_{\mathrm{NDI}} \mathrm{COF} / \mathrm{CNT}$ showed a stable rate capability at current rates of $2.4-12 \mathrm{C}$ and excellent cycling stability, maintaining almost $100 \%$ of the original capacity after 700 cycles at $2.4 \mathrm{C}$. The measured capacity approached $90 \%$ of the theoretical value. However, as $\mathrm{D}_{\mathrm{TP}}-\mathrm{A}_{\mathrm{NDI}} \mathrm{COF} / \mathrm{CNT}$ intrinsically contained a small number of redox-active NDI molecules, the capacity was always less than $70 \mathrm{~mA} \mathrm{~h} \mathrm{~g}^{-1}$.

Subsequently, numerous researchers focused on (1) studying highly conductive carbon nanostructures and their intimate interaction with COFs and (2) increasing the concentration of
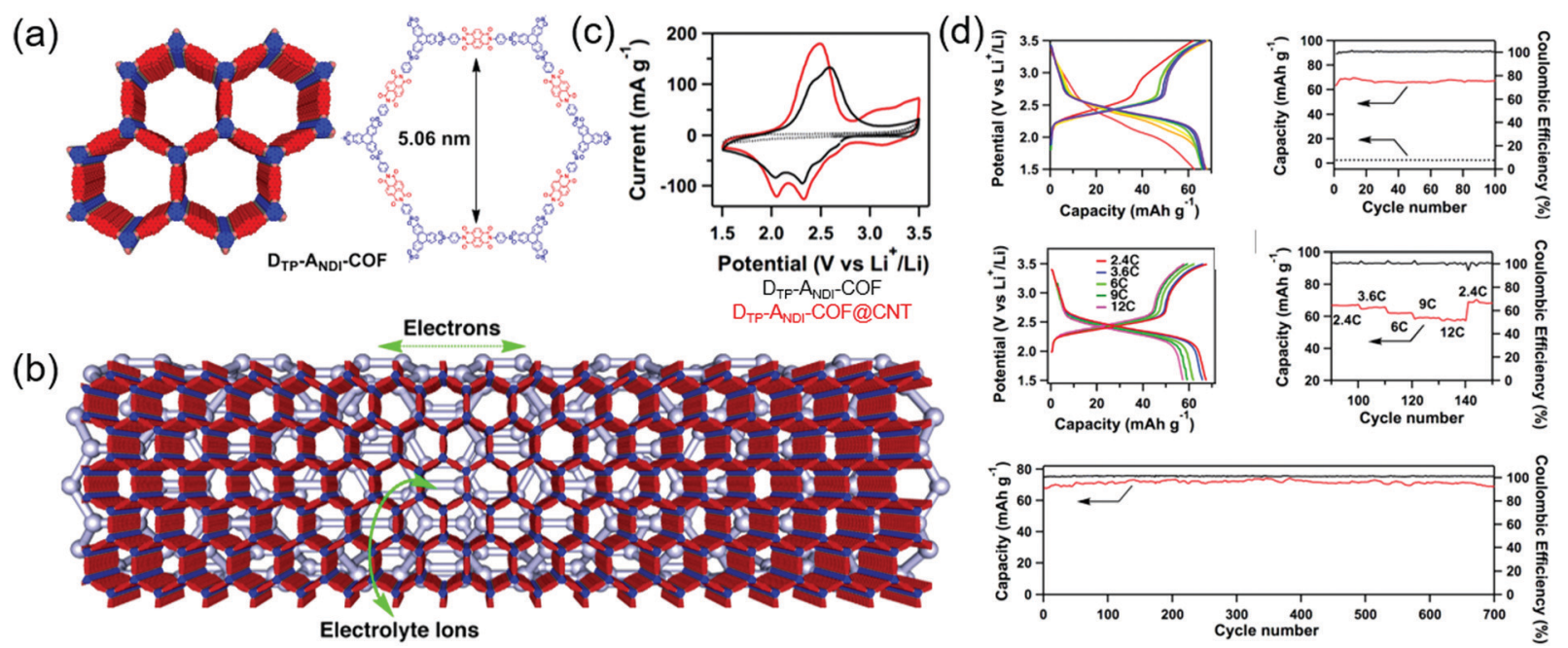

Fig. 9 Depiction of COF growth over CNTs and Li-ion battery performance. (a) AA-stacked and chemical structure of COF with interlocked redox-active naphthalene diimide unit. (b) Representation of COFaCNT along with possible electron conduction and ion transport channel. (c) CV curves of COF and COF@CNT at $0.5 \mathrm{mV} \mathrm{s}^{-1}$. (d) COF@CNT performance in Li-ion batteries. Reproduced with permission. ${ }^{88}$ Copyright 2015, Nature Publishing Group. 
redox-active functionalities anchored to COFs. Chen's group designed microporous poly(imide-benzoquinone) (PIBN)-based COFs, using quinone and pyromellitic dianhydride moieties to create two redox sites with plentiful of carbonyl groups. ${ }^{89}$ The COFs were deposited on graphene through in situ polymerization to afford PIBN/G composites. Notably, charge transfer resistance decreased after the integration of PIBN with graphene. Galvanostatic testing of PIBN/G revealed two voltage plateaus and a capacity of $270 \mathrm{~mA} \mathrm{~h} \mathrm{~g}^{-1}$ at $0.1 \mathrm{C}$ ( $96.8 \%$ of the theoretical value), whereas the capacity of PIBN COF was $86.1 \%$ of the theoretical value, which indicated that graphene served as a suitable conducting platform. PIBN/G showed a stable rate capability at a current rate of 10C. After lithiation/delithiation, the disappearance and appearance of imide carbonyl and quinone carbonyl bands was confirmed by in situ Fourier transform infrared spectroscopy. Zhang's group synthesized a COF containing the maximum number of redox-active groups and minimized the concentration of redox-inactive linkages. The resulting BQ1-COF had twelve quinone $\mathrm{O}$ atoms and six imine $\mathrm{N}$ atoms and was therefore capable of $\mathrm{a}$ total of 18 electron transfer processes per repeating molecular unit. ${ }^{90}$ The observable capacity approached $502.4 \mathrm{~mA} \mathrm{~h} \mathrm{~g}^{-1}$ at $0.05 \mathrm{C}$, which corresponded to $65 \%$ of the theoretical value. In addition, $81 \%$ capacity retention was observed after 1000 cycles at 2C. Zhang's group attempted to increase the total content of the COF (active material) to $70 \mathrm{wt} \%$ by mixing it with CNTs (30 wt\%) without a binder. ${ }^{91}$ The researchers integrated a redox-active pyrene4,5,9,10-tetraone unit with four $\mathrm{C}=\mathrm{O}$ groups with a planar boroxine $\left(\mathrm{B}_{3} \mathrm{O}_{3}\right)$ to form binder-free PPTODB COFs, which delivered a capacity of $198 \mathrm{~mA} \mathrm{~h} \mathrm{~g}^{-1}$ at $20 \mathrm{~mA} \mathrm{~g}^{-1}$. However, a significant capacity loss of $\sim 31.7 \%$ was observed after 150 cycles at $20 \mathrm{~mA} \mathrm{~g}^{-1}$ because of the susceptibility of $\mathrm{B}_{3} \mathrm{O}_{3}$ linkages to nucleophilic attack.

There have also been many alternative studies on COF design aimed at charge transfer enhancement. Wang's group exfoliated a DAAQ-Tp COF using mechanical milling. The exfoliated
DAAQ COF, denoted as DAAQ-ECOF, had a thickness of 3-5 nm (10-15 atomic layers) and thus offered the benefit of small $\mathrm{Li}^{+}$diffusion length. ${ }^{60}$ Two pairs of redox events were observed at 2.34 and $2.48 \mathrm{~V}$ and were ascribed to DAAQ/DAAQ ${ }^{\bullet-}$ and DAAQ ${ }^{\bullet}-$ DAAQ $^{2-}$ conversions, respectively. The DAAQ-ECOF cell utilized $96 \%$ of the total DAAQ and achieved a capacity of $145 \mathrm{~mA} \mathrm{~h} \mathrm{~g}^{-1}$ (at $20 \mathrm{~mA} \mathrm{~g}^{-1}$ ), which was $\sim 1.3$ times higher than that of DAAQ-Tp COF. Moreover, DAAQ-ECOF showed a $98 \%$ capacity retention after 1800 cycles at $500 \mathrm{~mA} \mathrm{~g}^{-1}$, featuring a capacity close to $50 \%$ of the theoretical value even at $3000 \mathrm{~mA} \mathrm{~g}^{-1}$. Huang's group prepared exfoliated pyromellitic imide-based COFs (PI-ECOF-1 and PI-ECOF-2) using tris(4-aminophenyl)amine and 1,3,5-tris(4-aminophenyl)benzene as the monomers (Fig. 10). ${ }^{92}$ Electrodes were reproducibly prepared from a mixture of ECOF composites with reduced graphene oxide (rGO). ${ }^{89}$ PI-ECOF-1 cells showed a $79 \%$ capacity utilization at $0.1 \mathrm{C}$, while a value of $60 \%$ was obtained for PI-COF- 1 cells. For a $1 / 1$ mass ratio of $\mathrm{COF} / \mathrm{rGO}$, a close-to-theoretical capacity was observed at 0.1C. After 300 cycles at 10 and $1 \mathrm{C}$, capacity retentions of $\sim 63$ and $75 \%$ were observed.

A more groundbreaking way of ameliorating charge transport is the synthesis of highly conductive COFs with enhanced $\pi$-conjugation structures. Bu's group compared two COFs: A partially conjugated NDI-based COF with imine linkages (Tb-DANT COF) and a non-conjugated NDI-based COF with $\beta$-ketoenamine linkages (Tp-DANT COF). ${ }^{93}$ The initial capacity of Tb-DANT COF at 1.4C $\left(\sim 123 \mathrm{~mA} \mathrm{~h} \mathrm{~g}^{-1}\right)$ exceeded that of Tp-DANT COF $\left(\sim 92 \mathrm{~mA} \mathrm{~h} \mathrm{~g}^{-1}\right)$. After 300 cycles, Tb-DANT COF cells still maintained $85 \%$ of their initial capacity at $3.4 \mathrm{C}$. Dichtel's group demonstrated that suitable redox-active functionalities can increase the energy and power density of bulk COFs (Fig. 11), ${ }^{94}$ as exemplified by the introduction of a redoxactive phenazine group into a $\beta$-ketoenamine linkage to produce DAPH-Tp COF. The power density of this COF approached $2268 \mathrm{~W} \mathrm{~kg}^{-1}$ and was three times greater than that of DAAQ-Tp COF despite their comparable $S_{\mathrm{BET}}$ values of $\sim 1150 \mathrm{~m}^{2} \mathrm{~g}^{-1}$.
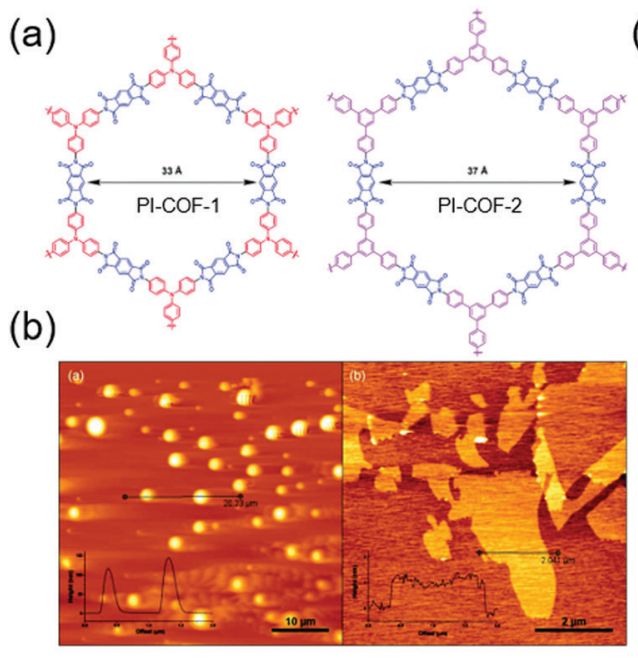

(c)
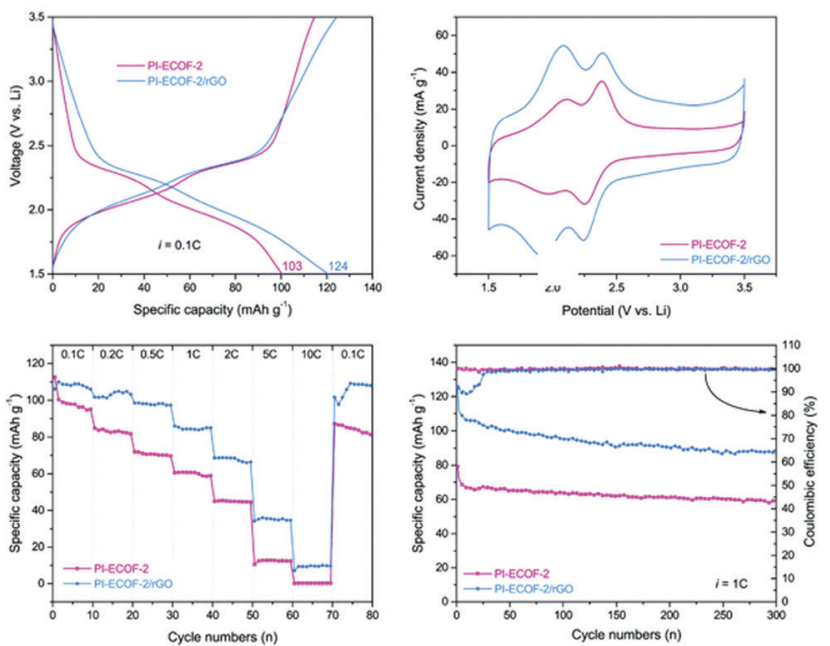

Fig. 10 Exfoliation and rGO composite of COFs and Li-ion battery performance. (a) Chemical structure of COFs with interlocked redox-active phthalimide unit. (b) Atomic force microscopic images of PI-COF-1 and exfoliated PI-COF-1. (c) Li-Battery performance of PI-ECOF-2 and its rGo composite. Reproduced with permission. ${ }^{92}$ Copyright 2019, Royal Society of Chemistry. 

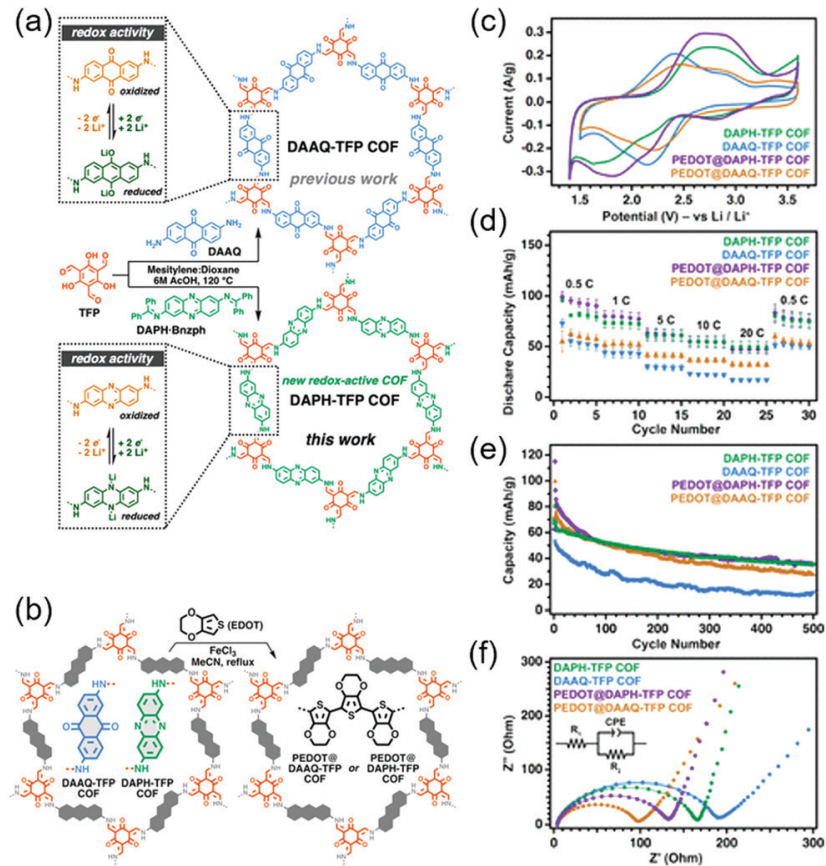

(d)

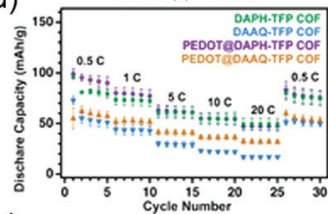

(e)

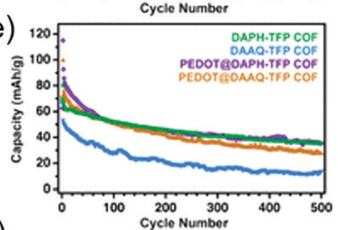

(f)

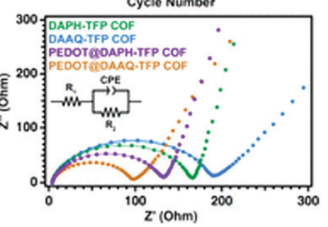

Fig. 11 (a) Design and synthesis of phenazine and anthraquinone-based COFs. (b) Depiction of incorporation of polyethylenedioxythiophene (PEDOT) into COF pores. (c) CV curves of COFs and PEDOT-modified COFs. (d) Rate capability of all COFs. (e) 500 Galvanostatic chargedischarge cycles for all COFs. (f) Impedance measurement of all COFs in a coin cell. Reproduced with permission. ${ }^{94}$ Copyright 2020, American Chemical Society.

This difference was attributed to the higher $\mathrm{Li}^{+}$diffusion coefficient of DAPH-Tp $\left(1.1 \times 10^{-9} \mathrm{~cm}^{2} \mathrm{~s}^{-1}\right)$ compared to that of DAAQ-Tp $\left(1.6 \times 10^{-10} \mathrm{~cm}^{2} \mathrm{~s}^{-1}\right)$. The presence of conductive PEDOT did not significantly affect the power density and $\mathrm{Li}^{+}$ diffusion coefficient of DAPH-Tp, possibly because this COF exhibited an intrinsically high electrical conductivity. However, both DAPH-Tp and DAAQ-Tp showed a capacity retention of $\sim 50 \%$ after 500 cycles, which indicated the electrochemical instability of their $\beta$-ketoenamine linkages.
Similarly to commercial graphite, COFs can be used as $\mathrm{Li}^{+}$-intercalating electrode materials at very negative potentials. Wang's group incorporated CNTs into an imine-linked COF with 1,3,5-terformylbenzene and $p$-diaminobenzene moieties, expecting the $\pi$-electron cloud of the benzene ring to trigger 14-electron redox chemistry in the $0.0-3.0 \mathrm{~V}$ range. ${ }^{95}$ The COF itself maintained a capacity of $125 \mathrm{~mA} \mathrm{~h} \mathrm{~g}^{-1}$ for 300 cycles at $100 \mathrm{~mA} \mathrm{~g}^{-1}$, although $S_{\text {BET }}$ was low $\left(44.36 \mathrm{~m}^{2} \mathrm{~g}^{-1}\right)$ because of the poor COF crystallinity. In contrast, the capacity of the COF/CNT system continuously increased (e.g., from 383 to $1021 \mathrm{~mA} \mathrm{~h} \mathrm{~g}^{-1}$ after 325 cycles) during cycling. Using various analyses, the researchers found that the COF interlayer distance increased after lithiation at $<1.0 \mathrm{~V}$ and suggested that the above capacity increase upon cycling might be caused by the activation of this process. $\mathrm{Li}^{+}$intercalation into benzene rings accounted for $\sim 85 \%$ of the capacity at the 500 th cycle. Density functional theory (DFT) calculations indicated that two $\mathrm{Li}^{+}$ions reacted with the imine linkage at $1.4-2.7 \mathrm{~V}$, while the remaining $12 \mathrm{Li}^{+}$ions were intercalated into COF interlayers. The same group designed an imine-linked TFPB-COF constituting 1,2,4,5tetrakis-(4-formylphenyl)benzene units and chemically exfoliated this COF to nanosheets (CONs). ${ }^{82}$ These nanosheets were mixed with $\mathrm{MnO}_{2}$ nanoparticles to prevent the close stacking of the former and promote smooth $\mathrm{Li}^{+}$intercalation. ${ }^{95}$ Wang's group also prepared fluorinated triazine-based CONs (named E-FCTF) with a thickness of 4-5 nm (Fig. 12). ${ }^{96}$ Within a potential range of 0.0-3.0 V, E-FCTF demonstrated 1000 stable cycles, delivering a capacity of $581 \mathrm{~mA} \mathrm{~h} \mathrm{~g}^{-1}$ at $2 \mathrm{~A} \mathrm{~g}^{-1}$. DFT calculations showed that the CON bandgap was reduced to $1.45 \mathrm{eV}$ because of the presence of fluorine substituents, which was held responsible for increased electrical conductivity and improved electrochemical performance. Vaidyanathan's group utilized selfexfoliated triazole CONs, (IISERP)-CON1, with a thickness of 2-6 $\mathrm{nm}$ as a $\mathrm{Li}^{+}$-intercalating electrode. ${ }^{97}$ The $S_{\mathrm{BET}}$ of these CONs equaled $507 \mathrm{~m}^{2} \mathrm{~g}^{-1}$, while capacity reached $720 \mathrm{~mA} \mathrm{~h} \mathrm{~g}^{-1}$ at $100 \mathrm{~mA} \mathrm{~g}^{-1}$ in the potential range of $0.0-3.0 \mathrm{~V}$. The observation of a weak redox signal of the imine linkage suggested the predominance of $\mathrm{Li}^{+}$intercalation. After $\mathrm{Li}^{+}$intercalation, (a)

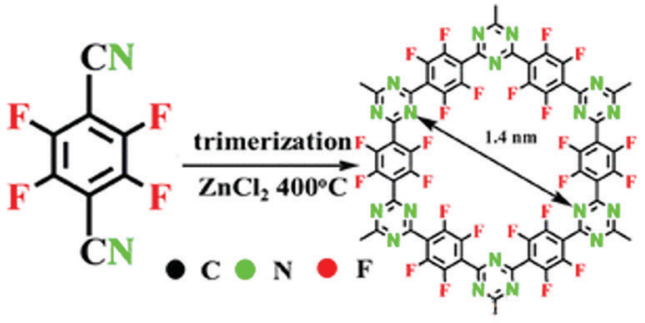

(b)

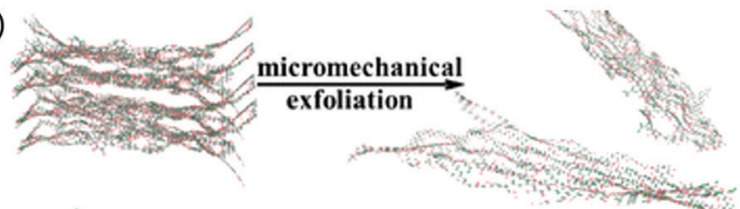

(c)
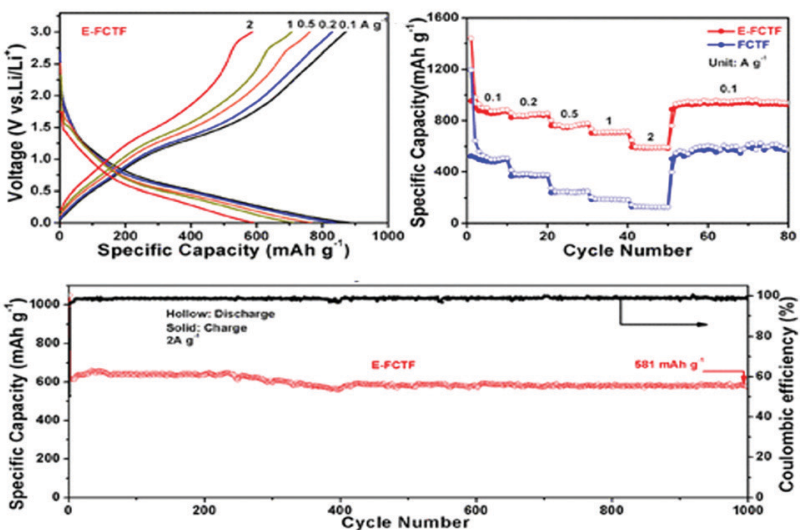

Fig. 12 Fluorinated triazine COFs performance in Li-ion battery. (a) Design and synthesis of fluorinated COF (FCTF). (b) Exfoliation of FCTF by micromechanical ball-milling method to few-layered E-FCTF. (c) Electrochemical performances of E-FCTF and FCTF for in lithium ion battery. Reproduced with permission. ${ }^{96}$ Copyright 2019, American Chemical Society. 
the bandgap was reduced to $0.144 \mathrm{eV}$. Sun's group employed both azo $(\mathrm{N}=\mathrm{N})$ and $\mathrm{C}=\mathrm{O}$ functional groups as redox moieties. ${ }^{98}$ Azobased small molecules underwent two-electron transfer in the potential range of $1.2-1.6 \mathrm{~V} \cdot{ }^{99} \mathrm{~A} \beta$-ketoenamine-linked azo COF, Tp-AZO COF, showed a capacity of $306 \mathrm{~mA} \mathrm{~h} \mathrm{~g}{ }^{-1}$ at $1 \mathrm{~A} \mathrm{~g}^{-1}$ for 3000 cycles within $0.0-3.0 \mathrm{~V}^{100}$ Although many reports determined the total number of transferred electrons from capacity, $\mathrm{Li}^{+}$intercalation at negative potentials was always accompanied by electrolyte solution decomposition, and future work should therefore address the concomitant formation of solid-electrolyte interphases.

Zhang's group adopted a new approach to COF electrode fabrication for all-solid-state LIBs. Specifically, a truxenonebased $\beta$-ketoenamine-linked COF, named as COF-TRO, was assembled with argyrodite and a 77.5 as solid-state electrolytes and with InLi as the electrode. ${ }^{101}$ The major lithiation/delithiation events using $6 \mathrm{Li}^{+}$occurred at $1.55 \mathrm{~V}$ at the multiple $\mathrm{C}=\mathrm{O}$ groups of truxenone, whereas the carbonyl groups of $\beta$-ketoenamine linkages were not significantly involved in lithiation/delithiation. The all-solid-state LIB based on the above COF showed a capacity of $268 \mathrm{~mA} \mathrm{~h} \mathrm{~g}^{-1}$ at $0.1 \mathrm{C}$, which demonstrated the versatile applicability of $\mathrm{COF}$ electrodes to various battery configurations.

Aside from the redox moiety, the role of linkage is pivotal. The linkage often governs the electron-transfer rate of the redox core and chemical/structural stability of the COF electrode. Byon's group highlighted this issue by designing three linkages, thiazole-fused ring, imine, and $\beta$-ketoenamine, introduced to the azo moiety, and examined these COF electrodes in Li-ion cells. ${ }^{102}$ The azo integrated with the thiazole-fused ring showed the concerted two-electron transfers within 1.5-2.0 V. The extended $\pi$-conjugation structure formed by the thiazole-fused ring stabilized the COF structure during the discharging and charging processes and delivered stable 5000 cycles at 10C. In addition, an excellent rate capability and a power density of $2800 \mathrm{~W} \mathrm{~kg}^{-1}$ at $40 \mathrm{C}$ were evaluated, envisioning that the overlapping $\mathrm{p}$ orbitals of azo moieties enhanced electronic conductivity toward out-of-plane of the COF electrode. By contrast, the imine and $\beta$-ketoenamine linkages incorporated with azo exhibited a slow two-step electron-transfer process and structural deformation that caused the partial dissolution of COF electrode and impotent cyclability.

\section{Sodium- and potassium-COF batteries}

Na- and K-ion batteries have been intensively investigated because of their low cost. ${ }^{103-106}$ Graphite is the most commonly used negative electrode material for commercial LIBs, where $\mathrm{Li}^{+}$intercalates into the graphitic layers to form $\mathrm{LiC}_{6}$ (enthalpy of formation, $\Delta H_{\mathrm{f}}=$ $-16.4 \mathrm{~mol}^{-1}$ ). For $\mathrm{Na}^{+}$and $\mathrm{K}^{+}, \Delta H_{\mathrm{f}}$ for $\mathrm{NaC}_{6} / \mathrm{NaC}_{8}$ and $\mathrm{KC}_{8}$ equals +20 and $-27.5 \mathrm{~kJ} \mathrm{~mol}^{-1}$, respectively. ${ }^{107}$ The difficulty of $\mathrm{Na}^{+}$ intercalation into graphite highlights the development of alternative carbon materials featuring both amorphous and crystalline structures. In addition, the redox events of sodiation play a more significant role in maintaining a proper capacity level. Considering these characteristics, several COFs have been used as the negative electrodes.

Lei and co-workers first demonstrated that organic molecules with an extended $\pi$-conjugation can withstand severe volume changes during $\mathrm{Na}^{+}$insertion, revealing that this effect is further improved in layered structures. ${ }^{108}$ Pradhan's group reported COF-based sodium-ion batteries (SIBs) ${ }^{109}$ In the corresponding COF, 1,3,5-tris(4-formylphenyl)benzene and 1,3,5-tris(4aminophenyl)triazine were interlocked through imine linkages to create C3-C3 symmetry. The CV curve of this TFPB-TAPT COF showed two pairs of redox peaks at $0.9 \mathrm{~V}$ and $0.35 \mathrm{~V} v s . \mathrm{Na} / \mathrm{Na}^{+}$, which corresponded to the redox reactions of imine and triazine $\mathrm{N}$ atoms with $\mathrm{Na}^{+}$, respectively. However, the related galvanostatic profiles did not show apparent voltage plateaus, suggesting the predominance of $\mathrm{Na}^{+}$intercalation and not that of $\mathrm{N}$ atom and $\mathrm{Na}^{+}$reactions. At $30 \mathrm{~mA} \mathrm{~g}{ }^{-1}$, the capacity approached $246 \mathrm{~mA} \mathrm{~h} \mathrm{~g}^{-1}$ for the first cycles and $125 \mathrm{~mA} \mathrm{~h} \mathrm{~g}{ }^{-1}$ after 500 cycles, that is, the capacity decay per cycle equaled $0.1 \%$. When current density increased from 30 to $200 \mathrm{~mA} \mathrm{~g}^{-1}$, specific capacity decreased from 245 to $145 \mathrm{~mA} \mathrm{~h} \mathrm{~g}{ }^{-1}$. High-resolution transmission electron microscopy imaging showed that the interlayer distance of TFPB-TAPT COF increased from 3.4 to $3.8 \AA$ through $\mathrm{Na}^{+}$intercalation (sodiation). Park's group used several layered CONs to mitigate structural distortion during sodiation. ${ }^{110}$ In this case, monomers were dispersed in an organic solvent and subjected to Stille cross-coupling reactions under solvothermal and reflux conditions. The solvothermal method provided CONs with fibrous morphologies, whereas agglomerated sheets were obtained under reflux conditions. Various types of CONs were prepared by integration of the planar structure of triazine/thiophene or the distorted structure of triphenylamine/thiophene. Among these CONs, the solvothermally synthesized planar triazine/thiophene CON-16 featured the best performance, delivering a capacity of $250 \mathrm{~mA} \mathrm{~h} \mathrm{~g}{ }^{-1}$ for 30 cycles at $100 \mathrm{~mA} \mathrm{~g}^{-1}$, which was ascribed to efficient ion mass transport caused by a large surface area $\left(300 \mathrm{~m}^{2} \mathrm{~g}^{-1}\right)$.

During the cathodic reaction, the redox core is converted to radical intermediates, which may diminish the chemical stability of COFs by favoring chemical decomposition and dimerization. The design of $\pi-\pi$ and $\mathrm{p}-\pi$ conjugation systems for delocalizing electrons can mitigate this problem. ${ }^{111,112} \mathrm{Lu}$ and co-workers investigated radical intermediates using a DAAQ-Tp COF electrode (Fig. 13). ${ }^{113}$ During sodiation, four stepwise processes were observed (as demonstrated by electron paramagnetic resonance spectroscopy, Raman spectroscopy, and computational simulations), namely the formation of the anthraquinone $\mathrm{C}-\mathrm{O}^{\bullet}$ radical, the $\alpha-\mathrm{C}$ radical, the $\beta$-ketoenamine $\mathrm{C}-\mathrm{O}^{\bullet}$ radical, and the $\alpha-\mathrm{C}$ anion. The stability of the $\alpha-\mathrm{C}$ radical was critical for determining electrode stability and depended on COF thickness. Four different thicknesses of DAAQTp COF (4-12, 50-85, 100-180, and 100-250 nm) were investigated to reveal that with decreasing stacking thickness, the $\alpha$-C radical became stabilized, while electron self-exchange between adjacent small-molecule radicals was suppressed. The 4-12 nm-thick DAAQ-Tp COF exhibited a stable capacity of $420 \mathrm{~mA} \mathrm{~h} \mathrm{~g}^{-1}$ at $50 \mathrm{~mA} \mathrm{~g}^{-1}$ and the lowest charge transfer resistance of $146 \Omega$. During 10000 cycles at $5 \mathrm{~A} \mathrm{~g}^{-1}$, this electrode retained $\sim 100 \%$ of its capacity, showing the best performance among the $\mathrm{Na}^{+}$-intercalating electrodes for SIBs.

Chen's group increased the number of redox-active sites using nitrogen-rich pyrazine and carbonyl functionalities to 
(a)

accommodate $\mathrm{Na}^{+}$ions at high concentrations. ${ }^{114}$ The corresponding honeycomb-morphology TQBQ COF was prepared with a thickness of $5 \mathrm{~nm}$, providing an electronic conductivity of $1.973 \times 10^{-9} \mathrm{~S} \mathrm{~cm}^{-1}$. Twelve- $\mathrm{Na}^{+}$redox chemistry was involved in the potential range of $1.0-3.5 \mathrm{~V} v s$. Na/ $\mathrm{Na}^{+}$. As a result, a high specific capacity of $453 \mathrm{~mA} \mathrm{~h} \mathrm{~g}^{-1}$ was obtained at $20 \mathrm{~mA} \mathrm{~g}^{-1}$, and a capacity retention of $96 \%$ was obtained after 1000 cycles at $1.0 \mathrm{~A} \mathrm{~g}^{-1}$. Using a similar strategy, Vaidyanathan's group implanted multiple $\mathrm{N}$ heteroatoms into $\beta$-ketoenaminelinked COFs to adjust their electronic energy levels. ${ }^{115}$ These COFs, IISERP-COF16, -17 , and -18, contained terphenyl spacers, $s$-tetrazine units, and $s$-tetrazine bispyridine units, respectively. The lowest unoccupied molecular orbital (LUMO) energy of IISERP-COF18 was estimated as $-4.31 \mathrm{eV}$, which was lower than that of IISERP-COF16 $(-3.75 \mathrm{eV})$ owing to its high $\mathrm{N}$ content. Among them, IISERP-COF-18 showed a stable capacity of $300 \mathrm{~mA} \mathrm{~h} \mathrm{~g}{ }^{-1}$ over 1400 cycles at $1 \mathrm{~A} \mathrm{~g}^{-1}$. This was attributed to the lower charge transfer resistance of IISERP-COF-18 (225 $\Omega$ ) compared to those of IISERP-COF-16 (620 $\Omega$ ) and IISERP-COF-17 $(600 \Omega)$ due to the enhancement of $\mathrm{Na}^{+}$transport by the bispyridinetetrazine segment established along the nanochannel.

Reports on potassium-ion batteries (PIBs) are scarce. Wang's group interlocked 4,4-biphenyldiboronic acid and 2,3,6,7,10,11hexahydroxytriphenylene to form a boronic ester-linked $\mathrm{COF}^{116}$ with a LUMO energy of $-4.23 \mathrm{eV}$, which was suitable for the negative electrodes of PIBs. ${ }^{117}$ The related capacity was $203 \mathrm{~mA} \mathrm{~h} \mathrm{~g}{ }^{-1}$ at $25 \mathrm{~mA} \mathrm{~g}^{-1}$ in a potential range of $0.0-3.0 \mathrm{~V} v s . \mathrm{K} / \mathrm{K}^{+}$, significantly decreasing to $12 \mathrm{~mA} \mathrm{~h} \mathrm{~g}{ }^{-1}$ at $5000 \mathrm{~mA} \mathrm{~g}^{-1}$. The deposition of boronic ester-linked COFs on CNTs increased the capacity to 330 and $68 \mathrm{~mA} \mathrm{~h} \mathrm{~g}^{-1}$ at 25 and $5000 \mathrm{~mA} \mathrm{~g}^{-1}$, respectively, which was ascribed to the increased conductivity and better interaction of $\mathrm{K}^{+}$through the aromatic $\pi$-cloud. This PIB electrode

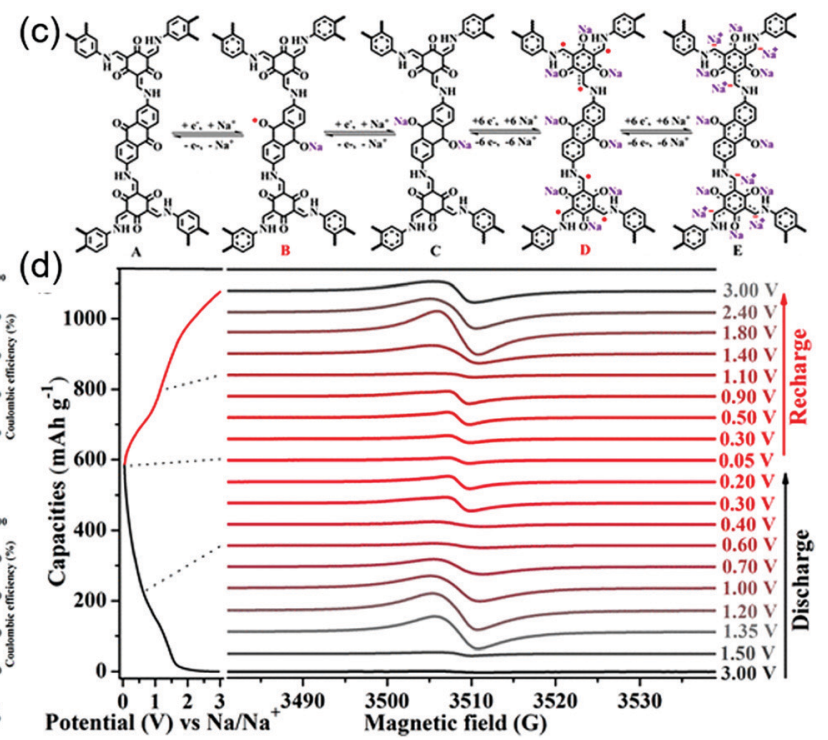
and $1 \mathrm{~A} \mathrm{~g}^{-1}$, respectively.

\section{Aqueous zinc-COF batteries}

Recently, numerous efforts have been made to construct rechargeable batteries utilizing multivalent metal ions, particularly $\mathrm{Zn}^{2+}$ ions, in aqueous electrolytes. Compared to alkali-ion batteries, which require strict atmospheric conditions, aqueous zinc-ion batteries (ZIBs) offer the benefits of low Zn cost, high capacity (820 mA h g ${ }^{-1}$ for $\mathrm{Zn}$ anode), low redox potential of $\mathrm{Zn}^{2+} / \mathrm{Zn}$ $(-0.76 \mathrm{~V} v$ s. SHE), and facile battery fabrication. However, the activation energy for the migration of $\mathrm{Zn}^{2+}$ is greater than that for the migration of monovalent $\mathrm{Li}^{+}$, as these ions have similar sizes ( 0.74 and $0.76 \AA$, respectively) but different charges, that is, the increased solvation of $\mathrm{Zn}^{2+}$ ions impedes charge transfer. Consequently, organic electrodes are indispensable for ZIBs, offering the advantages of structural flexibility and ease of coordination with multivalent metal ions. In this case, COFs can play an important role in facilitating $\mathrm{Zn}^{2+}$ migration through porous channels while minimizing coulombic repulsion by efficient molecular design.

In their earliest work on zinc-COF batteries, Banerjee's group designed $\beta$-ketoenamine-linked and benzoquinonebased HqTp COF electrodes (Fig. 14). ${ }^{118}$ The electron-rich HqTp backbone comprising $\mathrm{C}=\mathrm{O}$ and $\mathrm{N}-\mathrm{H}$ groups could easily coordinate $\mathrm{Zn}^{2+}$ to form $\mathrm{HqTp} \cdot \mathrm{Zn}^{2+}$, which enhanced layer stabilization relative to pristine HqTp. Electrostatic potential mapping predicted that the electrochemical reaction of $\mathrm{Zn}^{2+}$ occurred entirely at $\mathrm{C}=\mathrm{O}$ groups, while $\mathrm{N}-\mathrm{H} \cdots \mathrm{Zn}^{2+}$ interactions contributed to chemical stabilization. Aqueous HqTP COF cells showed a capacity of $276 \mathrm{~mA} \mathrm{~h} \mathrm{~g}^{-1}$ at $125 \mathrm{~mA} \mathrm{~g}^{-1}$ in the potential window of $0.2-1.8 \mathrm{~V}$, revealing the participation of 
(a)
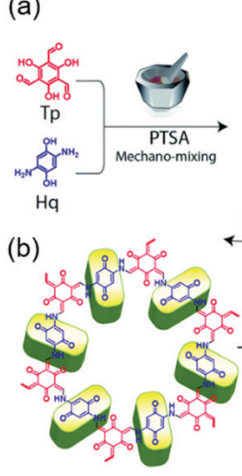
$\stackrel{[0]}{\longleftarrow}$
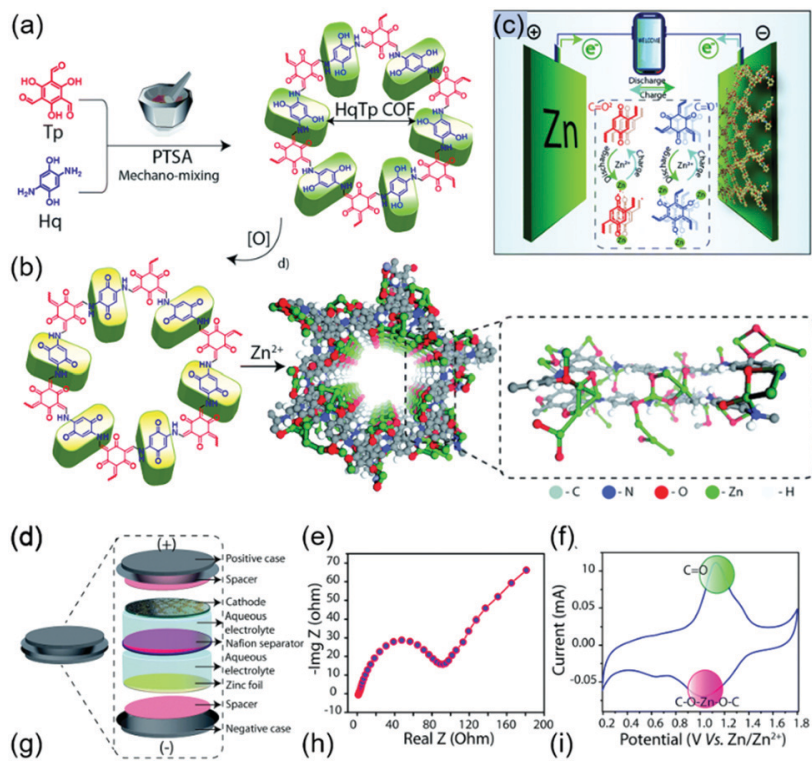

(e)
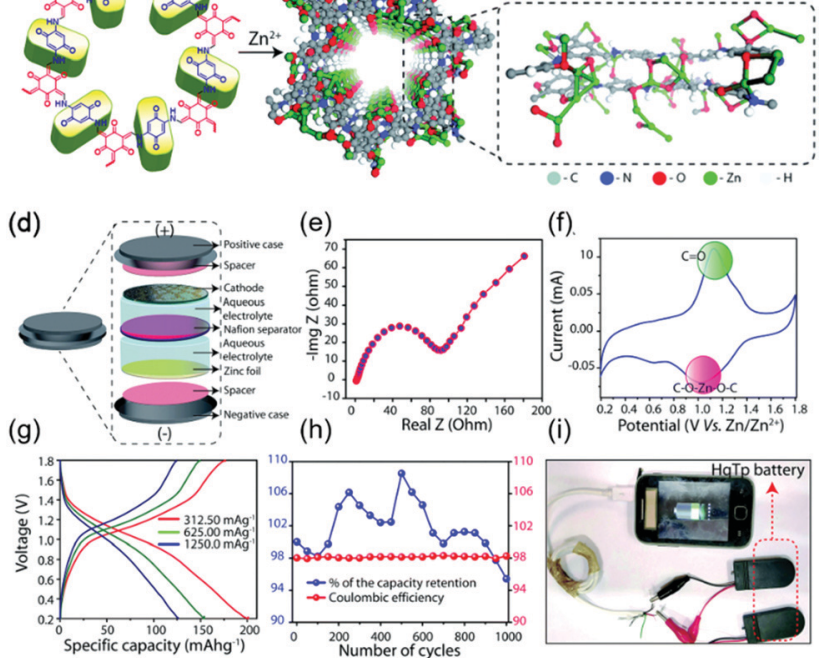

(f).

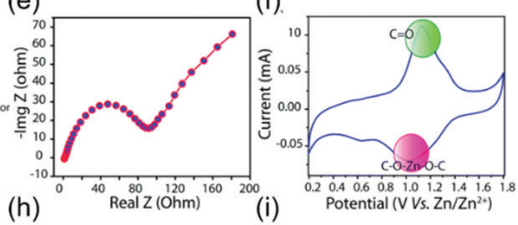

Fig. 14 COFs electrode in aqueous Zn-ion battery. (a) Design and synthesis of HqTp COF. (b) Redox process involving quinone-hydroquinone pair in COF. Also provided is a molecular model of COF showing the interlayer interaction of $\mathrm{Zn}^{2+}$. (c) Depiction of the aqueous $\mathrm{Zn} / \mathrm{HqTp}$ battery. (d) Depiction of a $\mathrm{Zn} / \mathrm{HqTp}$ coin cell. (e) Impedance measurement of $\mathrm{Zn} / \mathrm{HqTp}$ coin cell. (f) $\mathrm{CV}$ profile of $\mathrm{Zn} / \mathrm{HqTp}$ coin cell. (g) Charge-discharge profiles at various current densities. (h) Stable 1000 charge-discharge cycles. (i) Device fabrication using $\mathrm{Zn} / \mathrm{HqTp}$ combination shown to charge a smartphone. Reproduced with permission. ${ }^{118}$ Copyright 2019, Royal Society of Chemistry.

$7.5 \mathrm{Zn}^{2+}$ ions per unit cell. Even at a very high current density of $3750 \mathrm{~mA} \mathrm{~g}^{-1}$, the cell sustained a capacity of $85.0 \mathrm{~mA} \mathrm{~h} \mathrm{~g}^{-1}$ and showed a capacity loss of only 5\% after 1000 cycles. Later experiments revealed that not only $\mathrm{Zn}^{2+}$ ions but also $\mathrm{H}^{+}$ions were involved in the operation of aqueous $\mathrm{Zn}$ cells. ${ }^{119}$ Therefore, ZIBs with COFs are likely to have both battery and capacitor characteristics and are therefore called capatteries. Alshareef's group demonstrated the co-participation of $\mathrm{Zn}^{2+}$ and $\mathrm{H}^{+}$in reactions with a phenanthroline-based COF (PA-COF) in a zinc-ion capattery. ${ }^{120}$ The $\mathrm{N}$ atoms of PA-COF acted as $\mathrm{Zn}^{2+}$ coordination sites, allowing a maximum of $18 \mathrm{Zn}^{2+}$ ions per unit structure to participate in discharge. At a current density of $0.1 \mathrm{~A} \mathrm{~g}^{-1}$ and within a potential range of $0.15-1.75 \mathrm{~V}$, the capacity approached $247 \mathrm{~mA} \mathrm{~h} \mathrm{~g}{ }^{-1}$. A capacity loss of $0.38 \%$ per cycle was recorded over 10000 galvanostatic cycles at $1.0 \mathrm{~A} \mathrm{~g}^{-1}$. When $\mathrm{D}_{2} \mathrm{O}$ was used, solid-state NMR spectroscopy revealed the presence of $\mathrm{D}^{+} / \mathrm{OD}^{-}$and $\mathrm{D}_{2} \mathrm{O}$ in the PA-COF electrode after discharge, demonstrating the protonation of $\mathrm{COF}$ layers. In addition, the precipitation of the triclinic crystals of $\mathrm{Zn}_{4}(\mathrm{OH})_{6} \mathrm{SO}_{4} \cdot 5 \mathrm{H}_{2} \mathrm{O}$ on PA-COF suggested protonation, as this precipitate could be observed at high local $\mathrm{pH}$. The contribution of $\mathrm{Zn}^{2+}$ to the overall capacity was measured as $60 \%$ by inductively coupled plasma atomic emission spectroscopy, indicating that the contribution of $\mathrm{H}^{+}$ions equaled $\sim 40 \%$.

Table S3 (ESI $\dagger$ ) summarizes all COFs in alkali and zinc ion battery. These numerous studies using COFs as alkali-ion battery electrodes have clearly addressed the advantages and challenges of organic-based redox moieties. Although chemical and structural stability could be improved through certain COF designs, future works should still focus on improving both energy and power density for practical use.

\section{COF-Based lithium-sulfur batteries}

Lithium-sulfur (Li-S) batteries, which can theoretically deliver a capacity of $\sim 1675 \mathrm{~mA} \mathrm{~h} \mathrm{~g}^{-1}$ and a specific energy density of $2600 \mathrm{~W} \mathrm{~h} \mathrm{~kg}{ }^{-1}$, are considered as next-generation Li battery. However, the reduction of elemental sulfur $\left(\mathrm{S}_{8}\right)$ to polysulfides (PSs; $\mathrm{Li}_{2} \mathrm{~S}_{n}, 2<n<8$ ) during discharge (Fig. 15) results in serious active material loss due to dissolution. This problem can be mitigated through the use of porous materials, which can be impregnated with sulfur up to a loading of $\sim 70 \mathrm{wt} \%$. Various mesoporous carbon electrodes and conducting polymers have been used as positive electrodes for Li-S cells. COFs have also been applied as an electrode platform, and the effects of pore size and molecular moiety on PS species were systematically investigated. In particular, two methods of sulfur confinement have been intensively studied, namely the physisorption/infusion of elemental sulfur into the micro/mesopores of COFs using melt-diffusion methods and the covalent attachment of sulfur (as PS chains) to COF moieties by post-synthetic modifications or as a protective coating on separators. In the former case, the PSs are gradually dissolved during long-term cycling, which results in a notable shuttling effect, namely the transportation of PSs to the negative electrode side. The introduction of sulfiphilic moieties into COFs allows the PSs to preferentially stay around these COFs and suppresses the shuttling effect, which suggests that the two methods can be combined to synergistically enhance the cyclability of Li-S cells.

Wang's group began studying COF-based sulfur cells using a covalent triazine framework denoted as CTF-1. Annealing of the mixture of CTF- 1 and elemental sulfur at $155{ }^{\circ} \mathrm{C}$ allowed the sulfur to infiltrate the COF pores. ${ }^{121}$ Compared to pristine CTF-1, CTF-1 with sulfur-filled pores (CTF-1/S) featured a lower crystallinity
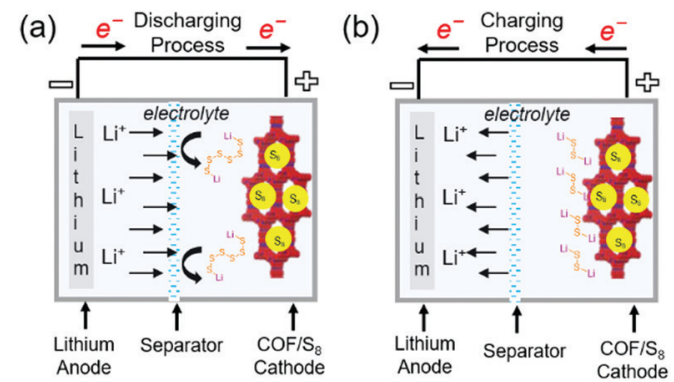

Fig. 15 Representation of working principles in COF-based Li-sulfur batteries. (a) Discharging process (b) charging process in COF-based $\mathrm{Li}-$ sulfur batteries. 
and BET surface area $\left(1.6 \mathrm{~m}^{2} \mathrm{~g}^{-1}\right.$ vs. $\left.789 \mathrm{~m}^{2} \mathrm{~g}^{-1}\right)$. Sulfur was physically adsorbed on the CTF-1 pores and accounted for $34 \mathrm{wt} \%$ of the total mass. The COF cells exhibited a typical discharge curve with short (at $2.3 \mathrm{~V}$ ) and long (at $\sim 2.1 \mathrm{~V}$ ) plateaus corresponding to the reduction of sulfur to $\mathrm{Li}_{2} \mathrm{~S}_{n}(2<n<8)$ and the deposition of solid lithium sulfides $\left(\mathrm{Li}_{2} \mathrm{~S}_{2}\right.$ and $\left.\mathrm{Li}_{2} \mathrm{~S}\right)$, respectively. A charge plateau typically appeared at $\sim 2.3 \mathrm{~V}$. CTF-1/S showed a capacity retention of $63.65 \%$ after 50 cycles at $0.1 \mathrm{C}$, which suggested the dissolution of PSs from CTF-1. Zhang's group attempted to confine sulfur in a $\beta$-ketoenamine linked Azo COF with a pore size of $2.7 \mathrm{~nm}$ and a pore volume density of $0.90 \mathrm{~cm}^{3} \mathrm{~g}^{-1},{ }^{122}$ showing that the sulfur content can be increased to $40 \mathrm{wt} \%$ owing to the high pore volume density. Wang's group succeeded in confining sulfur (55 wt\%) loaded into a porphyrin-based COF with a pore volume density of $0.71 \mathrm{~cm}^{3} \mathrm{~g}^{-1}$ and a pore size of $1.55 \mathrm{~nm} .{ }^{123}$ The low capacity decay of $0.16 \%$ per cycle observed for 200 cycles at $0.5 \mathrm{C}$ was attributed to the trapping of lithium PSs in small pores. ${ }^{124,125}$ Practical sulfur batteries require $\mathrm{S}$ contents of at least $70 \mathrm{wt} \%$. The same group succeeded in achieving this value using an electron-rich pyrene (Py) unit-based Py-COF ${ }^{126}$ which was ascribed to the large pore volume density $\left(1.25 \mathrm{~cm}^{3} \mathrm{~g}^{-1}\right)$ and $S_{\mathrm{BET}}\left(2093 \mathrm{~m}^{2} \mathrm{~g}^{-1}\right)$ of this COF. A capacity decay of $0.048 \%$ per cycle was observed over 550 cycles at 5C.

The addition of heteroatoms other than $\mathrm{N}$ has been used to suppress PS dissolution and, hence, the shuttle effect. Wang's group studied the impact of fluorine introduction using a sulfur-loaded fluorinated triazine framework, FCTF/S, ${ }^{127}$ showing that polar semi-ionic $\mathrm{C}-\mathrm{F}$ bonds attract PSs. The CV profiles of FCTF/S displayed cathodic and anodic waves positively and negatively shifted compared to those of fluorine-free $\mathrm{COF} / \mathrm{S}$, respectively, suggesting the occurrence of a fast redox reaction between PSs and $\mathrm{F}$ atoms. The initial capacity of $1131 \mathrm{~mA} \mathrm{~h} \mathrm{~g}^{-1}$ at $0.5 \mathrm{C}$ exceeded that of the fluorine-free $\mathrm{COF} / \mathrm{S}\left(862 \mathrm{~mA} \mathrm{~h} \mathrm{~g}^{-1}\right)$. The FCTF/S COF cells also exhibited a $73.7 \%$ capacity retention after 150 cycles at $0.5 \mathrm{C}$, which, however, was similar to that of the fluorine-free COF/S. ${ }^{121}$ Zhang's group prepared fluorinated crystalline COF-F/S where sulfur was covalently linked through partial nucleophilic substitution. ${ }^{128}$ Although a sulfur loading of $60 \mathrm{wt} \%$ was achieved through covalent bonding and physisorption in COF-F/S pores, a $40 \mathrm{wt} \%$ sulfur loss was observed during annealing at $160-225{ }^{\circ} \mathrm{C}$ attributed to physisorbed sulfur. The COF-F/S cells showed a capacity decay of $0.04 \%$ per cycle at $0.1 \mathrm{C}$. A similar strategy was put forward by Chen's group, who synthesized a vinyl-functionalized COF (COF-V) and subjected it to inverse vulcanization for the covalent linkage of $67 \mathrm{wt} \%$ sulfur. ${ }^{129}$ As a result, capacity decay rates of $0.31 \%$ per cycle over 100 cycles at $0.2 \mathrm{C}$ and $0.057 \%$ per cycle over 1000 cycles at $1 \mathrm{C}$ were achieved.

Tang's group considered that positively polarized B and negatively polarized $\mathrm{O}$ atoms were responsible for the chemisorption of $\mathrm{S}_{x}{ }^{2-}$ and the trapping of $\mathrm{Li}^{+}$in lithium PSs, respectively. These researchers synthesized a boronate esterbased COF-1 and impregnated it with sulfur to $40 \mathrm{wt} \%$ (Fig. 16). ${ }^{130}$ The initial capacity of $1655 \mathrm{~mA} \mathrm{~h} \mathrm{~g}^{-1}$ was reduced to $929 \mathrm{~mA} \mathrm{~h} \mathrm{~g}^{-1}$ after 100 cycles at $0.2 \mathrm{C}$. DFT calculations revealed the presence of highly designed lithiophilic and sulfiphilic sites in COFs for the effective trapping of lithium PSs. Triazine units as lithiophilic sites and boroxine units as sulfiphilic sites were used to prepare TB-COF/S with a $40 \mathrm{wt} \%$ sulfur loading. ${ }^{131}$ The maximum capacity of this COF $\left(1390 \mathrm{~mA} \mathrm{~h} \mathrm{~g}^{-1}\right)$ observed after the initial few activations decreased to $945 \mathrm{~mA} \mathrm{~h} \mathrm{~g}^{-1}$ after 250 cycles with a coulombic efficiency of $96.5 \%$. When TB-COF/S was dipped into a $\mathrm{Li}_{2} \mathrm{~S}_{6}$ solution, the solution color changed from orange to
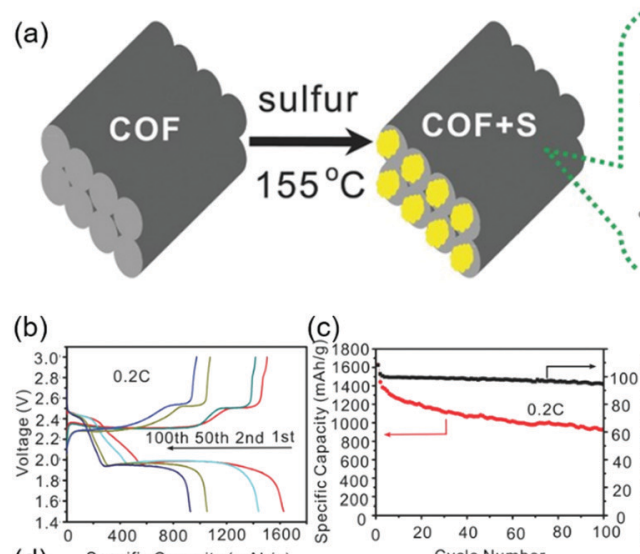

(c)
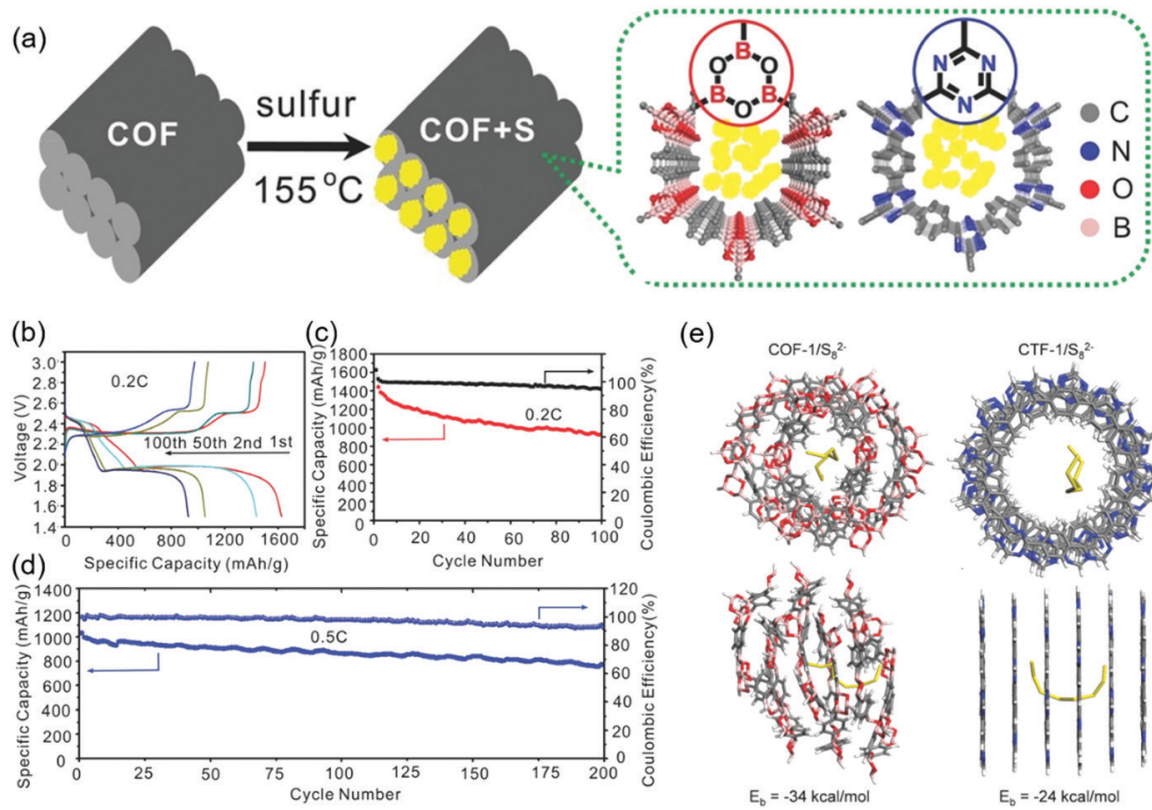

(e)

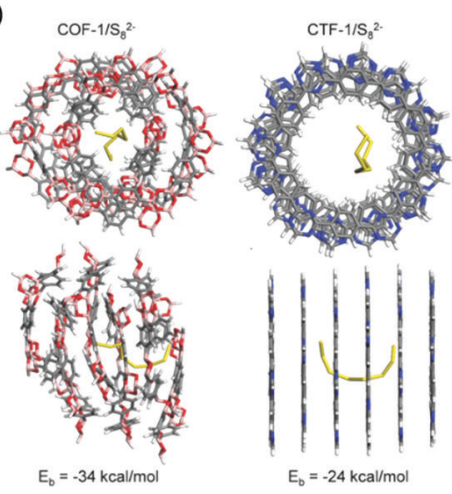

Fig. 16 Lithiophilic and sulfiphilic COF for Li-sulfur battery. (a) Illustration of COF synthesis and chemical structure of $\mathrm{N}$ and B doped COF. (b) Galvanostatic charge-discharge profiles at different stages of cycling at $0.2 \mathrm{C}$. (c) 100 charge-discharge cycles at $0.2 \mathrm{C}$. (c and d) 200 chargedischarge cycles at $0.5 \mathrm{C}$. (e) Quantum mechanical calculation of adsorption energy for $\mathrm{S}_{8}{ }^{2-}$ anions in COF-1 pores compared to a triazine framework CTF-1. Reproduced with permission. ${ }^{130}$ Copyright 2016, Wiley VCH. 
brown and then to yellow, which indicated the absorption of $\mathrm{Li}_{2} \mathrm{~S}_{6}$ on TB-COF/S. The binding energy of boron signals in the related X-ray photoelectron spectra followed the order of TB-COF > TB-COF/S > TB-COF/PSs, which indicated that the ability of the $\mathrm{B}$ atom to accept electron density through interactions with S and PSs decreased in the same order. Similar conclusions were drawn for the triazine $\mathrm{N}$ atom and $\mathrm{Li}^{+}$interaction.

To improve sulfiphilicity, Mak's group prepared a cationic ethidium bromide unit-containing COF (EB-COF-Br) and exchanged $\mathrm{Br}^{-}$ions for $\mathrm{S}_{8}{ }^{2-}$ (Fig. 17). ${ }^{132}$ Impregnation of elemental sulfur through physisorption afforded EB-COF-PS/S with a total sulfur content of $71.7 \mathrm{wt} \%$. The initial capacity was measured at $787 \mathrm{~mA} \mathrm{~h} \mathrm{~g}^{-1}$ at $0.5 \mathrm{C}$ and decreased to $555 \mathrm{~mA} \mathrm{~h} \mathrm{~g}{ }^{-1}$ after 500 cycles, which corresponded to a capacity decay of $0.058 \%$ per cycle. In the absence of the above anion exchange, EB-COF$\mathrm{Br} / \mathrm{S}$ showed an inferior capacity decay of $0.173 \%$ per cycle under the same conditions.

Yang's group embedded $\mathrm{TiO}_{2}$ nanodots $(\sim 10 \mathrm{~nm}$ in diameter) into a triazine $\mathrm{COF}$ to form a $\mathrm{TiO}_{2} / \mathrm{COF}$ structure with $S_{\mathrm{BET}}=809 \mathrm{~m}^{2} \mathrm{~g}^{-1}$ and a pore volume density of $0.87 \mathrm{~cm}^{3} \mathrm{~g}^{-1} \cdot{ }^{133}$ A shift of the Ti $2 \mathrm{p}$ binding energy in $\mathrm{TiO}_{2} / \mathrm{COF}$ indicated chemical interactions between $\mathrm{TiO}_{2}$ and triazine $\mathrm{N}$ atoms. After sulfur loading (70 wt $\%$ ), $\mathrm{TiO}_{2} / \mathrm{COF} / \mathrm{S}$ cells delivered an initial discharge capacity of $1224 \mathrm{~mA} \mathrm{~h} \mathrm{~g}^{-1}$ at $0.2 \mathrm{C}$, which decreased to $1053 \mathrm{~mA} \mathrm{~h} \mathrm{~g}{ }^{-1}$ after 300 cycles. The capacity decay of only $0.046 \%$ per cycle was the lowest reported for COF-based sulfur batteries thus far. At $0.5 \mathrm{C}$, the capacity decay was measured at $0.030 \%$ per cycle, and coulombic efficiency reached $\sim 100 \%$ after 800 cycles following the initial activation cycles, which indicating that PS shuttling was strongly inhibited.

Table S4 (ESI $\dagger$ ) summarizes all COFs in Li-sulfur battery. Works on controlling the PS shuttling effect to limit dissolution at desirable levels are still ongoing. Along with electrode development, the design of separators to block the crossover of PSs and the electrolyte solution to mitigate PS dissolution should be further explored to uplift the cyclability of Li-S cells.

\section{Ion conductors}

COFs containing ionic or chemical functionalities have been used as proton and ion conductors. Proton-conducting COFs are generally used in the proton-exchange membranes of polymer electrolyte membrane fuel cells (Fig. 18a) and typically contain groups with high proton affinities, e.g., sulfonic acid $\left(-\mathrm{SO}_{3}{ }^{-}\right)$, azo $(\mathrm{N}=\mathrm{N})$, pyrazine, imine $(\mathrm{C}=\mathrm{N})$, and perfluoroalkyl groups and exhibit intrinsic proton conductivity under both hydrous and anhydrous conditions. Alternatively, extrinsic conductivity can be achieved by loading COFs with protons. In most cases, COFs are immersed into acid (e.g., $\mathrm{H}_{3} \mathrm{PO}_{4}$ ) solutions, where protons interact with the triazole, imidazole, or anionic species of COFs. Proton conductivity measured by electrochemical impedance spectroscopy (EIS) indicates a proton-transfer mechanism, while activation energies $\left(E_{\mathrm{a}}\right)$ of less than $0.4 \mathrm{eV}$ indicate the Grotthuss hopping mechanism and, hence, fast proton transfer. Higher activation energies reflect vehicular proton transport. Ion-conducting COFs are typically used in battery separators and solid-state electrolytes (Fig. 18b). In the case of $\mathrm{Li}^{+}$conductors, either lithium salts or single ions are incorporated into COFs in the presence or absence of solvents. Nonetheless, the design of ionically conductive COFs is similar to that of protonconducting COFs. Table S6 (ESI $\dagger$ ) summarizes all COFs used in ion conduction.

\section{Proton conductors}

The first proton-conducting COF was prepared by Banerjee's group, where they crystallized an azo-interlocked, $\beta$-ketoenaminelinked TpAZO COF in the presence of $1.5 \mathrm{M} \mathrm{H}_{3} \mathrm{PO}_{4}(\mathrm{aq})$ to afford (a)
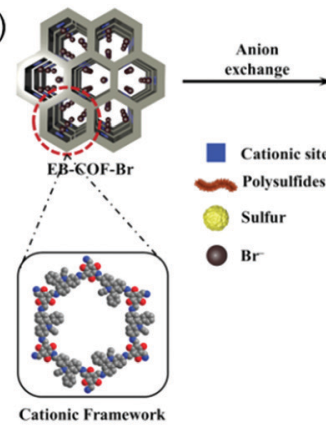

(b)

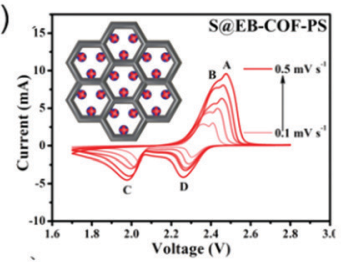

(c)
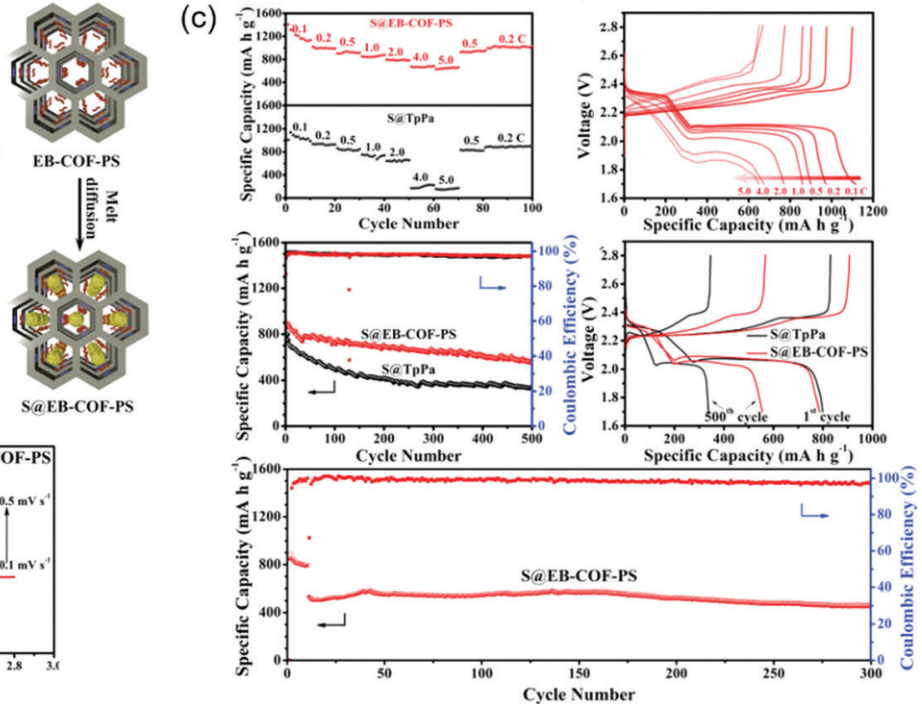

Fig. 17 Cationic COFs for trapping LiPSs in Li-sulfur battery. (a) Depiction of design, synthesis and sulfur loading in EB-COF. (b) Cyclic voltammogram of

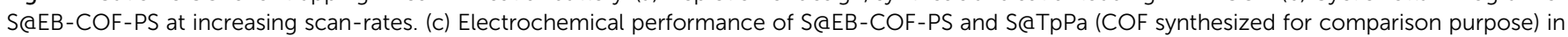
metal-COF-sulfur battery. Reproduced with permission. ${ }^{132}$ Copyright 2020, Wiley VCH. 
(a)

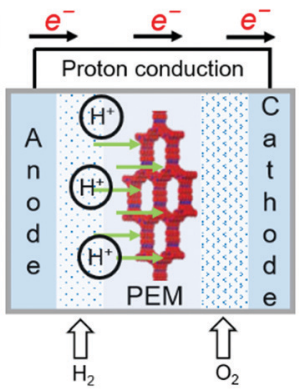

(b)

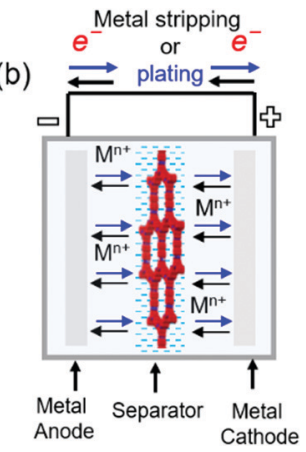

Fig. 18 Representation of working principles in (a) COFs proton conductor in polymer electrolyte membrane fuel cells (PEMFCs). (b) Metal stripping and plating through a COF based soli-state electrolyte acting as ion conductor.

PA@TpAZO (Fig. 19). ${ }^{100}$ In this COF, $\mathrm{H}^{+}$ions were anchored at the $\mathrm{N}$ atoms of the azo moieties, while the remaining $\mathrm{H}_{2} \mathrm{PO}_{4}{ }^{-}$ ions were stabilized through hydrogen bonding. For comparison, these researchers also synthesized an azo-free $\mathrm{COF}$ and impregnated with $\mathrm{H}_{3} \mathrm{PO}_{4}(\mathrm{aq})$ to afford $\mathrm{PA} / \mathrm{TpStb}$. The solid-state ${ }^{31} \mathrm{P}$ NMR spectrum of PA@TpAZO showed both $\mathrm{H}_{3} \mathrm{PO}_{4}$ and $\mathrm{H}_{2} \mathrm{PO}_{4}{ }^{-}$ signals, whereas that of $\mathrm{PA} / \mathrm{TpStb}$ displayed only the signal of $\mathrm{H}_{3} \mathrm{PO}_{4}$, indicating negligible protonation. The conductivity of PA@TpAZO was measured at $6.7 \times 10^{-5} \mathrm{~S} \mathrm{~cm}^{-1}$ at $340 \mathrm{~K}$ under the anhydrous conditions typical of a dry argon environment and increased to $9.9 \times 10^{-4} \mathrm{~S} \mathrm{~cm}^{-1}$ at a relative humidity (RH) of $98 \%$ at $332 \mathrm{~K}$. In comparison, PA/TpStb had a very low conductivity under anhydrous conditions, which increased to $2.3 \times 10^{-5} \mathrm{~S} \mathrm{~cm}^{-1}$ at $98 \%$ RH. The activation energy $\left(E_{\mathrm{a}}\right)$ of PA@TpAZO was as low as at $0.11 \mathrm{eV}$. Nonetheless, the proton conductivity of PA@TpAZO was lower than that of metal-organic frameworks, Nafion, and sulfonated polyether ether ketone. ${ }^{134-136}$ The same group used the covalent bonding of proton-conducting functional groups to improve intrinsic proton conductivity. ${ }^{137}$ Sulfonic acid $\left(-\mathrm{SO}_{3} \mathrm{H}\right)$ groups were integrated with the $\mathrm{COF}$ backbone to form $\mathrm{TpPa}-$ $\mathrm{SO}_{3} \mathrm{H}$. However, as the proton conductivity $\left(1.7 \times 10^{-5} \mathrm{~S} \mathrm{~cm}^{-1}\right.$ at $393 \mathrm{~K}$ under anhydrous conditions) of this COF was lower than that of PA@TpAZO, the researchers attempted to design a pyridine-based COF backbone and interlocked it with sulfonic acid groups to afford TpPa-( $\left.\mathrm{SO}_{3} \mathrm{H}-\mathrm{Py}\right)$. Subsequently, TpPa$\left(\mathrm{SO}_{3} \mathrm{H}-\mathrm{Py}\right)$ was immersed in a solution of phytic acid that was less volatile than $\mathrm{H}_{3} \mathrm{PO}_{4}(\mathrm{aq})$, which significantly increased proton conductivity. Pyridine units intimately interacted with phytic acid, and the proton conductivities of phytic acid-loaded TpPa-Py and TpPa- $\left(\mathrm{SO}_{3} \mathrm{H}-\mathrm{Py}\right)$ at $120{ }^{\circ} \mathrm{C}$ were determined as $3.0 \times 10^{-4}$ and $5 \times 10^{-4} \mathrm{~S} \mathrm{~cm}^{-1}$, respectively. Zhao and co-workers prepared a $\beta$-ketoenamine-linked COF with two $-\mathrm{SO}_{3} \mathrm{H}$ groups in the repeat unit (NUS-10), achieving a high conductivity of $3.96 \times 10^{-2} \mathrm{~S} \mathrm{~cm}^{-1}$ at room temperature and $97 \%$ RH due to the high concentration of sulfonic acid groups. ${ }^{138}$

Jiang's group developed a TPB-DMTP-COF that contained methoxy $(-\mathrm{OMe})$ groups to stabilize the interlayer repulsive force arising from imine linkages. ${ }^{139}$ This COF showed an $S_{\mathrm{BET}}$ of $2072 \mathrm{~m}^{2} \mathrm{~g}^{-1}$, which approached the theoretical value of $2098 \mathrm{~m}^{2} \mathrm{~g}^{-1}$, and a large pore size of $3.26 \mathrm{~nm}$. TPB-DMTP-COF/ triazole, obtained after the loading of triazole units (180 wt\%) into TPB-DMTP-COF pores through vapor diffusion, showed a proton conductivity of $1.1 \times 10^{-3} \mathrm{~S} \mathrm{~cm}^{-1}$ at $403 \mathrm{~K}$. The use of imidazole instead of triazole resulted in a proton conductivity of $4.37 \times 10^{-3} \mathrm{~S} \mathrm{~cm}^{-1}$ under similar conditions. A Grotthuss hopping mechanism was proposed to explain this proton

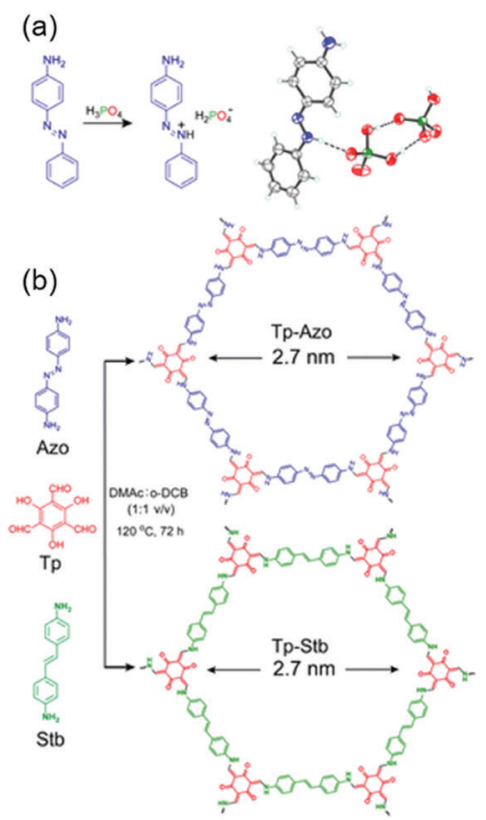

(c)
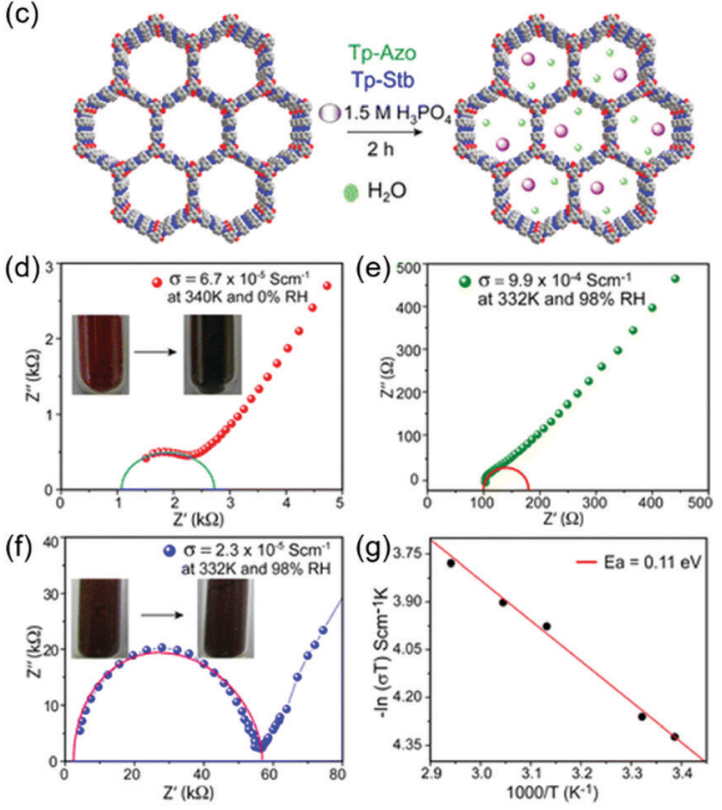

Fig. 19 COFs as proton conductors using azo-moiety. (a) Protonation of azo N-atom by $\mathrm{H}_{3} \mathrm{PO}_{4}$ (PA). (b) Design and synthesis of COFs. (c) Doping of $\mathrm{H}_{3} \mathrm{PO}_{4}$ doping in COFs. (d) Proton conductivity of PA@Tp-Azo at $0 \%$ relative humidity at $340 \mathrm{~K}$. (e) Proton conductivity of PA@Tp-Azo at $98 \%$ relative humidity at $332 \mathrm{~K}$. (f) Proton conductivity of PA@Tp-Stb at $98 \% \mathrm{RH}$ at $332 \mathrm{~K}$. (g) Calculation of activation energy ( $E_{\mathrm{a}}$ ) for PA@Tp-Azo in hydrous conditions by the methods of Arrhenius. Reproduced with permission. ${ }^{100}$ Copyright 2014, American Chemical Society. 
conduction based on an activation energy $\left(E_{\mathrm{a}}\right)$ of $0.38 \mathrm{eV}$. Both triazole- and imidazole-containing TPB-DMTP-COFs retained $~ 90 \%$ of their original weights after storage at $130{ }^{\circ} \mathrm{C}$ for one month.

Zhu's group exchanged the bromide counter-ions of a cationic COF (EB-COF-Br) for $\mathrm{PW}_{12} \mathrm{O}_{40}{ }^{3-}\left(\mathrm{PW}_{12}\right)$ to afford EB-COF-PW ${ }_{12}{ }^{140}$ This anion exchange perturbed crystallinity and the occupancy of pore spaces with the large-size $\mathrm{PW}_{12}$, thus decreasing $S_{\mathrm{BET}}$ from 774 to $8 \mathrm{~m}^{2} \mathrm{~g}^{-1}$. The proton conductivity of EB-COF-Br was measured at $2.82 \times 10^{-6} \mathrm{~S} \mathrm{~cm}^{-1}$ at room temperature and $97 \%$ $\mathrm{RH}$, increasing to $3.32 \times 10^{-3} \mathrm{~S} \mathrm{~cm}^{-1}$ for EB-COF-PW $\mathrm{CH}_{12}$ under similar conditions. The role of anions was probed by several experiments. In particular, low conductivity was observed when phosphotungstic acid was directly mixed with EB-COF-Br. In deuterated solvents, the proton conductivity of EB-COF-Br was reduced by $50 \%$, which suggested that protons originated from dissociated water in a humid environment. The hydrophilic $\mathrm{PW}_{12} \mathrm{O}_{40}{ }^{3-}$ anion could form hydrogen bonds with water molecules. As an alternative approach, N-rich COFs have been employed for proton conduction. For example, aza-COF-1 was synthesized using 2,3,6,7,10,11-hexaaminotriphenylene, and aza-COF-2 was prepared using 1,2,4,5-benzenetetramine, both of which were used as co-precursors, while hexaketocyclohexane was the common precursor. ${ }^{141}$ The aza units could be protonated in an acidic solution and could also interact with water molecules via hydrogen bonding $(\mathrm{O}-\mathrm{H} \cdots \mathrm{N}) \cdot{ }^{142,143}$ The intrinsic proton conductivity under anhydrous conditions was poor $\left(10^{-8}-10^{-9} \mathrm{~S} \mathrm{~cm}^{-1}\right.$ at $\left.323 \mathrm{~K}\right)$ but significantly increased (to $10^{-5}-10^{-6} \mathrm{~S} \mathrm{~cm}^{-1}$ ) at $97 \% \mathrm{RH}$. The $E_{\mathrm{a}}$ values of aza-COF-1 and aza-COF-2 were measured at 0.78 and $0.96 \mathrm{eV}$, respectively, suggesting vehicular mechanism-based proton transport. However, after $\mathrm{H}_{3} \mathrm{PO}_{4}$ treatment, the proton conductivities of aza-COF-1 and aza-COF-2 at $323 \mathrm{~K}$ and $97 \% \mathrm{RH}$ increased to $1.23 \times$ $10^{-3}$ and $4.80 \times 10^{-3} \mathrm{~S} \mathrm{~cm}^{-1}$, respectively. The respective $E_{\mathrm{a}}$ values were measured at 0.29 and $0.45 \mathrm{eV}$, suggesting a mixture of hopping and vehicle transport mechanisms. The higher $E_{\mathrm{a}}$ of aza-COF-2 was ascribed to the smaller crystallite size and numerous grain boundaries, which could increase resistance to proton transport.

Banerjee's group prepared flexible free-standing COF membranes without using pelletization, ${ }^{144}$ as the high pressure required for this process reduces the crystallinity of COFs and disrupts pore channels to decrease protonic conductivity. Among the three synthesized COFs (TpAZO, TpBD(Me $)_{2}$, and TpBPy), the first one comprised a proton-conducting azo moiety, while the latter two contained 3,3'-dimethylbiphenyl-4, $\mathbf{4}^{\prime}$-diamine and 2,2'-bipyridine units, respectively, both of which had no proton-conducting groups. Then, amino-p-toluene sulfonic acid $\left(\right.$ PTSA $\left.\cdot \mathrm{H}_{2} \mathrm{O}\right)$ was impregnated into COF pores to achieve a loading of $8-12 \mathrm{wt} \%$. PTSA-impregnated TpAZO with a thickness of 100-300 $\mu \mathrm{m}$ showed superior proton conductivity, measured to $6.3 \times 10^{-2} \mathrm{~S} \mathrm{~cm}^{-1}$ at $303 \mathrm{~K}$ and $95 \% \mathrm{RH}$ and $7.8 \times 10^{-2} \mathrm{~S} \mathrm{~cm}^{-1}$ at $353 \mathrm{~K}$ and $95 \% \mathrm{RH}$. The corresponding $E_{\mathrm{a}}(0.23 \mathrm{eV})$ suggested fast $\mathrm{H}^{+}$transfer based on the Grotthuss hopping mechanism. In the case of no PTSA $\mathrm{H}_{2} \mathrm{O}$ impregnation or simple mixing with PTSA $\cdot \mathrm{H}_{2} \mathrm{O}$, the proton conductivity was as low as $10^{-5}-10^{-6} \mathrm{~S} \mathrm{~cm}^{-1}$. Despite pelletization, the breaking strain reached $5.4 \%$, a value suitable for flexible membranes. Fuel cells with a proton exchange membrane prepared from PTSA-impregnated TpAZO achieved a maximum power output of $24 \mathrm{~mW} \mathrm{~cm}^{-2}$ at a current density of $90 \mathrm{~mA} \mathrm{~cm}{ }^{-2}$. Zhang's group introduced proton-accepting azo and protondonating phenolic hydroxy groups into a COF with a pore size of $1.8 \mathrm{~nm}$ to afford NKCOF- $1 .{ }^{145}$ The proton conductivities of NKCOF-1 and a similar NKCOF with larger pores $(2-3.5 \mathrm{~nm})$ were in the range of $10^{-4}-10^{-3} \mathrm{~S} \mathrm{~cm}^{-1}$ at $353 \mathrm{~K}$ and $98 \% \mathrm{RH}$, highlighting the important role of hydroxyl groups. After the impregnation of NKCOF-1 with $\mathrm{H}_{3} \mathrm{PO}_{4}$, proton conductivity at $353 \mathrm{~K}$ and $98 \% \mathrm{RH}$ dramatically increased to $1.13 \times$ $10^{-1} \mathrm{~S} \mathrm{~cm}^{-1}$, which was comparable to that of Nafion and one order of magnitude greater than that of PTSA-impregnated TpAZO. ${ }^{144,146}$ The $E_{\mathrm{a}}$ values of NKCOF-1 and $\mathrm{H}_{3} \mathrm{PO}_{4}$-impregnated NKCOF-1 ( 0.24 and $0.14 \mathrm{eV}$, respectively) indicated that proton transport was dominated by fast $\mathrm{H}^{+}$hopping. $\mathrm{H}_{3} \mathrm{PO}_{4}$-impregnated NKCOF-1 was also used as a proton exchange membrane in fuel cells, in which case a power density of $81 \mathrm{~mW} \mathrm{~cm}{ }^{-2}$ was achieved at $456 \mathrm{~mA} \mathrm{~cm} \mathrm{~cm}^{-2}$.

The aforementioned studies showed that COF films may exhibit high conductivities under humid conditions, whereas low conductivities are commonly observed under dry conditions. Recently, several reports have focused on enhancing intrinsic proton conductivity regardless of humidity. Horike's group designed superhydrophobic COFs using three perfluoroalkyldecorated hydrazone-linked 2D COFs, named COF-F $F_{x}(x=6,8$, 10) (Fig. 20). ${ }^{147}$ Although these COFs exhibited a water contact angle of $144^{\circ}$, that is., were superhydrophobic, their $\mathrm{N}$ sites and $\mathrm{CF}_{2}$ chains easily accommodated $\mathrm{H}_{3} \mathrm{PO}_{4}$ via hydrogen bonding in the porous channels, as evidenced by $2 \mathrm{D}{ }^{1} \mathrm{H}_{-}{ }^{31} \mathrm{P}$ and ${ }^{19} \mathrm{~F}^{31} \mathrm{P}$ NMR spectra. At an $\mathrm{H}_{3} \mathrm{PO}_{4}$ content of $62 \mathrm{wt} \%$, COF- $\mathrm{F}_{6}$ had a conductivity of $4.2 \times 10^{-2} \mathrm{~S} \mathrm{~cm}^{-1}$ at $313 \mathrm{~K}$ under anhydrous conditions, whereas $\mathrm{COF}^{-\mathrm{F}_{8}}$ and $\mathrm{COF}^{-\mathrm{F}_{10}}$ showed lower conductivities, possibly because of the blocking of porous channels by long perfluoroalkyl chains. The $E_{\mathrm{a}}$ values $(0.09-0.54 \mathrm{eV})$ suggested that proton conduction occurred via the Grotthuss mechanism.

To understand the effect of hydrogen bonding on proton conductivity under anhydrous conditions, Ma's group introduced various (e.g., neutral, polar, Lewis-basic, and positively charged) moieties into the porous channels of COFs. ${ }^{148}$ The corresponding four COFs, namely the neutral phenylenediaminebased PD-COF, the DAAQ-COF with $\mathrm{C}=\mathrm{O}$ groups, the 2,4,6triaminopyrimidine TAP-COF with basic $\mathrm{N}$ sites, and the EB-COF with positively charged $\mathrm{N}$ atoms were loaded with either $\mathrm{H}_{3} \mathrm{PO}_{4}$ through simple mixing or with 1,2,4-triazole by vapor diffusion to generate proton conductivity. Molecular simulations indicated that both $\mathrm{H}_{3} \mathrm{PO}_{4}$ and triazole could be aligned to the porous COF channels via hydrogen bonding with polar groups. Furthermore, $\mathrm{H}_{3} \mathrm{PO}_{4}$-loaded COFs had lower proton dissociation energies than the corresponding triazole-loaded COFs. In particular, EB-COF had the lowest dissociation energy $(2.38 \mathrm{eV})$, which was ascribed to the formation of an ion pair with $\mathrm{H}_{2} \mathrm{PO}_{4}{ }^{-}$. Long-range hydrogen bonding in the $\mathrm{H}_{3} \mathrm{PO}_{4^{-}}$or triazole-loaded EB-COF was further confirmed using a dielectric spectrometer. The observed high dielectric constants reflected fast proton dissociation arising from ion pairs in EB-COF. Indeed, the $\mathrm{H}_{3} \mathrm{PO}_{4}$-loaded EB-COF showed the highest proton conductivity of $2.77 \times 10^{-2} \mathrm{~S} \mathrm{~cm}^{-1}$ at $453 \mathrm{~K}$ 
(a)
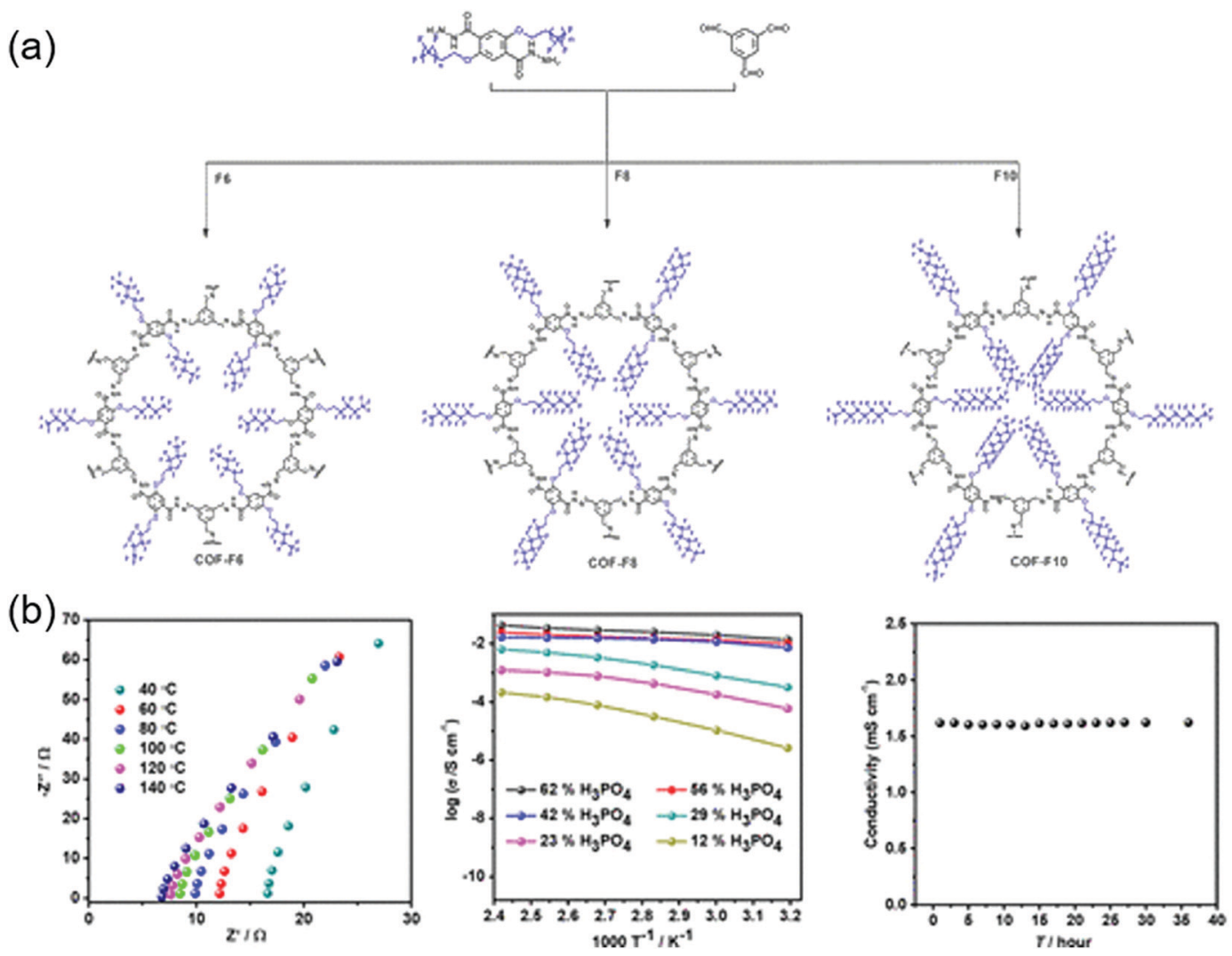

Fig. 20 Hydrophobic COFs as anhydrous proton conductor. (a) Design and synthesis of perfluoroalkylated COFs. (b) Performance of COF-F6-H in protonic conductivity in terms of impedance at various temperatures, different loading of $\mathrm{H}_{3} \mathrm{PO}_{4}$ and long time-scale testing. Reproduced with permission. ${ }^{147}$ Copyright 2018, American Chemical Society.

under anhydrous conditions, and the corresponding $E_{\mathrm{a}}(0.35 \mathrm{eV})$ implied Grotthuss mechanism-based proton transfer. Wang and co-workers improved the concept of hydrogen bonding modulation using imine functional groups on COFs. ${ }^{149}$ These researchers synthesized imine-linked thiophene-pyrene COFs to further improve electronic conductivity and introduced imidazole into porous channels via vapor diffusion. DFT calculations revealed that the hydrogen-bonding distance between imidazole and imine $(\mathrm{N}-\mathrm{H} \cdots \mathrm{N})$ in thiophene-loaded and thiophene-free COFs was estimated to $\sim 1.933$ and $1.957 \AA$, respectively. The shorter hydrogen bonding distance in the former case increased the proton hopping rate and the resulting proton conductivity. At $403 \mathrm{~K}$ under anhydrous conditions, 50 wt $\%$ imidazole-impregnated thiophene and thiophene-free COFs had proton conductivities of $\sim 3 \times 10^{-3}$ and $8.20 \times 10^{-4} \mathrm{~S} \mathrm{~cm}^{-1}$, respectively. Jiang's group employed a similar concept, using 1,3,5-tri(4-aminophenyl)benzene (TPB) and 2,5dimethylterephthalaldehyde (DMeTP) to form an imine-linked TPB-DMeTP-COF. After the impregnation of its porous channels with neat $\mathrm{H}_{3} \mathrm{PO}_{4}$, this $\mathrm{COF}$ featured a conductivity of $1.91 \mathrm{~S} \mathrm{~cm}^{-1}$ at $433 \mathrm{~K}^{150}$ Neat $\mathrm{H}_{3} \mathrm{PO}_{4}$ as the proton carrier formed a long-range hydrogen bonding network with imine $\mathrm{N}$ atoms along the porous COF channel to enable a superior proton flow.

\section{Ion conductors}

The recent surge of interest in solid-electrolyte batteries has inspired numerous studies on ion conductors. In particular, anionic COFs have been extensively used to prepare $\mathrm{Li}^{+}$-conducting channels. Du and co-workers developed a spiro borate-linked COF (ICOF) and mixed it with $\mathrm{LiOH}$ as the $\mathrm{Li}^{+}$carrier during synthesis. $^{151}$ ICOF had an ionic conductivity of $3.05 \times$ $10^{-5} \mathrm{~S} \mathrm{~cm}^{-1}$ in propylene carbonate at room temperature. The $\mathrm{Li}^{+}$transference number measured by the Bruce-VincentEvans method was 0.80 . Feng's group designed a $\mathrm{Li}^{+}$-conducting spiroborate-linked anionic COF functionalized with $\gamma$-cyclodextrin (CD-COF-Li). ${ }^{152}$ The COF was kept in a $1.0 \mathrm{M}$ solution of $\mathrm{LiPF}_{6}$ in $1 / 1(\mathrm{v} / \mathrm{v}) \mathrm{EC} / \mathrm{DMC}$ for $12 \mathrm{~h}$, and the process was repeated twice, followed by centrifugation and pelletization to afford 20 wt\% $\mathrm{LiPF}_{6}$-loaded CD-COF-Li. The $\mathrm{Li}^{+}$conductivity was $2.7 \times 10^{-3} \mathrm{~S} \mathrm{~cm}^{-1}$ at $303 \mathrm{~K}$. Li metal cells based on CD-COFLi were stable during 220 cycles of lithium plating and stripping at $0.085 \mathrm{~mA} \mathrm{~cm} \mathrm{~cm}^{-2}$. The suppression of $\mathrm{Li}$ dendrite formation was ascribed to the diminishing anion concentration gradient and suppressed polarization effects. The same group also synthesized an anionic germanate-based COF that showed a $\mathrm{Li}^{+}$conductivity of $3.5 \times 10^{-3} \mathrm{~S} \mathrm{~cm}^{-1}$ at $373 \mathrm{~K}$ after soaking in a solution of 1.0 $\mathrm{M} \mathrm{LiPF}_{6}$ in EC/DMC. ${ }^{153}$

Chen's group utilized cationic CONs comprising guanidinium moieties and $\mathrm{Cl}^{-}$counter anions (Fig. 21). ${ }^{154}$ The chloride ions were replaced with TFSI $^{-}$upon exposure to an ethanolic solution of LiTFSI to yield Li-CON-TFSI, which featured $\mathrm{a} \mathrm{Li}^{+}$conductivity of $2.09 \times 10^{-4} \mathrm{~S} \mathrm{~cm}^{-1}$ at $343 \mathrm{~K}$ and an average $\mathrm{Li}^{+}$transference number of 0.61 . This $\mathrm{Li}^{+}$conductivity was attributed to the 
(a)

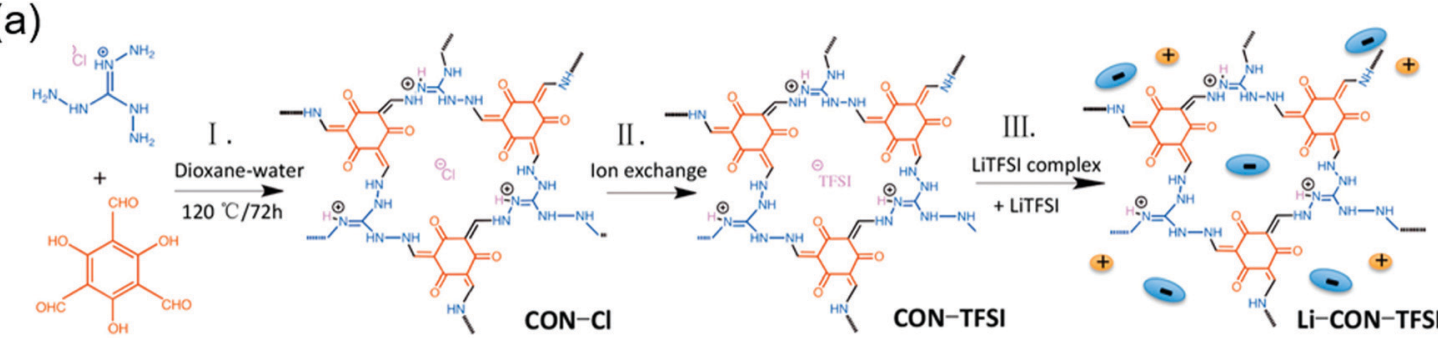

(b)

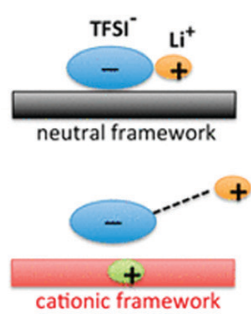

(d)

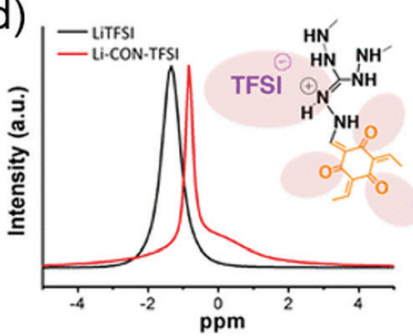

(c)

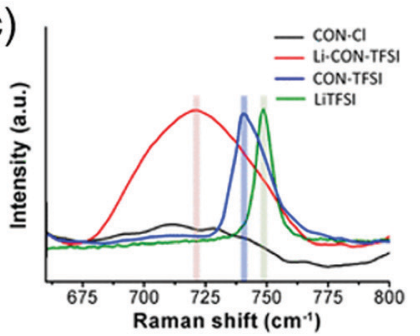

(e)

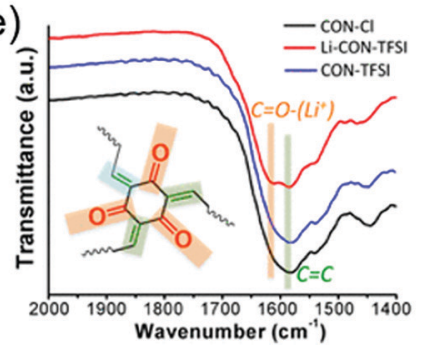

(f)

(g)
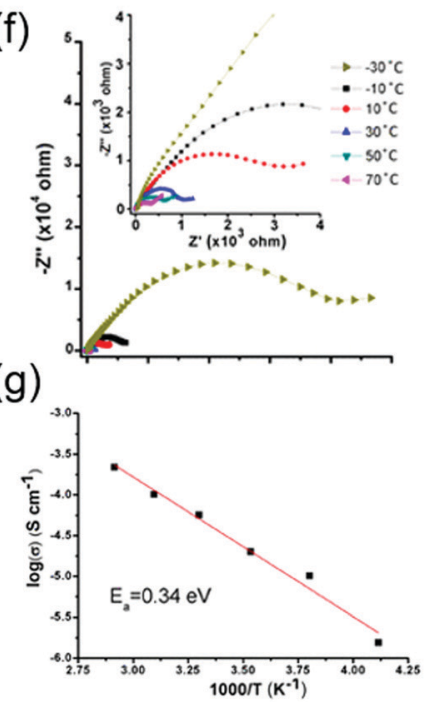

Fig. 21 Self-exfoliated, cationic COFs as Li-ion conductor. (a) Design and synthesis of cationic CONs for $\mathrm{Li}^{+}$conduction. (b) Differences in ion pair formation at neutral and cationic COF. (c) Raman spectra (d) ${ }^{7} \mathrm{Li}$ MAS NMR spectra (e) FTIR spectra of CONs and Li-CON-TFSI, establishing lithiation of CONs. (f) Temperature-dependent EIS of Li-CON-TFSI. (g) Calculation of activation energy $\left(E_{\mathrm{a}}\right)$ for Li-CON-TFSI in hydrous conditions by the methods of Arrhenius. Reproduced with permission. ${ }^{154}$ Copyright 2018, American Chemical Society.

separation of $\mathrm{Li}^{+}$ions from TFSI counter-anions anchored to the cationic framework. As strong ionic bonds often hamper ionic mobility, polyelectrolytes are alternatively employed. Jiang's group designed polyelectrolyte COFs by covalent attachment of 2,5-bis((2-methoxyethoxy)methoxy) or dimethoxy functional groups to afford the imine-linked TPB-BMTP-COF and TPBDMTP-COF, respectively. ${ }^{155}$ Subsequent $\mathrm{LiClO}_{4}$ loading onto these COFs through solution diffusion yielded $\mathrm{Li}^{+} @ \mathrm{TPB}-\mathrm{DMTP}-\mathrm{COF}$ and $\mathrm{Li}^{+}$@TPB-BMTP-COF, which exhibited conductivities of $5.37 \times$ $10^{-6}$ and $1.66 \times 10^{-4} \mathrm{~S} \mathrm{~cm}^{-1}$ at $353 \mathrm{~K}$, respectively. $\mathrm{Li}^{+} @ \mathrm{TPB}-$ BMTP-COF $(0.87 \mathrm{eV})$ had a lower $E_{\mathrm{a}}$ than $\mathrm{Li}^{+} @$ @TPB-DMTP-COF $(0.96 \mathrm{eV})$, as the multiple $\mathrm{O}$ atoms of BMTP were arrayed at the polyelectrolyte interface for $\mathrm{Li}^{+}$transfer. However, the above conductivities were not impressive. Subsequently, the above researchers synthesized triethyleneoxide (TEO)-decorated COFs with TEO ratios of $0-0.5 .^{156}$ In the case of TPB-DMTP-COF, $\mathrm{Li}^{+}$@[TEO $]_{0.33}$-TPB-DMTP-COF and $\mathrm{Li}^{+} @[\mathrm{TEO}]_{0.5}$-TPB-DMTP$\mathrm{COF}$ showed $\mathrm{Li}^{+}$conductivities of $2.05 \times 10^{-4}$ and $2.49 \times$ $10^{-4} \mathrm{~S} \mathrm{~cm}^{-1}$ at $353 \mathrm{~K}$, respectively, which exceeded those of TEO-free $\mathrm{Li}^{+} @$ @PB-DMTP-COF. The conductivity of $\mathrm{Li}^{+} @[\mathrm{TEO}]_{0.5^{-}}$ TPB-BMTP-COF was smaller than that of the TEO-free COF, probably because of the lower loading of $\mathrm{Li}^{+}$in the highly condensed structure determined by pore volume shrinkage from $0.96 \mathrm{~cm}^{3} \mathrm{~g}^{-1}$ in TPB-BMTP-COF to $0.09 \mathrm{~cm}^{3} \mathrm{~g}^{-1}$ in
[TEO $]_{0.5}$-TPB-BMTP-COF before $\mathrm{Li}^{+}$loading. Horike's group introduced polyethylene oxide functionalities to form COFPEO- $x$, where $x=3,6$, or 9 represents the number of PEO units. ${ }^{157} \mathrm{Li}^{+}$@COF-PEO-9, obtained after impregnation with LiTFSI, showed a high conductivity of $1.33 \times 10^{-3} \mathrm{~S} \mathrm{~cm}^{-1}$ at $473 \mathrm{~K}$. When milled Li ${ }^{+}$@COF-PEO-9 was applied to Li-ion cells assembled with $\mathrm{Li} \mid \mathrm{LiFePO}_{4}$, galvanostatic cycling within 2.5-4.2 $\mathrm{V}$ at $100{ }^{\circ} \mathrm{C}$ showed a coulombic efficiency of $\sim 95 \%$ after 10 cycles. Feng's and Wang's groups loaded polyethylene glycol (PEG) onto various types of COFs with neutral, anionic, and cationic moieties through simple soaking in PEG solutions. ${ }^{158}$ After $\mathrm{LiClO}_{4}$ addition, the cationic PEG-Li $\mathrm{C}^{+}$@ethidium bromide unit (EB)${\mathrm{COF}-\mathrm{ClO}_{4}}_{4}$ showed the highest $\mathrm{Li}^{+}$conductivity of $1.78 \times$ $10^{-3} \mathrm{~S} \mathrm{~cm}^{-1}$ at $393 \mathrm{~K}$ and $\mathrm{a} \mathrm{Li}^{+}$transference number of 0.60 . Similarly, Chen's group synthesized a heteroporous dibenzo[ $g, p]$ chrysene-based COF through the introduction of PEG-LiBF which resulted in $\mathrm{a} \mathrm{Li}^{+}$conductivity of $2.31 \times 10^{-3} \mathrm{~S} \mathrm{~cm}^{-1} .159$

To increase the $\mathrm{Li}^{+}$transference number, Lee and co-workers and Lee proposed the use of a solvent-free single Li-ion conductor and fabricated TpPa-SO $\mathrm{S}_{3} \mathrm{Li} \mathrm{COF}$ (Fig. 22). ${ }^{160}$ This sulfonated COF had a $\mathrm{Li}^{+}$conductivity of $2.7 \times 10^{-5} \mathrm{~S} \mathrm{~cm}^{-1}$ and a $\mathrm{Li}^{+}$transference number of 0.9 . The very high transference number was attributed to the small distance required for $\mathrm{Li}^{+}$hopping between the abundant carbonyl $\mathrm{O}$ atoms and sulfonate $\mathrm{O}$ atoms, which were 

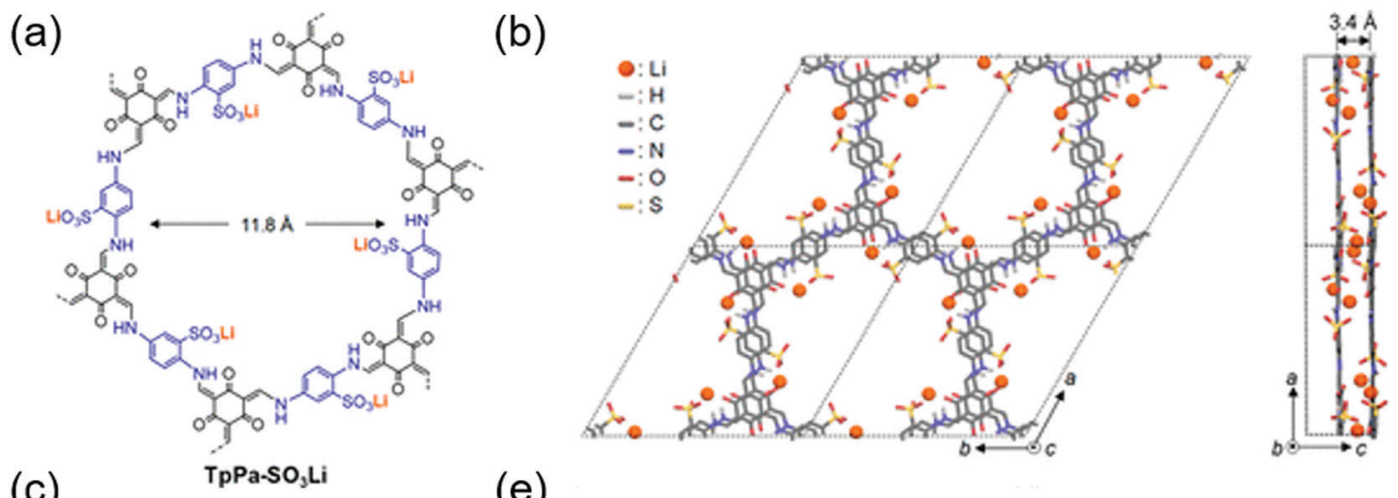

(c)
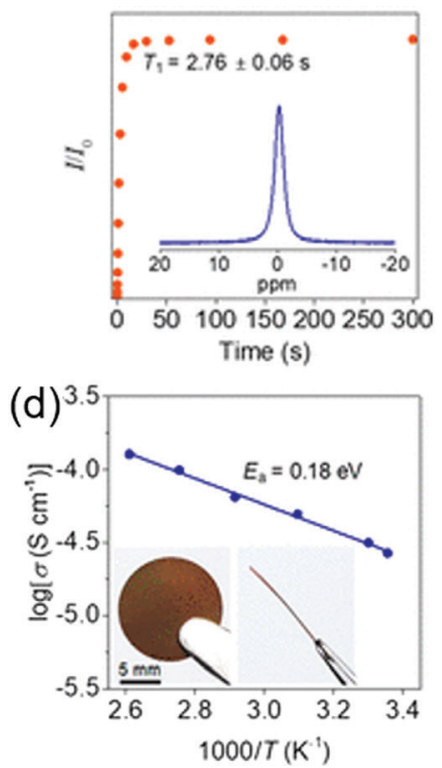

(e)

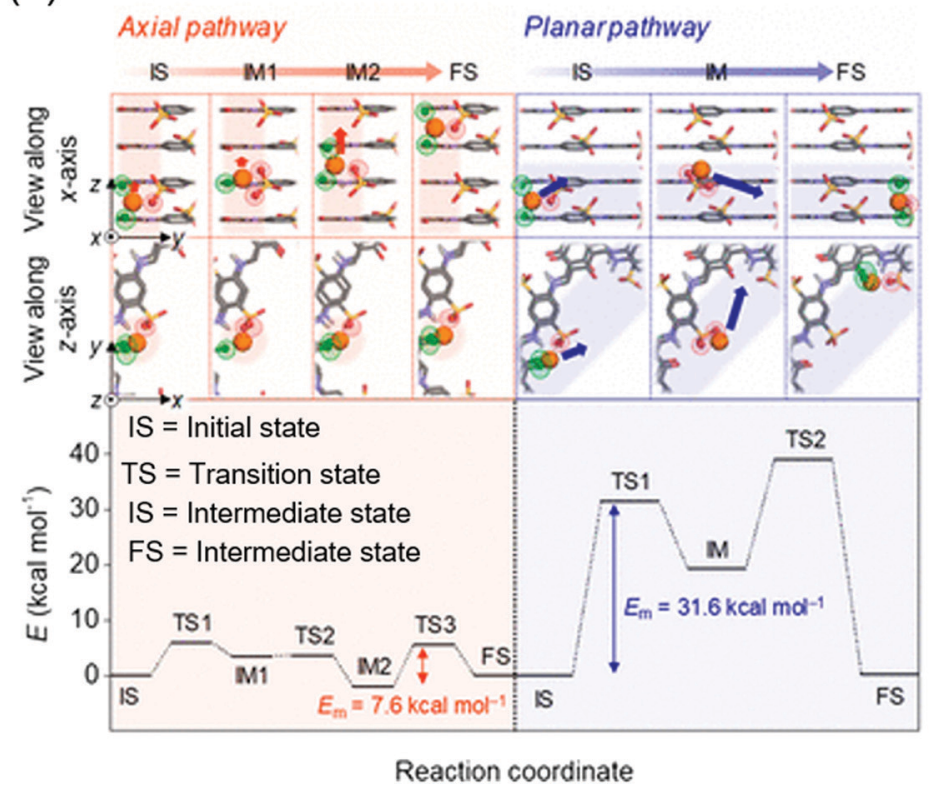

Fig. 22 Solvent-less, single $\mathrm{Li}$-ion conduction in COFs. (a) Chemical structure of lithiated COF for $\mathrm{Li}^{+}$conduction. (b) Simulated structure of $\mathrm{TpPa}-\mathrm{SO} \mathrm{Li}^{\mathrm{Li}}$ along $c$ - and $b$-axes. (c) Saturation recovery plot (for complete lithiation of COF) from ${ }^{7}$ Li MAS NMR spectra. (d) Calculation of activation energy ( $E_{\mathrm{a}}$ ) for LiCON-TFSI in hydrous conditions by the methods of Arrhenius. (e) Depiction of $\mathrm{Li}^{+}$migration inside the pore through axial or planar pathway. Reproduced with permission. ${ }^{160}$ Copyright 2019, American Chemical Society.

aligned in the axial direction of COF nanochannels. The axial migration barrier $\left(7.6 \mathrm{kcal} \mathrm{mol}^{-1}\right)$ was lower than the in-plane migration barrier $\left(31.6 \mathrm{kcal} \mathrm{mol}^{-1}\right)$. Lee, Zhang and co-workers also prepared a single Li-ion conductor COF from lithium imidazolate COFs (Li-ImCOFs). ${ }^{161}$ Three imidazolate COFs with $\mathrm{H},-\mathrm{CH}_{3}$, and $-\mathrm{CF}_{3}$ substituents were synthesized to impart different electronic conductivities. In the presence of $20 \mathrm{wt} \%$ propylene carbonate (PC), the $\mathrm{Li}^{+}$ionic conductivity/Li $\mathrm{Li}^{+}$transference numbers of $\mathrm{H}-\mathrm{Li}-\mathrm{ImCOF}, \mathrm{CH}_{3}-\mathrm{Li}-\mathrm{ImCOF}$, and $\mathrm{CF}_{3}-\mathrm{Li}-\mathrm{ImCOF}$ were $5.3 \times$ $10^{-3} \mathrm{~S} \mathrm{~cm}^{-1} / 0.88,8.0 \times 10^{-5} \mathrm{~S} \mathrm{~cm}^{-1} / 0.93$, and $7.2 \times 10^{-3} \mathrm{~S} \mathrm{~cm}^{-1} /$ 0.81 , respectively. The high conductivities of $\mathrm{H}-\mathrm{Li}-\mathrm{ImCOF}$ and $\mathrm{CF}_{3}{ }^{-}$ $\mathrm{Li}$-ImCOF were ascribed to the high structural order of these COFs and the weak ionic interactions therein.

A COF-based solid-state electrolyte was also applied to multiple charge carriers. Kwak, Lee and co-workers used a $\mathrm{TpPa}-\mathrm{SO}_{3} \mathrm{H}$ COF single-ion conductor for $\mathrm{Zn}^{2+}$ after replacing $\mathrm{H}^{+}$with $\mathrm{Zn}^{2+}{ }^{162}$ The resulting TpPa- $\mathrm{SO}_{3} \mathrm{Zn}_{0.5} \mathrm{COF}$ had a high $\mathrm{Zn}^{2+}$ conductivity of $2.2 \times 10^{-4} \mathrm{~S} \mathrm{~cm}^{-1}$ at room temperature, and its hydrated form showed a transference number of 0.91 .
Furthermore, these researchers used $\mathrm{TpPa}-\mathrm{SO}_{3} \mathrm{Zn}_{0.5}$ as a solid-state electrolyte in symmetric $\mathrm{Zn}$ cells to achieve stable operation for up to $500 \mathrm{~h}$, while the overpotential decreased from 100 to $60 \mathrm{mV}$. For $\mathrm{Zn} \| \mathrm{MnO}_{2}$ cells with the above solidstate electrolyte, a capacity retention of $73 \%$ was observed after 800 cycles at $0.6 \mathrm{~A} \mathrm{~g}^{-1}$.

\section{Summary and outlook}

We highlighted the advances in the development of COFs for use as the electrodes of organic capacitors and batteries or as ionic conductors for membranes. The rich diversity of synthetic methods and the feasibility of chemical designs make COFs attractive for customized organic materials. In addition, structural characteristics such as pore diameter, pore volume, surface area, interlayer interactions, and thickness determine the stability, chemical reactivity, and ionic/electronic conductivity of COFs. In the COF structure, the role of chemical functional 
groups can be addressed with respect to rigidity and electrochemical activity. Studies of design-dependent cell performance and mechanistic elucidation have accumulated the knowledge, which allows us to develop better organic materials and improve storage performance.

Despite the significant progress in this field, future works should still focus on improving conductivity, increasing the concentrated integration of active moieties, enhancing chemical stability, and lowering synthetic cost and time to make COFs practically useful. At this point, we would like to note some important but less spotlighted issues. Typically, ion transport in bulk and crystalline COFs preferentially occurs in the axial direction through porous channels. ${ }^{160}$ However, electron transport in the stacking direction remains unexplored, although this factor determines the electronic conductivity of bulk COF electrodes. The presence of $\mathrm{p} \pi-\mathrm{p} \pi$ orbital coupling to the axial direction may further amplify this electron transport, which suggests the need for COFs with interlayered designs. ${ }^{102,163}$ The fabrication of thin films using exfoliation and direct thin-film growth has been extensively investigated to solve the problem of low electronic conductivity. However, thin films contain only a small amount of active material, which is not acceptable for industrial production. Therefore, a more practical direction of the research approach should be needed.

We should also point out that reconstructed COFs typically comprise a redox core moiety and linkages. Although linkages are essentially responsible for the chemical and mechanical rigidity of the electrode structure, they can eventually reduce the specific capacity and gravimetric energy density. Therefore, it is encouraged that linkages not only determine structural rigidity but also act as redox-active sites.

Overall, the redox molecule quantity, concentrated integration, and conductivity of COFs should be balanced for practical electrode materials. All research directions are based on a fundamental understanding of electrochemical and chemical processes. A systematic comparison of a series of COF structures, chemical motifs, and computational calculations is expected to deepen our knowledge of the related redox mechanisms and interfacial reactions. The reduction of synthetic costs and the number/complexity of synthetic processes are the following step required for mass production. We believe that the development of a new class of future electrodes offers numerous opportunities and will change our lives and technologies.

\section{Conflicts of interest}

The authors declare no conflict of interest.

\section{Acknowledgements}

This work was supported by the Samsung Research Funding \& Incubation Center of Samsung Electronics under Project Number SRFC-MA1702-05.

\section{References}

1 Z. Yang, J. Zhang, M. C. Kintner-Meyer, X. Lu, D. Choi, J. P. Lemmon and J. Liu, Chem. Rev., 2011, 111, 3577-3613.

2 D. R. Rolison and L. F. Nazar, MRS Bull., 2011, 36, 486-493.

3 A. Manthiram, Y. Fu and Y.-S. Su, Acc. Chem. Res., 2013, 46, 1125-1134.

4 X.-P. Gao and H.-X. Yang, Energy Environ. Sci., 2010, 3, 174-189.

5 T. Kim, W. Song, D.-Y. Son, L. K. Ono and Y. Qi, J. Mater. Chem. A, 2019, 7, 2942-2964.

6 D. Chen, Z. Lou, K. Jiang and G. Shen, Adv. Funct. Mater., 2018, 28, 1805596.

7 A. M. Zamarayeva, A. E. Ostfeld, M. Wang, J. K. Duey, I. Deckman, B. P. Lechêne, G. Davies, D. A. Steingart and A. C. Arias, Sci. Adv., 2017, 3, e1602051.

8 J. B. Goodenough, Energy Environ. Sci., 2014, 7, 14-18.

9 V. Augustyn, P. Simon and B. Dunn, Energy Environ. Sci., 2014, 7, 1597-1614.

10 M. Shao, Q. Chang, J.-P. Dodelet and R. Chenitz, Chem. Rev., 2016, 116, 3594-3657.

11 N.-T. Suen, S.-F. Hung, Q. Quan, N. Zhang, Y.-J. Xu and H. M. Chen, Chem. Soc. Rev., 2017, 46, 337-365.

12 A. Eftekhari, Int. J. Hydrogen Energy, 2017, 42, 11053-11077.

13 S. Fang, D. Bresser and S. Passerini, Adv. Energy Mater., 2020, 10, 1902485.

14 D. Larcher and J.-M. Tarascon, Nat. Chem., 2015, 7, 19-29.

15 P. Poizot, J. Gaubicher, S. Renault, L. Dubois, Y. Liang and Y. Yao, Chem. Rev., 2020, 120, 6490-6557.

16 D. Xu, M. Liang, S. Qi, W. Sun, L.-P. Lv, F.-H. Du, B. Wang, S. Chen, Y. Wang and Y. Yu, ACS Nano, 2021, 15, 47-80.

17 T. B. Schon, B. T. McAllister, P.-F. Li and D. S. Seferos, Chem. Soc. Rev., 2016, 45, 6345-6404.

18 Z. Zhao-Karger, P. Gao, T. Ebert, S. Klyatskaya, Z. Chen, M. Ruben and M. Fichtner, Adv. Mater., 2019, 31, 1806599.

19 S. Lee, G. Kwon, K. Ku, K. Yoon, S. K. Jung, H. D. Lim and K. Kang, Adv. Mater., 2018, 30, 1704682.

20 A. Saal, T. Hagemann and U. S. Schubert, Adv. Energy Mater., 2020, 2001984.

21 J. Lopez, D. G. Mackanic, Y. Cui and Z. Bao, Nat. Rev. Mater., 2019, 4, 312-330.

22 J. F. Mike and J. L. Lutkenhaus, ACS Macro Lett., 2013, 2, 839-844.

23 A. P. Cote, A. I. Benin, N. W. Ockwig, M. O'Keeffe, A. J. Matzger and O. M. Yaghi, Science, 2005, 310, 1166-1170.

24 H. M. El-Kaderi, J. R. Hunt, J. L. Mendoza-Cortés, A. P. Côté, R. E. Taylor, M. O'Keeffe and O. M. Yaghi, Science, 2007, 316, 268-272.

25 X. Feng, X. Ding and D. Jiang, Chem. Soc. Rev., 2012, 41, 6010-6022.

26 S.-Y. Ding and W. Wang, Chem. Soc. Rev., 2013, 42, 548-568.

27 N. Huang, P. Wang and D. Jiang, Nat. Rev. Mater., 2016, 1, 1-19.

28 S. Kandambeth, K. Dey and R. Banerjee, J. Am. Chem. Soc., 2019, 141, 1807-1822.

29 M. S. Lohse and T. Bein, Adv. Funct. Mater., 2018, 28, 1705553. 
30 H. Wang, Z. Zeng, P. Xu, L. Li, G. Zeng, R. Xiao, Z. Tang, D. Huang, L. Tang, C. Lai, D. Jiang, Y. Liu, H. Yi, L. Qin, S. Ye, X. Ren and W. Tang, Chem. Soc. Rev., 2019, 48, 488-516.

31 J. L. Segura, M. J. Mancheño and F. Zamora, Chem. Soc. Rev., 2016, 45, 5635-5671.

32 D. Rodríguez-San-Miguel and F. Zamora, Chem. Soc. Rev., 2019, 48, 4375-4386.

33 X. Guan, F. Chen, Q. Fang and S. Qiu, Chem. Soc. Rev., 2020, 49, 1357-1384.

34 X. Li and K. P. Loh, ACS Mater. Lett., 2019, 1, 327-335.

35 J.-M. Seo, H.-J. Noh, H. Y. Jeong and J.-B. Baek, J. Am. Chem. Soc., 2019, 141, 11786-11790.

36 E. Jin, Z. Lan, Q. Jiang, K. Geng, G. Li, X. Wang and D. Jiang, Chem, 2019, 5, 1632-1647.

37 A. Halder, M. Ghosh, M. A. Khayum, S. Bera, M. Addicoat, H. S. Sasmal, S. Karak, S. Kurungot and R. Banerjee, J. Am. Chem. Soc., 2018, 140, 10941-10945.

38 B. P. Biswal, S. Chandra, S. Kandambeth, B. Lukose, T. Heine and R. Banerjee, J. Am. Chem. Soc., 2013, 135, 5328-5331.

39 V. Singh, S. Jang, N. K. Vishwakarma and D.-P. Kim, NPG Asia Mater., 2018, 10, e456.

40 X. Guan, Y. Ma, H. Li, Y. Yusran, M. Xue, Q. Fang, Y. Yan, V. Valtchev and S. Qiu, J. Am. Chem. Soc., 2018, 140, 4494-4498.

41 B. Diaz de Greñu, J. Torres, J. García-González, S. Muñoz-Pina, R. de los Reyes, A. M. Costero, P. Amorós and J. Ros-Lis, ChemSusChem, 2021, 14, 208-233.

42 Y. Peng, W. K. Wong, Z. Hu, Y. Cheng, D. Yuan, S. A. Khan and D. Zhao, Chem. Mater., 2016, 28, 5095-5101.

43 S. Karak, S. Kandambeth, B. P. Biswal, H. S. Sasmal, S. Kumar, P. Pachfule and R. Banerjee, J. Am. Chem. Soc., 2017, 139, 1856-1862.

44 S. Kandambeth, A. Mallick, B. Lukose, M. V. Mane, T. Heine and R. Banerjee, J. Am. Chem. Soc., 2012, 134, 19524-19527.

45 S. K. Yang, A. V. Ambade and M. Weck, J. Am. Chem. Soc., 2010, 132, 1637-1645.

46 S. Cai, B. Sun, X. Li, Y. Yan, A. Navarro, A. Garzón-Ruiz, H. Mao, R. Chatterjee, J. Yano, C. Zhu, J. A. Reimer, S. Zheng, J. Fan, W. Zhang and Y. Liu, ACS Appl. Mater. Interfaces, 2020, 12, 19054-19061.

47 F. Auras, L. Ascherl, A. H. Hakimioun, J. T. Margraf, F. C. Hanusch, S. Reuter, D. Bessinger, M. sDöblinger, C. Hettstedt and K. Karaghiosoff, J. Am. Chem. Soc., 2016, 138, 16703-16710.

48 L. Ascherl, T. Sick, J. T. Margraf, S. H. Lapidus, M. Calik, C. Hettstedt, K. Karaghiosoff, M. Döblinger, T. Clark and K. W. Chapman, Nat. Chem., 2016, 8, 310-316.

49 C. R. DeBlase, K. Hernández-Burgos, K. E. Silberstein, G. G. Rodríguez-Calero, R. P. Bisbey, H. D. Abruña and W. R. Dichtel, ACS Nano, 2015, 9, 3178-3183.

50 A. M. Evans, L. R. Parent, N. C. Flanders, R. P. Bisbey, E. Vitaku, M. S. Kirschner, R. D. Schaller, L. X. Chen, N. C. Gianneschi and W. R. Dichtel, Science, 2018, 361, 52-57.
51 S. Haldar, K. Roy, S. Nandi, D. Chakraborty, D. Puthusseri, Y. Gawli, S. Ogale and R. Vaidhyanathan, Adv. Energy Mater., 2018, 8, 1702170.

52 S. Haldar, K. Roy, R. Kushwaha, S. Ogale and R. Vaidhyanathan, Adv. Energy Mater., 2019, 9, 1902428.

53 C. Liu, Y. Yu, W. Zhang, Q. Zeng and S. Lei, Chem. - Eur. J., 2016, 22, 18412-18418.

54 G. Zhan, Z.-F. Cai, M. Martínez-Abadía, A. Mateo-Alonso and S. De Feyter, J. Am. Chem. Soc., 2020, 142, 5964-5968.

55 Z.-F. Cai, G. Zhan, L. Daukiya, S. Eyley, W. Thielemans, K. Severin and S. De Feyter, J. Am. Chem. Soc., 2019, 141, 11404-11408.

56 D. Rodríguez-San-Miguel, C. Montoro and F. Zamora, Chem. Soc. Rev., 2020, 49, 2291-2302.

57 Z. Kang, Y. Peng, Y. Qian, D. Yuan, M. A. Addicoat, T. Heine, Z. Hu, L. Tee, Z. Guo and D. Zhao, Chem. Mater., 2016, 28, 1277-1285.

58 M. A. Khayum, S. Kandambeth, S. Mitra, S. B. Nair, A. Das, S. S. Nagane, R. Mukherjee and R. Banerjee, Angew. Chem., 2016, 128, 15833-15837.

59 S. Mitra, S. Kandambeth, B. P. Biswal, M. A. Khayum, C. K. Choudhury, M. Mehta, G. Kaur, S. Banerjee, A. Prabhune, S. Verma, S. Roy, U. K. Kharul and R. Banerjee, J. Am. Chem. Soc., 2016, 138, 2823-2828.

60 S. Wang, Q. Wang, P. Shao, Y. Han, X. Gao, L. Ma, S. Yuan, X. Ma, J. Zhou, X. Feng and B. Wang, J. Am. Chem. Soc., 2017, 139, 4258-4261.

61 X.-H. Liu, C.-Z. Guan, S.-Y. Ding, W. Wang, H.-J. Yan, D. Wang and L.-J. Wan, J. Am. Chem. Soc., 2013, 135, 10470-10474.

62 P. Sharma and T. Bhatti, Energy Convers. Manage., 2010, 51, 2901-2912.

63 J. Ding, W. Hu, E. Paek and D. Mitlin, Chem. Rev., 2018, 118, 6457-6498.

64 C. R. DeBlase, K. E. Silberstein, T.-T. Truong, H. D. Abruña and W. R. Dichtel, J. Am. Chem. Soc., 2013, 135, 16821-16824.

65 Z. Zha, L. Xu, Z. Wang, X. Li, Q. Pan, P. Hu and S. Lei, ACS Appl. Mater. Interfaces, 2015, 7, 17837-17843.

66 Q. Xu, S. Dalapati and D. Jiang, ACS Cent. Sci., 2016, 2, 586-587.

67 C. R. Mulzer, L. Shen, R. P. Bisbey, J. R. McKone, N. Zhang, H. D. Abruña and W. R. Dichtel, ACS Cent. Sci., 2016, 2, 667-673.

68 M. A. Khayum, V. Vijayakumar, S. Karak, S. Kandambeth, M. Bhadra, K. Suresh, N. Acharambath, S. Kurungot and R. Banerjee, ACS Appl. Mater. Interfaces, 2018, 10, 28139-28146.

69 F. Xu, H. Xu, X. Chen, D. Wu, Y. Wu, H. Liu, C. Gu, R. Fu and D. Jiang, Angew. Chem., 2015, 127, 6918-6922.

70 A. M. Khattak, Z. A. Ghazi, B. Liang, N. A. Khan, A. Iqbal, L. Li and Z. Tang, J. Mater. Chem. A, 2016, 4, 16312-16317.

71 P. Bhanja, K. Bhunia, S. K. Das, D. Pradhan, R. Kimura, Y. Hijikata, S. Irle and A. Bhaumik, ChemSusChem, 2017, 10, 921-929.

72 S. Chandra, D. Roy Chowdhury, M. Addicoat, T. Heine, A. Paul and R. Banerjee, Chem. Mater., 2017, 29, 2074-2080.

73 S. Haldar, R. Kushwaha, R. Maity and R. Vaidhyanathan, ACS Mater. Lett., 2019, 1, 490-497. 
74 L. Li, F. Lu, R. Xue, B. Ma, Q. Li, N. Wu, H. Liu, W. Yao, H. Guo and W. Yang, ACS Appl. Mater. Interfaces, 2019, 11, 26355-26363.

75 A. Halder, S. Karak, M. Addicoat, S. Bera, A. Chakraborty, S. H. Kunjattu, P. Pachfule, T. Heine and R. Banerjee, Angew. Chem., Int. Ed., 2018, 57, 5797-5802.

76 S. Kandambeth, J. Jia, H. Wu, V. S. Kale, P. T. Parvatkar, J. Czaban-Jóźwiak, S. Zhou, X. Xu, Z. O. Ameur, E. AbouHamad, A.-H. Emwas, O. Shekhah, H. N. Alshareef and M. Eddaoudi, Adv. Energy Mater., 2020, 10, 2001673.

77 Y. Li, S. Zheng, X. Liu, P. Li, L. Sun, R. Yang, S. Wang, Z. S. Wu, X. Bao and W. Q. Deng, Angew. Chem., 2018, 130, 8124-8128.

78 B. Sun, J. Liu, A. Cao, W. Song and D. Wang, Chem. Commun., 2017, 53, 6303-6306.

79 J. Xu, Y. He, S. Bi, M. Wang, P. Yang, D. Wu, J. Wang and F. Zhang, Angew. Chem., 2019, 131, 12193-12197.

80 Y. Yusran, H. Li, X. Guan, D. Li, L. Tang, M. Xue, Z. Zhuang, Y. Yan, V. Valtchev, S. Qiu and Q. Fang, Adv. Mater., 2020, 32, 1907289.

81 T. Suga, H. Ohshiro, S. Sugita, K. Oyaizu and H. Nishide, Adv. Mater., 2009, 21, 1627-1630.

82 Y. Lu, X. Hou, L. Miao, L. Li, R. Shi, L. Liu and J. Chen, Angew. Chem., Int. Ed., 2019, 58, 7020-7024.

83 Y. Lu and J. Chen, Nat. Rev. Chem., 2020, 4, 127-142.

84 K. Zhang, C. Guo, Q. Zhao, Z. Niu and J. Chen, Adv. Sci., 2015, 2, 1500018.

85 W. Huang, Z. Zhu, L. Wang, S. Wang, H. Li, Z. Tao, J. Shi, L. Guan and J. Chen, Angew. Chem., Int. Ed., 2013, 52, 9162-9166.

86 Z. Zhu, M. Hong, D. Guo, J. Shi, Z. Tao and J. Chen, J. Am. Chem. Soc., 2014, 136, 16461-16464.

87 M. Wu, Y. Cui, A. Bhargav, Y. Losovyj, A. Siegel, M. Agarwal, Y. Ma and Y. Fu, Angew. Chem., 2016, 128, 10181-10185.

88 F. Xu, S. Jin, H. Zhong, D. Wu, X. Yang, X. Chen, H. Wei, R. Fu and D. Jiang, Sci. Rep., 2015, 5, 8225.

89 Z. Luo, L. Liu, J. Ning, K. Lei, Y. Lu, F. Li and J. Chen, Angew. Chem., Int. Ed., 2018, 57, 9443-9446.

90 M. Wu, Y. Zhao, B. Sun, Z. Sun, C. Li, Y. Han, L. Xu, Z. Ge, Y. Ren and M. Zhang, Nano Energy, 2020, 70, 104498.

91 C. J. Yao, Z. Wu, J. Xie, F. Yu, W. Guo, Z. J. Xu, D. S. Li, S. Zhang and Q. Zhang, ChemSusChem, 2020, 13, 2457-2563.

92 Z. Wang, Y. Li, P. Liu, Q. Qi, F. Zhang, G. Lu, X. Zhao and X. Huang, Nanoscale, 2019, 11, 5330-5335.

93 D.-H. Yang, Z.-Q. Yao, D. Wu, Y.-H. Zhang, Z. Zhou and X.-H. Bu, J. Mater. Chem. A, 2016, 4, 18621-18627.

94 E. Vitaku, C. N. Gannett, K. L. Carpenter, L. Shen, H. D. Abruña and W. R. Dichtel, J. Am. Chem. Soc., 2020, 142, 16-20.

95 Z. Lei, Q. Yang, Y. Xu, S. Guo, W. Sun, H. Liu, L.-P. Lv, Y. Zhang and Y. Wang, Nat. Commun., 2018, 9, 1-13.

96 H. Zhang, W. Sun, X. Chen and Y. Wang, ACS Nano, 2019, 13, 14252-14261.

97 S. Haldar, K. Roy, S. Nandi, D. Chakraborty, D. Puthusseri, Y. Gawli, S. Ogale and R. Vaidhyanathan, Adv. Energy Mater., 2018, 8, 1702170.
98 G. Zhao, Y. Zhang, Z. Gao, H. Li, S. Liu, S. Cai, X. Yang, H. Guo and X. Sun, ACS Energy Lett., 2020, 5, 1022-1031.

99 C. Luo, O. Borodin, X. Ji, S. Hou, K. J. Gaskell, X. Fan, J. Chen, T. Deng, R. Wang, J. Jiang and C. Wang, Proc. Natl. Acad. Sci. U. S. A., 2018, 115, 2004-2009.

100 S. Chandra, T. Kundu, S. Kandambeth, R. BabaRao, Y. Marathe, S. M. Kunjir and R. Banerjee, J. Am. Chem. Soc., 2014, 136, 6570-6573.

101 X. Yang, Y. Hu, N. Dunlap, X. Wang, S. Huang, Z. Su, S. Sharma, Y. Jin, F. Huang, X. Wang, S.-H. Lee and W. Zhang, Angew. Chem., Int. Ed., 2020, 59, 20385-20389.

102 V. Singh, J. Kim, B. Kang, J. Moon, S. Kim, W. Y. Kim and H. R. Byon, Adv. Energy Mater., 2021, DOI: 10.1002/aenm. 202003735.

103 N. Yabuuchi, K. Kubota, M. Dahbi and S. Komaba, Chem. Rev., 2014, 114, 11636-11682.

104 W. Zhang, F. Zhang, F. Ming and H. N. Alshareef, EnergyChem, 2019, 1, 100012.

105 J. C. Pramudita, D. Sehrawat, D. Goonetilleke and N. Sharma, Adv. Energy Mater., 2017, 7, 1602911.

106 Y.-S. Xu, S.-Y. Duan, Y.-G. Sun, D.-S. Bin, X.-S. Tao, D. Zhang, Y. Liu, A.-M. Cao and L.-J. Wan, J. Mater. Chem. A, 2019, 7, 4334-4352.

107 Z. Wang, S. M. Selbach and T. Grande, RSC Adv., 2014, 4, 4069-4079.

108 C. Wang, Y. Xu, Y. Fang, M. Zhou, L. Liang, S. Singh, H. Zhao, A. Schober and Y. Lei, J. Am. Chem. Soc., 2015, 137, 3124-3130.

109 B. C. Patra, S. K. Das, A. Ghosh, K. A. Raj, P. Moitra, M. Addicoat, S. Mitra, A. Bhaumik, S. Bhattacharya and A. Pradhan, J. Mater. Chem. A, 2018, 6, 16655-16663.

110 M.-S. Kim, W.-J. Lee, S.-M. Paek and J. K. Park, ACS Appl. Mater. Interfaces, 2018, 10, 32102-32111.

111 M. Kolek, F. Otteny, P. Schmidt, C. Mück-Lichtenfeld, C. Einholz, J. Becking, E. Schleicher, M. Winter, P. Bieker and B. Esser, Energy Environ. Sci., 2017, 10, 2334-2341.

112 S. Wu, W. Wang, M. Li, L. Cao, F. Lyu, M. Yang, Z. Wang, Y. Shi, B. Nan and S. Yu, Nat. Commun., 2016, 7, 1-11.

113 S. Gu, S. Wu, L. Cao, M. Li, N. Qin, J. Zhu, Z. Wang, Y. Li, Z. Li, J. Chen and Z. Lu, J. Am. Chem. Soc., 2019, 141, 9623-9628.

114 R. Shi, L. Liu, Y. Lu, C. Wang, Y. Li, L. Li, Z. Yan and J. Chen, Nat. Commun., 2020, 11, 178.

115 S. Haldar, D. Kaleeswaran, D. Rase, K. Roy, S. Ogale and R. Vaidhyanathan, Nanoscale Horiz., 2020, 5, 1264-1273.

116 X. Chen, H. Zhang, C. Ci, W. Sun and Y. Wang, ACS Nano, 2019, 13, 3600-3607.

117 Q. Xue, D. Li, Y. Huang, X. Zhang, Y. Ye, E. Fan, L. Li, F. Wu and R. Chen, J. Mater. Chem. A, 2018, 6, 12559-12564.

118 M. A. Khayum, M. Ghosh, V. Vijayakumar, A. Halder, M. Nurhuda, S. Kumar, M. Addicoat, S. Kurungot and R. Banerjee, Chem. Sci., 2019, 10, 8889-8894.

119 M. Na, Y. Oh and H. R. Byon, Chem. Mater., 2020, 32, 6990-6997.

120 W. Wang, V. S. Kale, Z. Cao, S. Kandambeth, W. Zhang, J. Ming, P. T. Parvatkar, E. Abou-Hamad, O. Shekhah, 
L. Cavallo, M. Eddaoudi and H. N. Alshareef, ACS Energy Lett., 2020, 5, 2256-2264.

121 H. Liao, H. Ding, B. Li, X. Ai and C. Wang, J. Mater. Chem. A, 2014, 2, 8854-8858.

122 X. Yang, B. Dong, H. Zhang, R. Ge, Y. Gao and H. Zhang, RSC Adv., 2015, 5, 86137-86143.

123 H. Liao, H. Wang, H. Ding, X. Meng, H. Xu, B. Wang, X. Ai and C. Wang, J. Mater. Chem. A, 2016, 4, 7416-7421.

124 A. Schneider, C. Weidmann, C. Suchomski, H. Sommer, J. r. Janek and T. Brezesinski, Chem. Mater., 2015, 27, 1674-1683.

125 Q. Pang and L. F. Nazar, ACS Nano, 2016, 10, 4111-4118.

126 Y. Meng, G. Lin, H. Ding, H. Liao and C. Wang, J. Mater. Chem. A, 2018, 6, 17186-17191.

127 F. Xu, S. Yang, G. Jiang, Q. Ye, B. Wei and H. Wang, ACS Appl. Mater. Interfaces, 2017, 9, 37731-37738.

128 D.-G. Wang, N. Li, Y. Hu, S. Wan, M. Song, G. Yu, Y. Jin, W. Wei, K. Han, G.-C. Kuang and W. Zhang, ACS Appl. Mater. Interfaces, 2018, 10, 42233-42240.

129 Q. Jiang, Y. Li, X. Zhao, P. Xiong, X. Yu, Y. Xu and L. Chen, J. Mater. Chem. A, 2018, 6, 17977-17981.

130 Z. A. Ghazi, L. Zhu, H. Wang, A. Naeem, A. M. Khattak, B. Liang, N. A. Khan, Z. Wei, L. Li and Z. Tang, Adv. Energy Mater., 2016, 6, 1601250.

131 Z. Xiao, L. Li, Y. Tang, Z. Cheng, H. Pan, D. Tian and R. Wang, Energy Storage Mater., 2018, 12, 252-259.

132 X.-F. Liu, H. Chen, R. Wang, S.-Q. Zang and T. C. W. Mak, Small, 2020, 16, 2002932.

133 Z. Yang, C. Peng, R. Meng, L. Zu, Y. Feng, B. Chen, Y. Mi, C. Zhang and J. Yang, ACS Cent. Sci., 2019, 5, 1876-1883.

134 T. Yamada, M. Sadakiyo and H. Kitagawa, J. Am. Chem. Soc., 2009, 131, 3144-3145.

135 X. Wu, X. Wang, G. He and J. Benziger, J. Polym. Sci., Part B: Polym. Phys., 2011, 49, 1437-1445.

136 V. G. Ponomareva, K. A. Kovalenko, A. P. Chupakhin, D. N. Dybtsev, E. S. Shutova and V. P. Fedin, J. Am. Chem. Soc., 2012, 134, 15640-15643.

137 S. Chandra, T. Kundu, K. Dey, M. Addicoat, T. Heine and R. Banerjee, Chem. Mater., 2016, 28, 1489-1494.

138 Y. Peng, G. Xu, Z. Hu, Y. Cheng, C. Chi, D. Yuan, H. Cheng and D. Zhao, ACS Appl. Mater. Interfaces, 2016, 8, 18505-18512.

139 H. Xu, S. Tao and D. Jiang, Nat. Mater., 2016, 15, 722-726.

140 H. Ma, B. Liu, B. Li, L. Zhang, Y.-G. Li, H.-Q. Tan, H.-Y. Zang and G. Zhu, J. Am. Chem. Soc., 2016, 138, 5897-5903.

141 Z. Meng, A. Aykanat and K. A. Mirica, Chem. Mater., 2018, 31, 819-825.
142 J. S. Fritz, F. W. Cagle and G. F. Smith, J. Am. Chem. Soc., 1949, 71, 2480-2482.

143 C. Swinnerton and M. V. Twigg, Transition Met. Chem., 1978, 3, 25-27.

144 H. S. Sasmal, H. B. Aiyappa, S. N. Bhange, S. Karak, A. Halder, S. Kurungot and R. Banerjee, Angew. Chem., 2018, 130, 11060-11064.

145 Y. Yang, X. He, P. Zhang, Y. H. Andaloussi, H. Zhang, Z. Jiang, Y. Chen, S. Ma, P. Cheng and Z. Zhang, Angew. Chem., Int. Ed., 2020, 59, 3678-3684.

146 K. A. Mauritz and R. B. Moore, Chem. Rev., 2004, 104, 4535-4586.

147 X. Wu, Y.-l. Hong, B. Xu, Y. Nishiyama, W. Jiang, J. Zhu, G. Zhang, S. Kitagawa and S. Horike, J. Am. Chem. Soc., 2020, 142, 14357-14364.

148 S. Chen, Y. Wu, Y. Zhang, W. Zhang, Y. Fu, W. Huang, T. Yan and H. Ma, J. Mater. Chem. A, 2020, 8, 13702-13709.

149 S. Li, Y. Liu, L. Li, C. Liu, J. Li, S. Ashraf, P. Li and B. Wang, ACS Appl. Mater. Interfaces, 2020, 12, 22910-22916.

150 S. Tao, L. Zhai, A. D. Dinga Wonanke, M. A. Addicoat, Q. Jiang and D. Jiang, Nat. Commun., 2020, 11, 1981.

151 Y. Du, H. Yang, J. M. Whiteley, S. Wan, Y. Jin, S.-H. Lee and W. Zhang, Angew. Chem., Int. Ed., 2016, 55, 1737-1741.

152 Y. Zhang, J. Duan, D. Ma, P. Li, S. Li, H. Li, J. Zhou, X. Ma, X. Feng and B. Wang, Angew. Chem., 2017, 129, 16531-16535.

153 S. Ashraf, Y. Zuo, S. Li, C. Liu, H. Wang, X. Feng, P. Li and B. Wang, Chem. - Eur. J., 2019, 25, 13479-13483.

154 H. Chen, H. Tu, C. Hu, Y. Liu, D. Dong, Y. Sun, Y. Dai, S. Wang, H. Qian, Z. Lin and L. Chen, J. Am. Chem. Soc., 2018, 140, 896-899.

155 Q. Xu, S. Tao, Q. Jiang and D. Jiang, J. Am. Chem. Soc., 2018, 140, 7429-7432.

156 Q. Xu, S. Tao, Q. Jiang and D. Jiang, Angew. Chem., Int. Ed., 2020, 59, 4557-4563.

157 G. Zhang, Y.-l. Hong, Y. Nishiyama, S. Bai, S. Kitagawa and S. Horike, J. Am. Chem. Soc., 2019, 141, 1227-1234.

158 Z. Guo, Y. Zhang, Y. Dong, J. Li, S. Li, P. Shao, X. Feng and B. Wang, J. Am. Chem. Soc., 2019, 141, 1923-1927.

159 Z. Xie, B. Wang, Z. Yang, X. Yang, X. Yu, G. Xing, Y. Zhang and L. Chen, Angew. Chem., 2019, 131, 15889-15893.

160 K. Jeong, S. Park, G. Y. Jung, S. H. Kim, Y.-H. Lee, S. K. Kwak and S.-Y. Lee, J. Am. Chem. Soc., 2019, 141, 5880-5885.

161 Y. Hu, N. Dunlap, S. Wan, S. Lu, S. Huang, I. Sellinger, M. Ortiz, Y. Jin, S.-H. Lee and W. Zhang, J. Am. Chem. Soc., 2019, 141, 7518-7525.

162 S. Park, I. Kristanto, G. Y. Jung, D. B. Ahn, K. Jeong, S. K. Kwak and S.-Y. Lee, Chem. Sci., 2020, 11, 11692-11698.

163 T. Sun, J. Xie, W. Guo, D. S. Li and Q. Zhang, Adv. Energy Mater., 2020, 10, 1904199. 